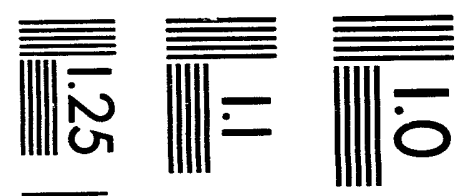

$$
\begin{aligned}
& \text { [F } \\
& \text { EFErt }
\end{aligned}
$$



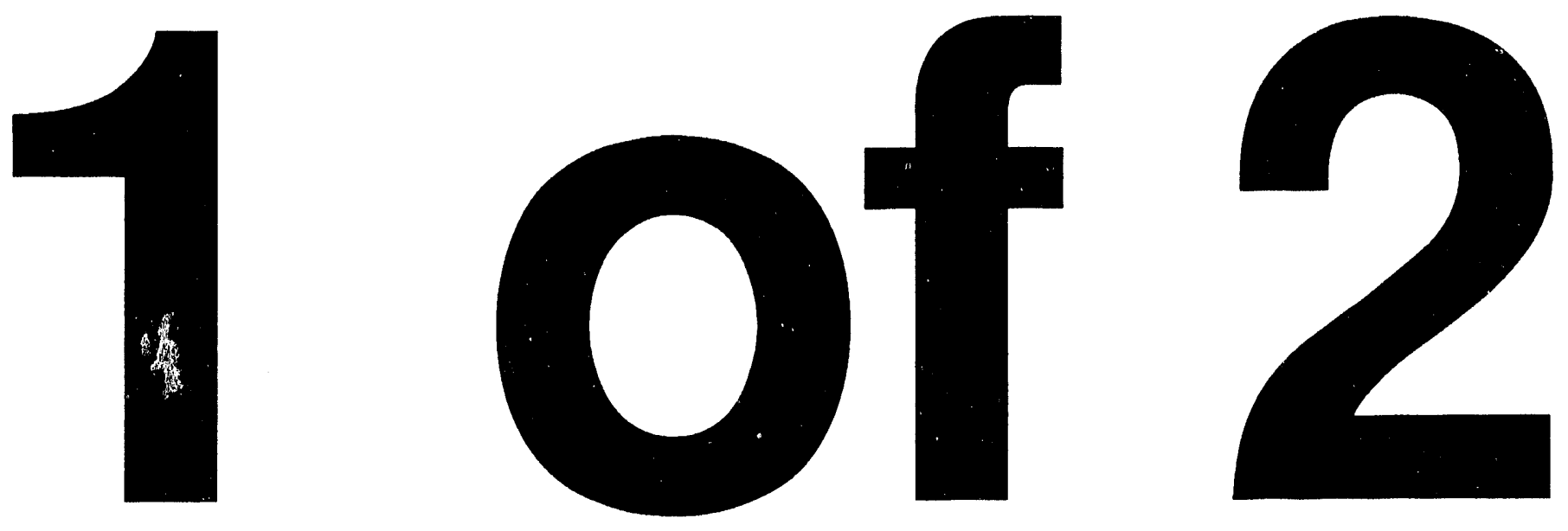
October 20, 1993

Mr. Carl P. Gertz

Mr. Dean Stucker

U.S. Department of Energy

Las Vegas, NV

Dear Carl and Dean:

Enclosed please find our Waste Package Project Quarterly Report, covering the period of July 1, 1993 to September 30, 1993. The report summarizes our most recent research activities pertinent to the project. Papers, published or recently submitted for publication, that are the byproduct of our project research, are included as a part of the task reports.

We look forward to continued cooperation with the U.S. Department of Energy on this important research effort.

Sincerely yours,

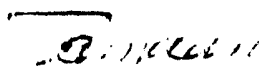

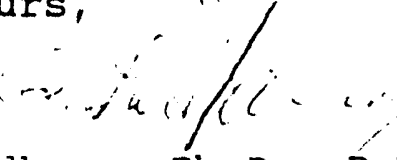

Samaan G. Ladkany, Ph.D., P.E.

Professor of Civil Engineering

Director of DOE Waste Package Project

SGL/pjn

Enclosures

cc: Office of Research and Grants, UNLV 
TABLE OF CONTENTS

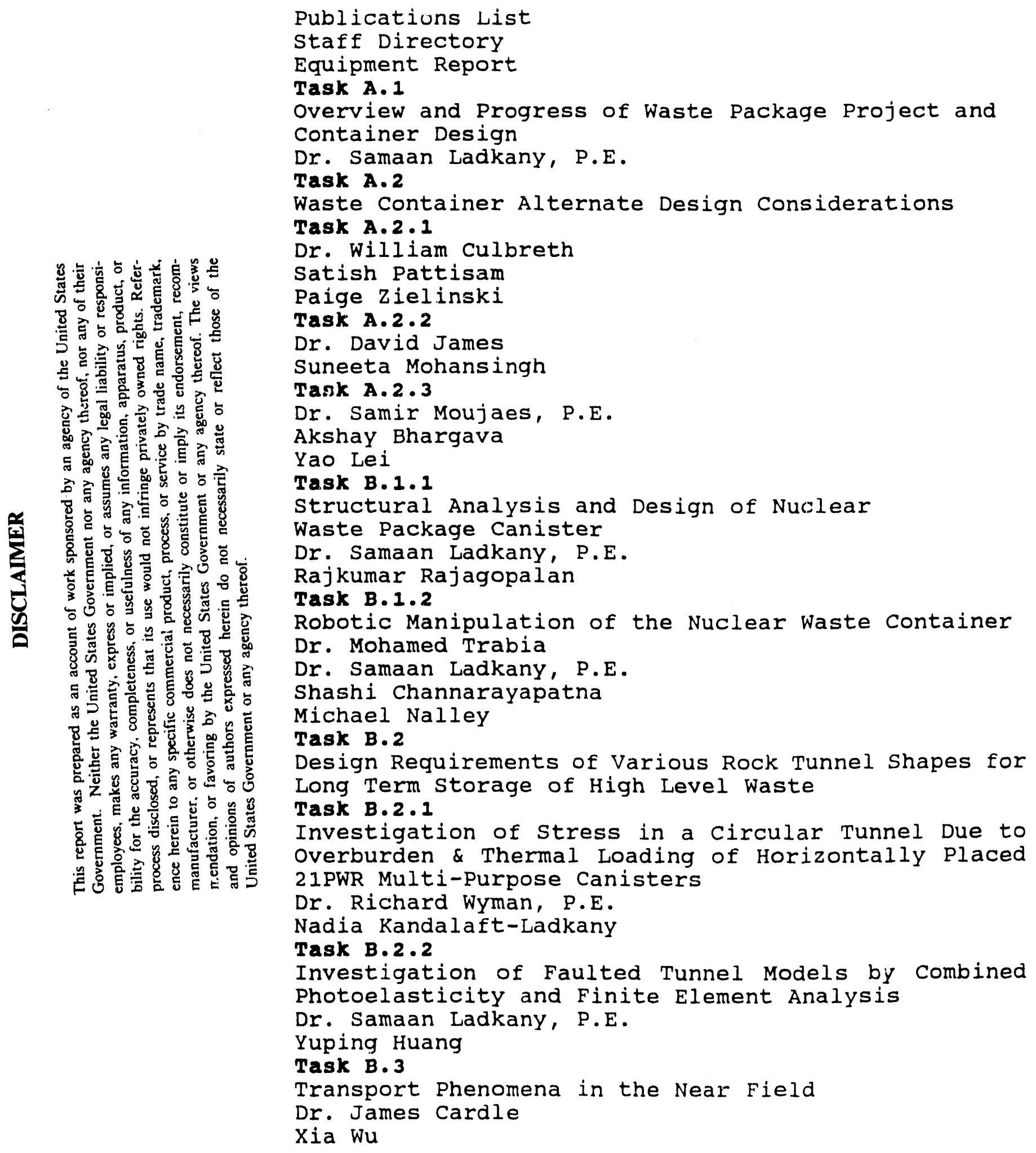




\section{RECENT PUBLICATIONS BY THE DOE NUCLEAR WASTE PACRAGE PROJECT FACULTY AND STAFF}

\section{JULY THROUGH BEPTEMBER 1993}

1. Cardle, J., "A Galerkin Method For The Convection - Diffusion Equation Using Asymmetric Weighting Functions", High-Level Radioactive Waste Management Conference \& Exposition IV, April 1993 .

2. Culbreth, W.G. and Zielinski, P.R. "The Effect of Fuel Burnup and Dispersed Water Intrusion on the Criticality of spent High Level Nuclear Fuel in a Geologic Repository," 1993 Materials Research Society Fall Meeting, $V$, Boston MA, November.

3. Joseph, M., "Heat Pipe Effect in Porous Medium", M.S. Thesis, Department of Civil and Environmental Engineering, University of Nevada, Las Vegas, December 1992, 84 pages.

4. Kandalaft-Ladkany, N., Wyman, R., Ladkany, S., "Investigation in 3-D of stress Distribution in a Circular Tunnel and Vertical Emplacement Holes Due to Thermal and overburden Loading in Tuff", High-Level Radioactive Waste Management Conference \& Exposition IV, April 1993.

5. Ladkany, S., Rajagopalan, R., "Critical stresses in Nuclear Waste Container Under Normal Handling Conditions", High-Level Radioactive Waste Management conference \& Exposition IV, April 1993 .

6. Ladkany, S., Rajagopalan, R. "In the structural stability of Large Steel spent Nuclear Fuel Canisters", DOE Waste Package Project, UNLV, Structural Stability Research Council, April 1993, pp 235-246.

7. Moujaes, S., Lei, Y., "Heat Transfer in Vertical Concentric Cylinders In A High Level Nuclear Waste Repository", High-Level Radioactive Waste Management Conference \& Exposition IV, April 1993 .

8. Trabia, M., "A Continuous Force Model For Elastic-Plastic Impact of Solids", DE-Vol.65-1, Advances in Design Automation Volume 1, ASME 1993.

9. Zielinski, P., "Parametric studies on the criticality of Radioactive spent Fuel Canisters in a Tuff Repository," M.S. Thesis, Department of Civil and Environmental Engineering, UNLV, April 1993, 125 pages. 
Project office TBE, Room B120

DOE WASTE PACRAGE PROJECT STAFF DIRECTORY

Graduate Assistant's Office TBE, Room B107

\section{Administration, Faculty and Staff}

Richard $v$. Wyman

Samaan G. Ladkany

William Culbreth

Phyllis J. Norris

James Cardle

David James

Samir Moujaes

Robert skaggs

Mohamed Trabia
Project Manager

Professor of Civil Engineering

BHS ROOM 309; 895-3940/3701

Director, Co-Project Investigator

Professor of Civil Engineering

TBE Room B-114; 895-3438/3701/4328

Associate Professor of Civil Engineering Co-Project Investigator

TBE Room B-136; 895-3426/4153

Management Assistant II

TBE Room B-120; 895-4328; FAX Number 895-0962

Associate Professor of Civil Engineering TBE Room B-128; 895-3941

Assistant Professor of Civil Engineering TBE Room B-138; 895-1067

Associate Professor of Mechanical Engineering TBE Room B-134; 895-3265

Professor of Mechanical Engineering

TBE Room B-112; 895-3139

Assistant Professor of Mechanical Engineering TBE Room B-124; 895-0957

Adjunct Faculty, Graduate Assistants and Students

Moses Rarakouzian

Associate Professor of Civil Engineering TBE RoOm B-132; 895-0959

Woosoon Yim

Assistant Professor of Mechanical Engineering TBE RoOm B-126; 895-0956

Nadia Ladkany (Project Assoc.)

Paige Zielinski (Project Assoc.) 


\section{DOE WASTE PACKAGE PROJECT (continued)}

\section{STAFF DIRECTORY}

Project office, TBE Room B120

Graduate Assistant's office, TBE Room B107

Sarath Abayaweera

Akshay Bhargava (GA)

Bharani Bhagi

sashidhar Channarayapatna

Robert DeGutes

Yuping Huang (GA)

Mark Jones

Anand Ranjerla

Raj sekhar Rona
Yao Lei

Suneeta Mohansingh

Michael Nalley

satish Pattisam (GA)

Rajkumax Rajagopalan (GA)

(Ph.D Candidate)

Prakash sankar

stuart Waymire

Xia (shaw) wu (GA)

(Ph.D Candidate) 


\section{QUARTERLY PROGRESB REPORT \\ ON THE DOE WABTE PACKAGE PROJECT \\ AT THE UNIVEREITY OF NEVADA, LAS VEGAB \\ JULY 1, 1993 TO 8EPTEMBER 30, 1993}

SUBMITTED TO THE U.8. DEPARTMENT OF ENERGY UNDER THE UNLY/DOE

COOPERATIVE AGREEMENT

PRESENTED BY

gAMAan G. LADKANY, PH.D., P.E. PROJECT DIRECTOR 
Task A.1 -- Overview and Progress of Waste Package Project and
Container Design

\author{
Dr. Samaan G. Ladkany, Ph.D., P.E. \\ Project Director, DOE Waste Package project
}

\author{
Quarterly Report \\ July 1, 1993 to september 30,1993
}




\section{A.1.1 Research Activities}

Our Waste Package Project was funded last August for a third year at the rate of $\$ 220,000$ per year with an additional $\$ 130,000$ expected in November 1993, under the DOE/UNLV Cooperative Agreement.

our normal research activities continued in all the research areas covered under the cooperative agreement. A copy of our updated staff and student directory is enclosed in this report. our research span multidisciplinary, areas which are:

a) Structural and stress analysis of the container including nonlinear yield and damage assessment and structural stability studies of the dynamic behavior of the steel waste package under normal handling conditions.

b) Nuclear fission criticality studies in the canisters.

c) Investigation of novel canister design concepts and corrosion studies.

d) Heat transfer studies in the canister air gap and adjacent rocks.

e) Fluid flow in porous media and phenomena transport of radio nucleiddes in the near field rock.

f) Studies of stresses and stability of the rock formations resulting from the thermal loading of the fuel elements and the multi tunnel concept being analyzed.

g) Characterization of a Faulted Rock Tunnel Model Using Photoelastic and Finite Element studies.

\section{A.1.2.1 Conferences}

our project staff submitted ten extended abstracts for 
the High Level Nuclear waste Conference to be held in Las Vegas this spring. Copies of these extended abstracts, which comprise summary of the project research work are included under the appropriate task numbers in our report, along with a list of our most recent publications. Dr. Wm. Culbreth and Project Associate P. Zielinski attended the 9 th International Conference on Mathematisal and Computing Modelling in San Francisco, CA to present two papers in July 1993. Dr. S. Ladkany was financially sponsored by the California Field and Iron Workers Academic Trust to attend the Portland Cement Association's (PCA) Conference and Workshop on advances in concrete technology and economics in August 1993. The conference/ workshop had important implications to the engineered barrier system studies of our waste Package Project. Dr. M. Trabia presented a paper at the ASME Design and Automation Conference in Alberquerque, N.M. in september 1993.

\section{A.1.2.2 Meetings}

Meetings with DOE/M \& O Staff, Drs. Ladkany, Culbreth, Moujaes Cardle, James and Skaggs held meetings with DOE/TRW/BWFC/SAIC staff. For the exchange of research ideas between the two groups took place.

\section{A.1.3 Purchases}

Hardware, software and laboratory equipment were purchased to support our ongoing research activities. Hardware purchases totaled $\$ 3,565.89$; office supplies, software, and miscellaneous expenses totaled $\$ 1,475.28$; and Conference Registration Fees totaled $\$ 330.00$. A list of equipment purchases and other expenditures is enclosed. 


\section{A.1.4 Conclusions}

our project staff have been very active in their professional. contacts and research activities in the various areas of storage of spent high level nuclear fuel.

Reports on the specific research activities in the various project tasks are enclosed. 


\section{Task A.2.1 -- Waste Container Design Considerations}

\section{subtask: Criticality Analysis}

Faculty Researcher: Dr. William Culbreth

Title: Associate Professor of Civil Engineering

Student Assistants: Paige Zielinski

Satish Pattisam

criticality Analysis

of Proposed spent Fuel Container Designs

The results of this work have been presented in a paper at the Ninth International Conference on Mathematical and Computer Modeling in Berkeley, California in July 1993. A paper for the conference proceedings titled: "Analysis of the Criticality of a spent Fuel Waste Package using Mathcad for Windows," by culbreth, W. G., and Zielinski, P. R. is in preparation with a due date of october 31 .

Arother paper will be presented in November 1993:

Culbreth, W. G., and Zielinski, P. R., "The Effect of Fuel Burnup and Dispersed Water Intrusion on the Criticality of spent High-Level Nuclear Fuel in a Geologic Repository," 1993 Materials Research Society Fall Meeting, $v$, Boston, MA, November.

Two extended abstracts submitted to the 1994 International High-Level Radioactive Waste Management Conference, Las Vegas, Nevada titled:

Culbreth, W. G., and Zielinski, P. R., "Long-Term Effects of Poison and Fuel Matrix Corrosion on Criticality"

Zielinski, P. R., and Culbreth, W. G., "Calculation of keff for Vitrified Plutonium Waste Packages"

Copies of these two extended abstracts are included with this report. 


\title{
Long-Term Effects of
}

\section{Poison and Fuel Matrix}

\section{Corrosion on Criticality}

\author{
William G. Culbreth, Associate Professor \\ Paige R. Zielinski, Research Associate
}

\section{Introduction}

Nuclear criticality is a situation that must be avoided in any proposed waste package intended for the long term storage of high-level nuclear waste. 10 CFR 60.131 requires that the effective neutron multiplication factor must remain below 0.95 in any foreseeable situation encountered in a geologic repository. Previous studies have shown that, in the presence of water, critical conditions can exist in spent fuel waste canisters at relatively low values of initial fuel enrichment ${ }^{1,2}$, even when the effect of fuel burnup is included ${ }^{3}$.

In current waste package designs, it is assumed that low values of $k_{\text {eff }}$ will always be ensured by adding a suitable neutron poison, boron, in an aluminum or steel matrix. Unfortunately, significant changes in criticality will take place over time if the boron poison is removed from the waste package by corrosion and leaching at a faster rate than the fuel matrix.

In this study, a probabilistic model was used to predict the breaching of the waste package canister, resaturation of the interior, and dissolution of an aluminum-boron poison as well as the zircaloy clad uranium ceramic fuel pellets. For a typical waste package design, the results clearly indicate that differential removal of poison and fuel will lead to supercritical conditions 
in the presence of water.

\section{Description}

The release of radionuclides and poison from a spent fuel canister is influenced by many variables including the mean lifetimes of the canister wall and the cladding, release times for poison and fuel matrix, and resaturation times. A reasonable approach to the combination of these effects to predict the loss rate of fuel and poisons from the waste package is presented by Wilson ${ }^{4}$ in an analysis employing probability distribution functions to represent canister failure, cladding failure, and leaching rates. By assuming appropriate values for the corrosion rate of aluminum-boron ${ }^{5}$ and uranium fuel, the release times for these two materials were computed. Other assumed and computed values are listed in Table 1.

The addition of boron increases the corrosion rate of aluminum-boron composites $^{5}$ and a regression fit of the available data yields:

$$
\text { Corrosion Rate (microns/year) }-22.665+1.605 *(\% \text { Boron })
$$

This data was obtained by placing samples in a $3.5 \% \mathrm{NaCl}$ solution at $294 \mathrm{~K}$. A computer program was written to compute the fraction of poison and fuel matrix remaining in the waste package as a function of time.

As shown in figure 2, rapid release of Al-B occurs at 700-1000 years shortly after canister breaching and resaturation of the interior. Zircaloy cladding has an expected lifetime of approximately 10,000 years ${ }^{4}$ and this postpones the release of fuel matrix. After 100,000 years, virtually all poison and fuel have been removed from the waste package canister.

Based on the fraction of poison and fuel remaining in the waste package, the value of $k_{\text {eff }}$ was computed at various times. KENO-V, a Monte Carlo criticality simulation code, was used 
in this analysis.

\section{Results}

The resulting values of $k_{\text {eff }}$ are shown in figure 3 for $3 \%$ unirradiated fuel. The simulation used a $4 \mathrm{~m}$ long, $1.38 \mathrm{~m}$ diameter canister containing $21 \mathrm{PWR}$ fuel assemblies, placed horizontally in the drift of a geologic repository. The package was completely surrounded by saturated tuff in this simulation. To decrease the initial value of $k_{\text {eff }}$ to 0.95 (assuming flooded conditions), an aluminum-boron composite was added with $10 \%$ boron.

The effect of the early removal of the Al-B is dramatic. It should be noted that the uranium fissile mass decreases by only $0.01 \%$ over 100,000 years due to decay. By year 700 , the waste package has become critical and supercritical conditions are sustained until the uranium content begins decreasing. By year 50,000, the waste package contents again return to subcritical conditions and after 100,000 years, the inventory of fuel is almost completely removed from the package.

Although the poison and fuel removal rates will vary depending upon the local flow rates and chemical environment, the differential removal was most dependent upon the rather long period of protection that the cladding offered the fuel matrix.

\section{Conclusions}

The results demonstrate that the differential removal of poison and fuel from proposed waste packages can eventually lead to supercritical conditions in the presence of water. The simple addition of a neutron poison only ensures the control of criticality in the short term.

We suggest that techniques be used to prevent the early corrosion of poison material, either 
by using poisons with low corrosion and solubility rates or by protecting the poison material in a manner similar to the protection offered the fuel matrix by tha zircaloy cladding.

Alternative techniques should be explored to provide long-term control of criticality, including:

1. Addition of more poison (B).

2. Selection of a more stable, corrosion-resistant poison.

3. Match poison removal rates to fuel matrix removal rates.

4. Provide mechanical protection to the poison to minimize losses by corrosion.

5. Diversify the choices of neutron poisons. (e.g. $\mathrm{Hf}, \mathrm{Cd}, \mathrm{Gd}, \mathrm{Ag}, \mathrm{Au}$ )

\section{References}

1. Weren, B. H., Capo, M. A., and O'Neal, W. C., "Nuclear Criticality Safety Analysis of a Spent Fuel Waste Package in a Tuff Repository," UCRL-15575, December 1983.

2. Culbreth, W. G., and Zielinski. P. R., "The Importance of Criticality in the Safety Analysis of the Spent-Fuel Waste Container," Mat. Res. Soc. Symp. Proc., Vol 294, pp. 73-78, 1993.

3. Culbreth, W. G., and Zielinski, P. R., "The Effect of Fuel Burnup and Dispersed Water Intrusion on the Criticality of Spent High-Level Nuclear Fuel in a Geologic Repository," accepted for presentation at the 1993 Materials Research Society Meeting, Boston.

4. Wilson, M. L., "A Simplified Radionuclide Source term for Total-System Performance Assessment," SAND91-0155, UC-814, November 1991, 72 pages.

5. Pohlman, S. L., "Corrosion and Electrochemical Behavior of Boron/Aluminum Composites," Corrosion-NACA, Vol. 34, No. 5, 1978, pp. 156-159. 
Table 1

Parameters Used to Predict

Fuel and Poison Release Rates

\begin{tabular}{|c|c|c|c|}
\hline Parameter & Description & Value Used & Notes \\
\hline$t_{m}$ & Release Time for Fuel Matrix & $55,459 \mathrm{yr}$ & c \\
\hline$t_{p}$ & Release Time for Poison & $438 \mathrm{yr}$ & c \\
\hline$t_{2}$ & Release Time for Cladding & $10,000 \mathrm{yr}$ & c \\
\hline$\tau_{\mathrm{b}}$ & Lower Limit for Resaturation & $150 \mathrm{yr}$ & 1 \\
\hline$\tau_{\mathrm{b}}$ & Upper Limit for Resaturation & $300 \mathrm{yr}$ & 1 \\
\hline$\tau_{c}$ & Mean Canister Lifetime & $300 \mathrm{yr}$ & 1 \\
\hline$\tau_{\mathrm{f}}$ & Mean Cladding Lifetime & $10,000 \mathrm{yr}$ & 1 \\
\hline $\mathrm{L}_{\mathrm{r} \cdot \mathrm{U} 02}$ & Removal Rate of UO2 & $0.003 \mathrm{~mol} / \mathrm{m}^{2}-\mathrm{yr}$ & 2 \\
\hline$L_{r \cdot A l B}$ & Removal Rate of Al-B Poison & $23 \mu / \mathrm{yr}$ & 3 \\
\hline Notes: & & & \\
\hline c & \multicolumn{3}{|l|}{ - indicates a computed value. } \\
\hline 1 & \multicolumn{3}{|c|}{ - see ref [4] for applicable range of values. } \\
\hline 2 & \multicolumn{3}{|c|}{ - range: 0.003 to $2 \mathrm{~mol} / \mathrm{m}^{2}-\mathrm{yr}$, ref [4]. } \\
\hline 3 & \multicolumn{3}{|c|}{ - using equation (1) for $10 \% \mathrm{~B}$, ref [5]. } \\
\hline
\end{tabular}




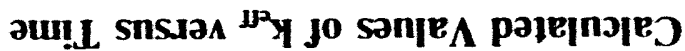
$z$ ansit

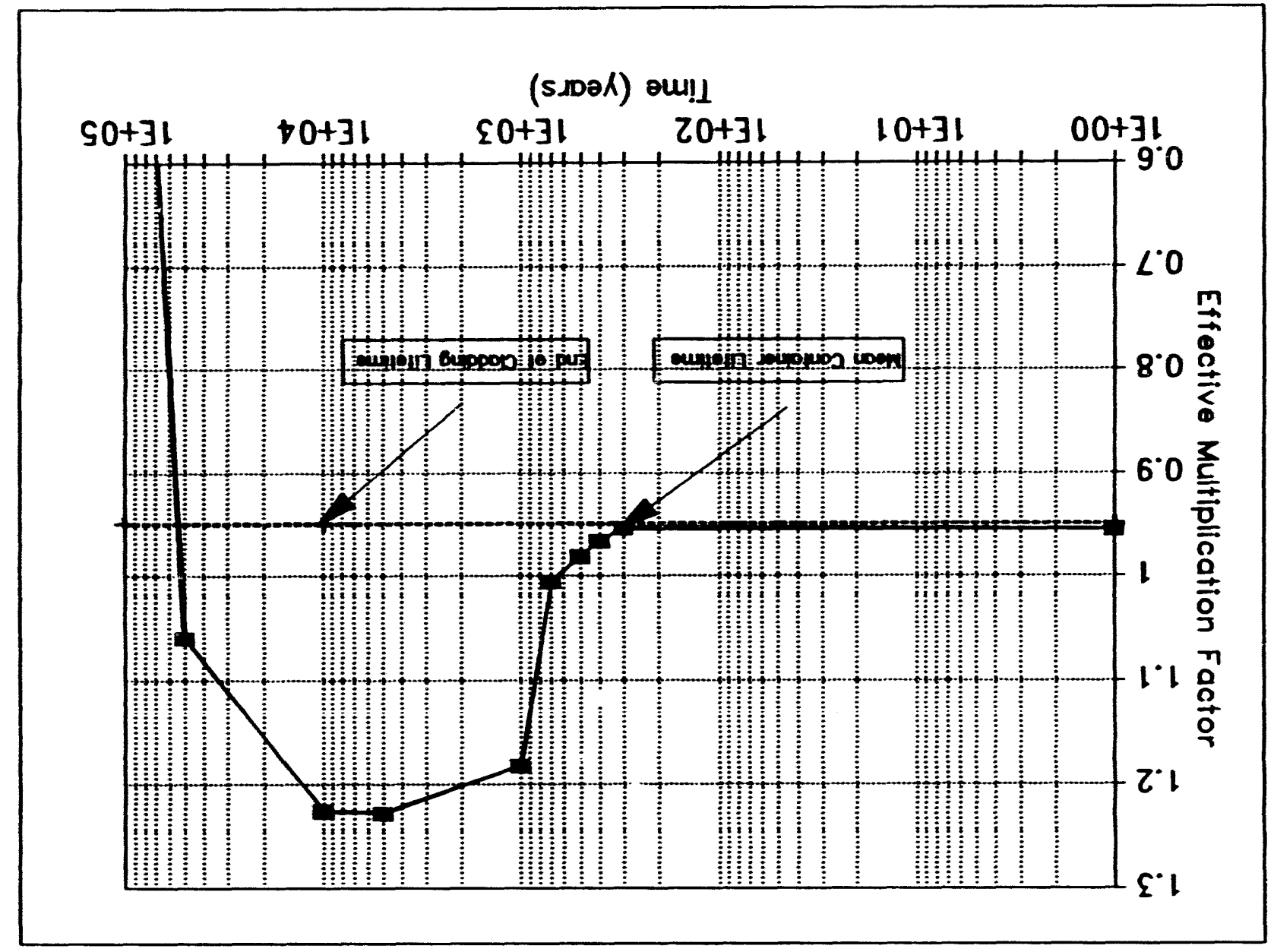




\title{
Calculation of $\mathbf{k}_{\mathrm{eff}}$ for \\ Vitrified Plutonium Waste Packages
}

\author{
Paige R. Zielinski, Research Associate \\ William G. Culbr sth, Associate Protessor \\ University of Nevada, Las Vegas
}

\section{Introduction}

Many studies of the proposed high level nuclear waste repository at Yucca Mountain, Nevada have concentrated on the problems associated with commercial spent fuel from pressurized and boiling water reactors. A considerable fraction of the waste destined for longterm storage will be defense high level waste with high quantities of fissionable plutonium. Current plans call for placement of $\mathrm{PuO}_{2}$ into borosilicate logs housed in thin walled 304L stainless steel containers. High fractional ratios of boron and lithium, two neutron poisons, in the glass are expected to ensure that the plutonium wastes will never attain criticality.

With a half life of 24,360 years, fissionable $\mathrm{Pu}-239$ poses potential criticality problem in the event that boron and lithium leach from the waste/glass mixture over time and are replaced by water. In this study, vitrified plutonium waste emplaced in boreholes in a tuff repository was analyzed for criticality in several cases that included the absence of a container wall, flooding of the surrounding air gap, loss of poisons, and fractional filling with water.

\section{Description}

The canister used in this analysis is depicted in figure 1 and is composed of a 3 meter high, 0.60 meter diameter 304L-SS container with a thickness of $10 \mathrm{~mm}$. The canister was surrounded with a $30 \mathrm{~mm}$ wide air gap and placed vertically into a borehole. To determine the worst possible critical case, it was assumed that the tuff was fully saturated with a porosity of $25 \%$ surrounded the canister. Tests were made with the air gap dry and completely flooded.

SRL-131 borosilicate glass was used in the model and varying quantities of $\mathrm{PuO}_{2}$ were added to the glass ranging from 0 to $3 \%$. This glass contains two principal neutron poisons, boron in the form $\mathrm{B}_{2} \mathrm{O}_{3}$ and lithium in the form $\mathrm{Li}_{2} \mathrm{O}$. The volume percentages of each of these oxides are $12.6 \%$ and $4.9 \%$ in the glass. In a geologic repository, it will take a very long period of time for the canister to be breached, to be resaturated with water, and for the poisons to be removed from the container. It was assumed that decay heat no longer exists at this point and liquid water will be in contact with the borosilicate glass. Without exploring the mechanisms that could lead to the elimination of the poisons, the worst case impact on criticality will occur if these poisons are removed entirely and if the void space left in the glass becomes flooded. To explore this worst hypothesized case, estimates were made of $k_{\text {eff }}$ for various degrees of flooding in this void space.

A neutron criticality-code, KENO5a4 was used to determine values of the effective neutron 
multiplication factor, $k_{\text {eff }}$ Hand calculations provided number densities and sigma-p corrections. In these simulations, the waste canister, canister wall, and air gap were surrounded by a cube of volcanic tuff 10 meters on each side.

\section{Results}

Computer analyses were conducted for $3 \% \mathrm{PuO}_{2}$ in borosilicate glass. The boron and lithium content of the glass was sufficient to suppress $k_{\text {eff }}$ to 0.115 for an intact canister wall with dry tuff and a dry air gap. By flooding the gap and saturating the surrounding volcanic tuff, the multiplication factor dropped slightly to 0.088 . Over time as the canister wall corrodes and is removed from the site, $k_{e f f}$ increased slightly to 0.091 for flooded conditions. The borosilicate glass did an

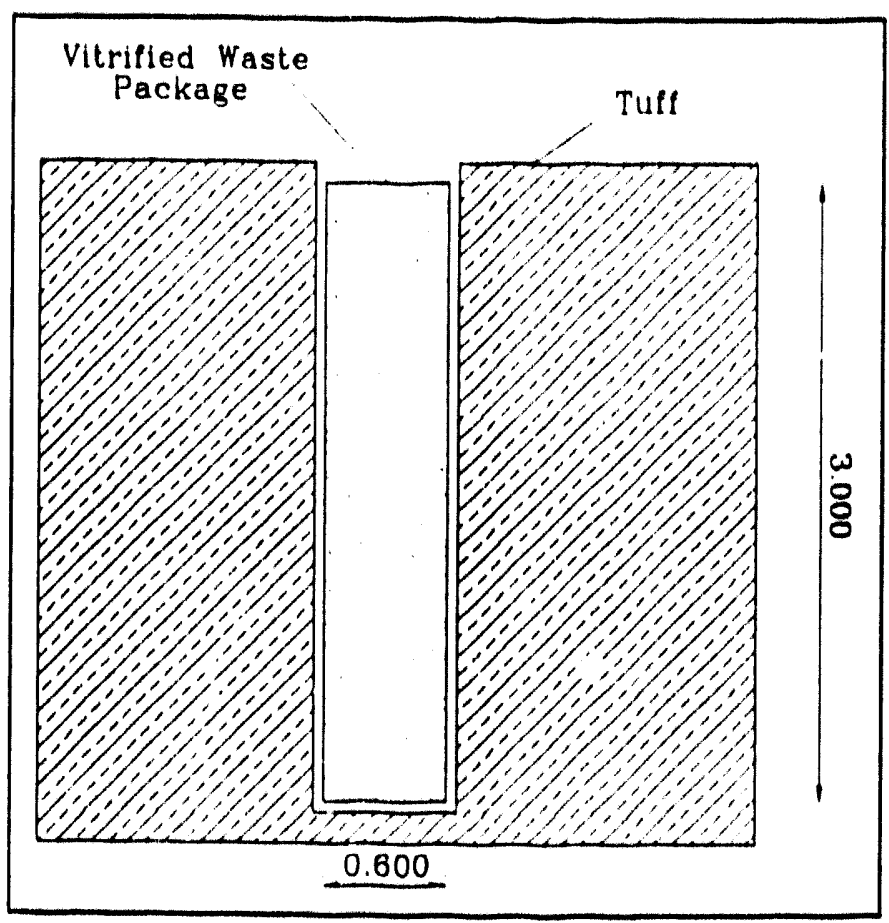

Figure 1

Vitrified Waste Container, Gap, and Surrounding Tuff excellent job in suppressing criticality under these conditions.

By assuming that both the lithium and boron oxides are removed from the vitrified waste, approximately $17.5 \%$ of the canister volume becomes available for water intrusion. Simply removing the poisons increases the multiplication factor to 0.59 . The effect of water added to the void fraction is dramatic increasing $\mathrm{k}_{\mathrm{eff}}$ to $1.08 \mathrm{in}$ the worst possible case. The results are shown graphically in figure 2. As seen in the figure, the point at which $k_{\text {eff }}$ exceeds the NRC limit of 0.95 occurs when nearly all available void space is filled with water. A linear regression of the data shows that this limit is attained when $12.2 \%$ of the original waste volume is filled with water.

\section{Conclusions}

The data demonstrates that critical conditions will exist in vitrified plutonium waste canisters only when all poisons were removed from the waste and water filled a considerable volume of the resulting void. Although this situation would not likely occur in a geologic repository, the addition of less water soluble neutron poisons would ensure that the effective neutron multiplication factor never exceeds 0.95 . This study suggests that the mechanisms that might lead to the differential removal of lithium, boron, and plutonium from the borosilicate glass shou!d be further studied. 


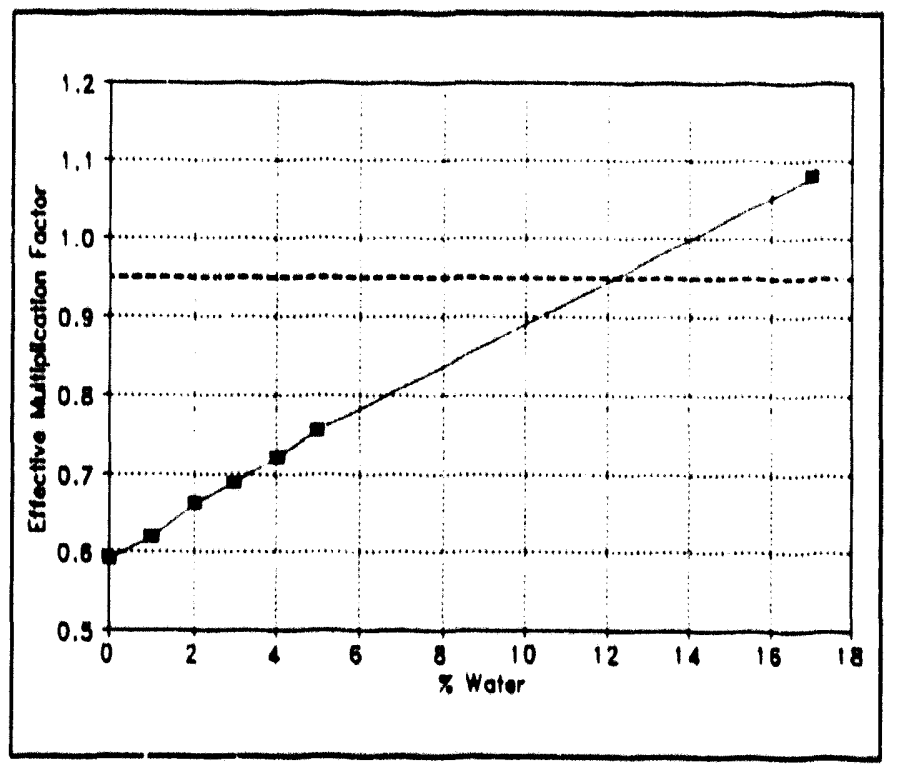

The test runs also showed that saturation of the tuff and flooding of the air gap surrounding the waste canister have very little impact on the criticality of the vitrified wastes.

Figlie 2

Multiplication Factor, $k_{\text {eff }}$ versus Water

Fraction

\section{References}

1. Schreiber, H. D, Schreiber, C. W., and Ward, C., "Redox Systematics in Model Glass Compositions from West Valley," Mat. Res. Soc. Symp. Proc. Vol. 294, 1993, pp. 8794.

2. Weren, B. H., Capo, M. A., and O'Neal, W. C., "Nuclear Criticality Safety Analysis of a Spent Fuel Waste Package in a Tuff Repository," UCRL-15575. December 1983. 
Task A.2.1 -- Waste Container Design Considerations

subtask: Experimental Drift Model

Faculty Researcher: Dr. William Culbreth

Title: Associate Professor of civil Engineering

student Assistant: Satish Pattisam

progress on topics in this category is summarized in the two attached abstracts that have been submitted to the $1994 \mathrm{High}$-Level Radioactive Waste Conference:

Culbreth, W. G., Pattisam, S., Jones, M. J., "Experimental Heat Transfer and Fluid Flow over Drift-Emplaced Canisters"

Culbreth, W. G., and Bhagi, "Review of Advanced Techniques for Waste Canister Labeling"

Results of computational studies related to the heat transfer in the repository were presented in a talk titled: "Computational Heat Transfer studies of the Proposed Nuclear Waste Repository". This talk was given at the Ninth International Conference on Mathematical and Computer Modeling held in Berkeley, California in July, 1993. A paper on the topic is under preparation for the conference proceedings and is to be completed by the end of october. 


\title{
Experimental Heat Transfer \\ and Fluid Flow over \\ Drift-Emplaced Canisters
}

\author{
William G. Culbreth, Associate Professor \\ Satish Pattisam, Graduate Resaarch Assistant
}

\section{Introduction}

The Jesign of canisters to be used for the long-term storage of high-level nuclear waste have progressed from the borehole model indicated in the original site characterization plan to driftemplaced multi-purpose containers. These canisters may contain 21 or more PWR fuel assemblies. Removal of decay heat becomes complicated since the zircalloy degradation temperature of $350 \mathrm{C}$ is not to be exceeded. In the preclosure drift system, air ventilation will provide convection cooling of the canister walls and radiative heat exchange with the drift walls

will remove decay heat. A proper design of the required ventilation system must be based on a knowledge of the total pressure drop experienced as the air passes through the drifts and over the waste canisters. The convective heat transfer from the canisters and the pressure drops may be determined through appropriate computer models, however, a scale experimental mor 31 of the drift/waste canister geometry will provide accurate results of dimensionless pressure drops and heat transfer coefficients as functions of air flow rate and ambient temperatures.

In this study, an experimental model of a repository drift was constructed at the University 
of Nevada, Las Vegas to investigate fluid flow and thermal transport. The model has provided pressure drop data, visualization of temperature distributions, and heat transfer coefficients.

\section{Description}

Three heat transfer mechanisms will affect the cooling of waste canisters in the repository drifts. Conduction through the pedestal, convection to the air, and radiation heat transfer to the drift wall all contribute to the removal of the maximum 21 kilowatis of heat from the package. Convective heat transfer is quantified through the non-dimensional Nusselt number:

$$
\mathrm{Nu}=\mathrm{hD} / \mathrm{k}
$$

where, $\quad h=$ convective heat transfer coefficient $\left(W / m^{2}-s\right)$.

$\mathrm{D}=$ characteristic dimension $(\mathrm{m})$.

$\mathrm{k} \quad=\quad$ air thermal conductivity $(\mathrm{W} / \mathrm{m}-\mathrm{s})$.

Nusselt numbers are functions of the air velocity, kinematic viscosity, drift and canister dimensions, and are best determined experimentally. As a non-dimensional parameter, Nusselt numbers obtained from a scale model can be directly applied to the full scale prototype.

The actual drifts will be approximately 7 meters in diameter and house waste canisters approximately 4 meters long with a diameter of $1.2 \mathrm{~m} .^{1}$ Crosstlowing air will be necessary to remove decay heat from the canisters and to provide an environment cool enough for human operators. The spacing between canisters will depend upon the desired area power density.

The laboratory model of the drift and emplaced wastes is shown in figure 2. Clear plexiglas tubing with an inner diameter of $152 \mathrm{~mm}$ was used to model the drift. The total length of the drift model was $8.5 \mathrm{~m}$. A slotted plate and flow straighteners were used to condition the input air flow. An automated pitot tube traverse with position feedback and a pressure transducer was 
used to measure the volumetric flowrate through the drift model. A computer-based data acquisition system controlled the traverse.

A 2 meter long test section housed models of the waste packages. The waste canister models were constructed from aluminum to a 1/50 scale. Core heaters were placed in the canister models to simulate the generation of decay heat. Variacs and power resistors were used to control the heat output and to measure the electrical power into each core heater. Thirteen type-K thermocouples ware used to measure the surface temperature of an instrumented canister and drift wall temperatures. The thermocouples wete connected to an amplifier/ice point reference. Data from the thermocouples was used to compuis Nusselt numbers as functions of both Reynolds and Prandtl numbers in the flow.

One canister model was coated with liquid crystals and photographs of the canister showed the temperature distribution as a function of ambient flow rate.

A precision micromanometer was used to calibrate the pitot tube traverse, measure the static pressure of the air inside the drift model, and to determine the pressure drop across the test section. The pressure drop data was nondimensionalized according to:

$$
C_{p}=\frac{\Delta p}{\frac{1}{2} \rho_{a i r} U^{2}}
$$

Additional instrumentation available in the laboratory included a Dantec two-component laser Duppler velocimeter and a TSI hot wire anemometer for air velocity measurements.

This flexible experimental setup has worked quite well for the measurement of pressure drops and heat transfer coefficients.

\section{Results}


Pressure drop data was acquired for a range of Reynolds numbers as shown in figure 2 . The spacing between canisters was varied and the data is valid for $d / L=0.375, \mathrm{~L} / \mathrm{D}=0.667$, and for $5,000<\mathrm{Re}_{\mathrm{b}}<60,000$. The data was obtained across a section that included 5 identical model canisters. The final report will contain curvefits of the accumulated data.

Color slides were taken of the canister coated with liquid crystals for various flowrates. The slides demonstrate that regions of limited flow exist near the bottom leading edge of each canister. These regions appear as hot spots and will affect the internal temperature of the spent fuel. Additional data to be presented in the final paper include overall Nusselt numbers as functions of Reynolds number, and canister spacing and geometry.

\section{Conclusions}

Proper modeling of the waste canister surface and internal temperature distribution will require a knowledge of the convective heat transfer that occurs in the drift. An experimental setup has been constructed that allows the measurement of overall and local Nusselt numbers. The ventilation system designer for the repository will require an accurate knowledge of the pressure drop to be experienced in the drifts due to the presence of the waste canisters and this data is also available from the setup. Results of the pressure drop and heat transfer experiments will be presented in the final paper.

\section{References}

1. Culbreth, W. G., "Computational Heat Transfer Studies of the Proposed Nuclear Waste Repository," Proceedings of the 9th International Conference on Mathematical and Computer Modelling, Berkeley, California, July 1993. 

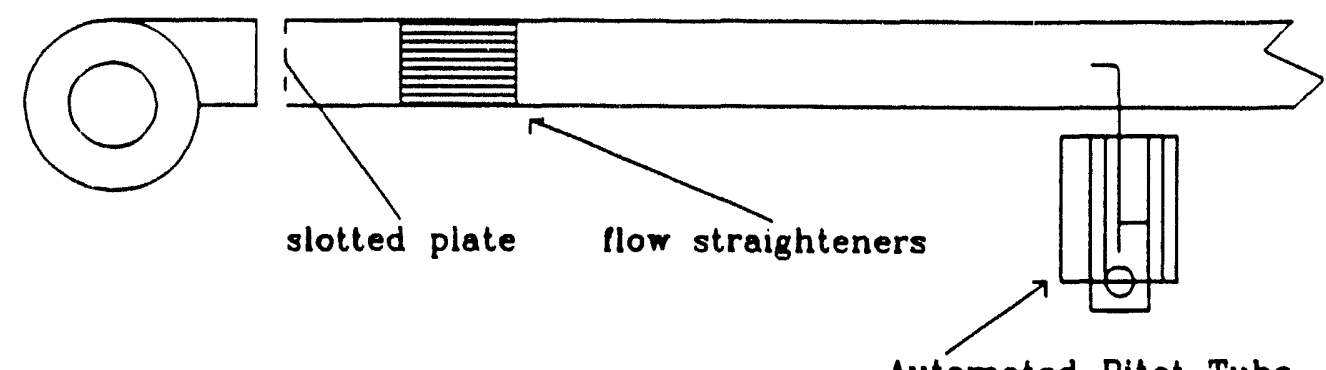

Automated Pitot Tube

Traverse

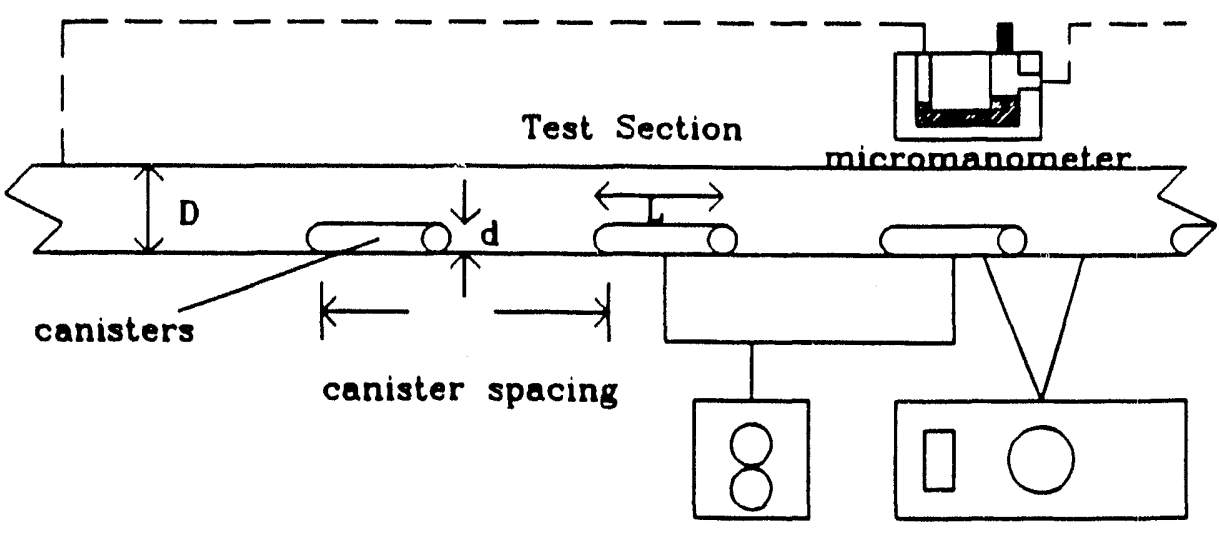

Core Heater

Thermocouple amplifier, variacs, ice point references, precision switch

resistors

Exit Section

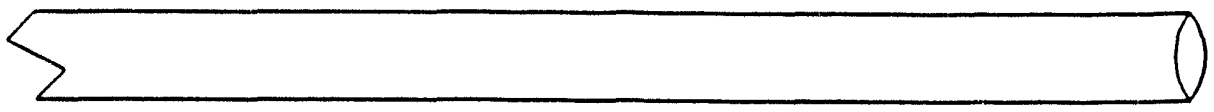

Total Length: $8.5 \mathrm{~m}$

Plexiglas Tube Inner Diameter: $0.15 \mathrm{~m}$

Figure 1

Experimental Setup for Fluid Flow and Heat Transfer Studies about Drift-Emplaced Waste Canisters 


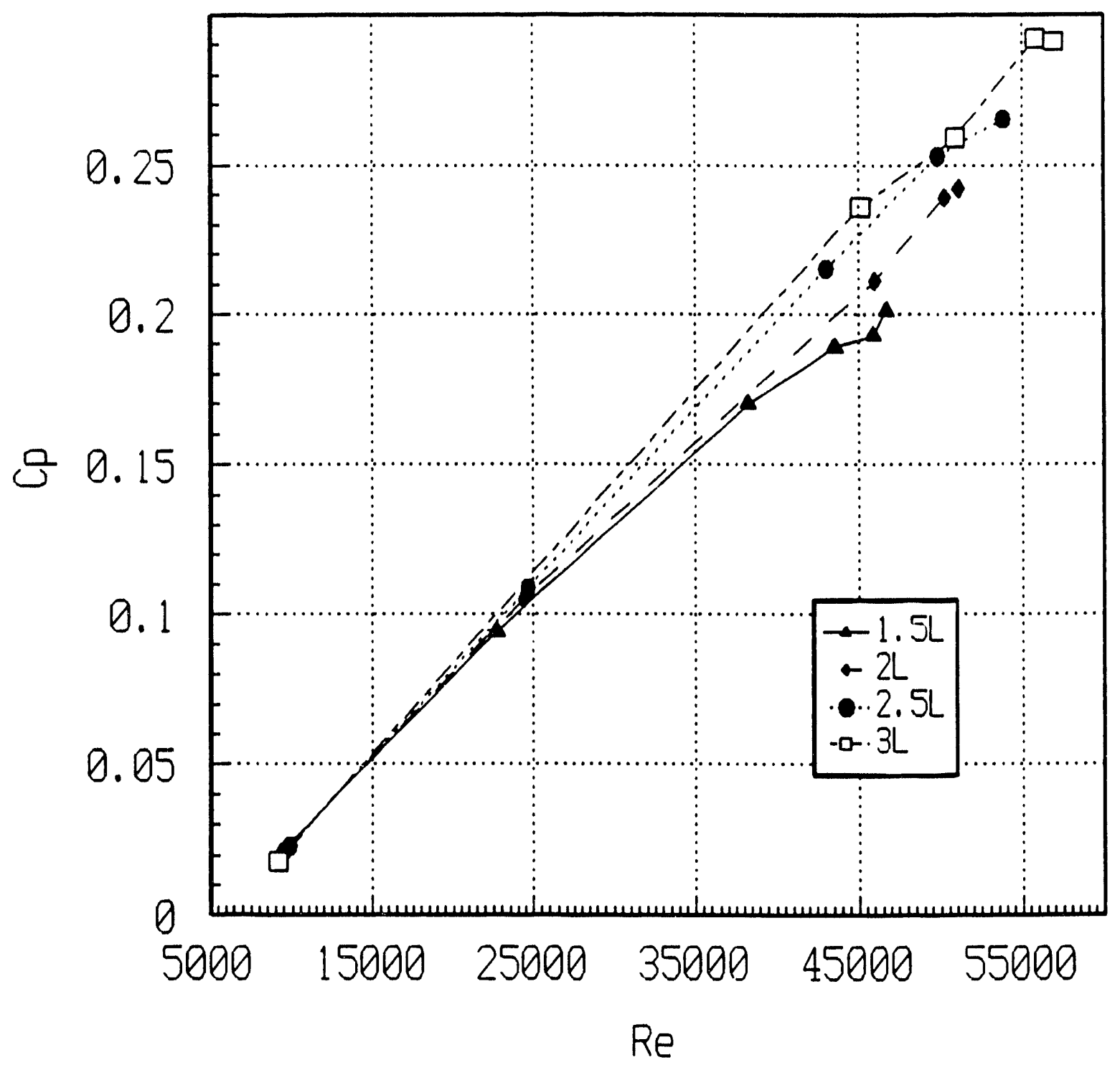

Figure 2

Pressure Drop Data for Drift-Emplaced Waste Canisters with Variable Canister Spacing 


\title{
Review of Advanced Techniques \\ for Waste Canister Labeling
}

\author{
William G. Culbreth, Associate Professor \\ Bharani Kumar Bhagi, Graduate Rescarch Assistant \\ Anand Kanjerla, Graduate Research Assistant \\ Department of Civil and Environmental Engineering \\ University of Nevada, Las Vegas $89154-4014$
}

\section{Introduction}

Federal regulation 10 CFR 60.135 will require that any spent fuel waste canister to be used in the proposed geologic repository must be labeled to uniquely identify the canister contents in a manner consistent with the repository's permanent records. This can be accomplished by embossing, machining, welding, or etching characters onto the side of each canister or affixing identification plates. These techniques have been discussed ${ }^{1}$, however, modern labeling methods used by industry provide new methods to meet the required goals while minimizing the chance of errors. These methods include radio frequency tagging systems, electronic tags, and advanced bar coding techniques.

\section{Description}




\section{Radio Frequency Systems}

Currently used by the shipping industry to track containers', these devices provide for an automated tracking of items. Basic RF systems are composed of a passive or active tag that is attached to an item. The tag contains memory, an antenna, and a transmitter/receiver system. It is activated by a reader also composed of an antenna and receiver. The tag may contain fixed information or be programmable. Active tags require a power source, usually lithium batteries lasting 5 years or less and have a cost between $\$ 50$ and $\$ 150$. They can transmit over a good distance and may contain several kilobytes of information that can be downloaded to the reader at high transmission rates.

Passive tags tend to survive better in harsh environments and are designed to receive power from the reader's antenna. These devices typically store only a few bits of information.

\section{Electronic Tags}

Electronic tag technology utilizes small transponder units that may be as small as a quarter ${ }^{2}$. Videx, Inc. of Corvallis, Oregon markets these units that hold a unique 56-bit identification number retrievable by touching it to a small handheld scanner. Electronic data carriers work in a similar fashion, but employ an inductively-coupled reader to read small button-sized tags over very short distances. These units store up to 16 kilobytes of information on an internal electronically-erasable programmable read only memory chip and work for up to 10 years with a limit of 10,000 program/erase cycles. Error detection techniques are used to maximize accuracy and reliability. ${ }^{5}$

\section{New Bar Coding Technology}


Bar coding technology is widely used in industry ${ }^{3}$ for the automated tracking of products. A Universal Code has made conventional bar codes widespread and they are currently used in nuclear power plants to track components and keep maintenance records. Conventional bar code is composed of parallel black and white strips holding 20 to 30 characters per inch. A denser format is now available in the form of two-dimensional bar code holding about 100 times the information in the same space as the conventional code. High speed laser scanners allow this code to be read rapidly. Symbol Technologies of Bohemia, New York is a major manufacturer of scanning equipment and now produces a system that allows scanners located on the end of robot arms to remotely read 2-D bar code from containers. New scanning systems allow users to read bar code from greater distances thereby increasing the safety of operators in radioactive or thermally hot environments. 2-D bar code often appears as a checkerboard with binary information coded in light and dark cells. Up to 1750 characters can be encoded in a small patch of bar code. Stacked and matrix 2-D bar codes offer greater reliability in the accurate retrieval of information that conventional bar code.

\section{Results}

Each of these new labeling techniques have advantages and disadvantages when considered for application to spent fuel canisters. Several of these may be summarized as follows:

\section{Passive RF Tags, Advantages}

1. Designed to withstand harsh chemical and hot environments.

2. Data may be received when the reader and the tag do not have a clear line of 
sight or visibility is low.

3. Tags are encapsulated to prevent damage by dirt, paint, liquids.

4. Very long lifespan.

5. Inexpensive (\$8 $-\$ 50$ per tag).

\section{Passive RF Tags, Disadvantages}

1. Limited memory, (only a few bits).

2. Data cannot be altered at certain stages of assembly or processing.

3. Transmission range is low.

4. Data is preprogrammed.

The results in the final paper will include a similar list for active RF tags, electronic data carriers, and 2-D bar code. A criteria matrix will be used to compare the relative usefulness of each of these techniques for application to waste canister labeling.

\section{Conclusions}

The three modern labeling techniques discussed earlier may be useful for meeting the goals of a unique labeling system compatible with the record keeping of the repository. They all lend themselves to a highly automated inventory/database system. The waste canisters may also benefit from redundant labeling to include an RF system for automated use and conventional welded characters for verification and backup. Bar coding and electronic tagging may be used for ancillary repository operations to keep track of instrumentation, maintenance recording, and 
supply inventory.

The relative merits of each of these modern labeling techniques will be discussed in the final paper.

\section{References}

1. Culbreth, W. G., and Chagari, A. K., "Labeling of the Spent Fuel Waste Package," Proceedings of the 3rd International High Level Radioactive Waste Management Conference, 1992.

2. Verity, J. W., "Goodbye Bar Codes, Hello Buttons," Business Week, May 18, 1992, p. $130 \mathrm{E}$.

3. Zipser, A., "Positive Identification," Barron's Mutual Funds, December 2, 1991, p. 44.

4. Hill, J. M., "Radio Frequency Identification - A Rundown on the Basics," Modern Materials Handling, June 1985, pp. 76-77.

5. Link, W., "Electronic Tags Replace Routing Forms," Machine Design, November 21, 1991, pp. 88-90. 


\title{
Task A.2.2 Waste Container Alternate Design Considerations David James, Assistant Professor of Civil Engineering Suneeta Mohansingh, Graduate student
}

\author{
Multi-Barrier Container Detailed Design
}

1. A paper abstract, "Multibarrier Borehole Canister Design for a Tuff Repository", by James, Skaggs and Mohansingh, has been submitted to the 5 th International High-Level Waste Conference in Las Vegas in May 1994. The abstract is attached in Appendix 1.

2. Calculations for several indices of corrosivity have been completed for J-13 well water. Ionic composition data for J-13 and simulated J-13 water were obtained from Beavers and Durr, 1991. They indicate that J-13 and simulated J-13 water used in corrosion tests, (absent any species produced by ionizing radiation) is a slightly depositing water type. Results:

$\begin{array}{llll}\text { CORROSION INDEX } & \text { WATER TYPE } & \text { TEMPERATURE } & \text { VALUE } \\ \text { Langelier Index } & \mathrm{J}-13 & 15^{\circ} \mathrm{C} & 0.043 \\ \text { Langelier Index } & \mathrm{J}-13 & 25^{\circ} \mathrm{C} & 0.041 \\ \text { Langelier Index } & \mathrm{J}-13 & 90^{\circ} \mathrm{C} & 0.027 \\ & & & \\ \text { Langelier Index } & \text { Simulated } \mathrm{J}-13 & 15^{\circ} \mathrm{C} & 0.042 \\ \text { Langelier Index } & \text { Simulated } \mathrm{J}-13 & 25^{\circ} \mathrm{C} & 0.039 \\ \text { Langelier Index } & \text { Simulated } \mathrm{J}-13 & 90^{\circ} \mathrm{C} & 0.029 \\ & & & 0.285 \\ \text { Larson's ratio } & \mathrm{J}-13 & 15^{\circ} \mathrm{C} & 0.293 \\ \text { Larson's ratio } & \text { Simulated } \mathrm{J}-13 & 15^{\circ} \mathrm{C} & \end{array}$

The Lanqelier index is used for assessing corrosivity of municipal drinking water supplies in water distribution systems. Waters with Langelier indices less than 0 are considered corrosive. Waters with indices greater than 0 are considered to be depositing. The higher the Larson's ratio value, the more corrosive the water. Waters with Larson's ratio greater than 1 are considered to be corrosive. According to JM Montgomery, 1985, numerical correlation between specific values of the Langelier index and Larson's ratio and corrosion rates of various types of pipe is poor; however, high Larson's ratios and negative Langelier indices are strong indicators of a tendency for rapid corrosion.

It must be noted, however, that aerated $\mathrm{J}-13$ water is not the most aggressive environment to which high-level waste canisters might be exposed. It is thought that hot, high-humidity air with oxidizing species produced by ionizing radiation will be the most aggressive environment for the canisters. Experimental results in Beavers and Durr, 1991, showed that the vapor phase caused pitting candidate copper-alloy container materials, and that the vapor phase of a 
solution containing 11202 raused pltind and itress orrosion cracking of alloy $304 \mathrm{~L}$.

3. We are considering several candidate materials for sacrificial anodes, including mild steel allo" 1010 , tinc, aluminum and inaqnesium, all of which are acti\%e ompared to andidate alloys being considered for container walls. Ver $i$ little corrosion data are available tor corrosion rates 1 the sacrificial materials in galvanic couples with container wall materials in J-13 or simulated J-13 waters. Cathodic protection handbooks recommend against. madnesium tor long-term applications. Some lata showing rapid corrosion of mild steel in contact with $304 \mathrm{~L}$ in $3-13$ are avaliable from CorTest columbus reports submitted to the II.S. Nuclear Regulatory Commission. These data were used for a preliminary sizing estimate for a sacrificial anode.

4. Using data from Beavers, Thompson and Durr, 1992, for corrosion of C1010 mild steel in simulated $J-13$ in contact with $304 \mathrm{~L}$, preliminary sizing calculations have been completed tor a mild steel sacrificial anode, giving a proliminary estimate of $45 \mathrm{ka}$ (with a factor of safet: of 2) for mild steel. Subsequent testina with other candidate alloys needs to be conducted to istimate corrosion rates for sacrificial anodes.

5. Reversal of corrosion potentials in einc-mild steel galvanic couples has been observed by some workers (Hoxeng \& Prutton, 1949, Hoxeng, 1950, Haney, 1982). Dissolved bicarbonate, carbonates and nitrates increased the reversal; dissolved sulfates and chlorides opposed the reversal. J-1.3 water contains significant quantities of bicarbonate, nitrate, and sulfate (Beavers and Durr 1991, p.15). Since Haney (1982) showed reversal occurring in $1-10$ hours at 50 $80^{\circ} \mathrm{C}$, similar short-term testing should be conducted to determine if potential reversal could occur for ainc (or other anodic candidates) in $\mathrm{J}-13$.

6. A request for a cost estimate from correst columbus rechnologies for corrosion testing of candidate mult ibarrier container materials was sent on september 18 . If the cost estimate is attractive, UNLV will initiate corrosion testing of candidate multibarrier container materials at their facility late in the 4 th quarter of 1993 . If the proposed costs are too high, INNLV will consider a start up of its own facility, with a start-up in the first quarter of 1994.

\section{REFERENCES}

Beavers, J.A., and C.L. Durr, "Immersion studies on Candidate Container Alloys tor the Tuff Repository" NUREG/CR-5598. Cortest Columbus Technologies, us Nuclear Requlatory Commission, office of Nuclear Regulatory Research, Washington DC. 108pp. (May 1991).

Beavers, J.A., N.G. Thompson, C.L. Durr, "Pitting, Galvanic and Lona-Term corrosion studies on candidate container Alloys for the Tutf Repository" NUREG/CR-5709. Cortest Columbus Technologies Inc, US Nuclear Regulatory Commission, office of Nuclear Regulatory Research, Washington DC 203 pp. 
Haney, E.G. "The inc-steel potential Reversal in athodic protection", Materials Pertormance, April 1982, pp.44-51.

Hoxena, R. and C. prutton, "Electrochemical Behavior of $:$ inc and steel in Aqueous Media," Corrosion, $\because 5$. pp.330-338 (1949).

Hoxena, R., "Electrochemical Behavior of zinc and steel in Aqueous Media-part II," Corrosion, $\because 6$, pp.308-312 (1950). Beavers, J.A.,

IM Montgomery, water rreatment. Principles and Desian. Wileyinterscience, New York. $1985 \mathrm{p}$. 
APPENDIX 1

GULTIBARRIER BOREHOLE CANISTER DESIGN FOR A TUFF REPOSITORY

David E. James', Robert L. Skaqgs', Suneeta Mohansingh

Department of Civil and Envirommental Enqineering,

Department of Mechanical Enaineerind

Iniversit $\because$ of Nevada, las Veqas 89154-4015

INTRODUCTION

Building on the concopt developed by skaqgs, et 11 . 1991, the authors have developed a desian for a multibarrier borehole canister that takes into account both current and tuture environmental conditions likely to occur in a tutf repository.

The proposed multibarrier design consists of an inner canister ot CDA 715, 708-308 copper-nickel alloy. The inner canister is similar in dimension to the 1983 baseline borehole canister desian developed by Lawrence Livermore National Labs in 1983. The inner canister sits on a speciall $;$ designed hiqh-lime concrete pedestal shaped to provide assistance in centering the canister. the inner canister is protected by a sacrificial anode which lowers the canister potential into the immune region. In this contiquration. the canister can be retrievol if a need subsequent: $\%$ develops to retrieve it.

once retrieval is ruled out, an outer canister at lacolloy 825 , lined with high-lime concrete ar sintered alumina is lowered onto the pedestal base. The pedestal base is contiqured to assist. centering and alignment of the outer shell. The outer shell is also protected with a sacrificial anode.

The outer shell is intended to provide resistance to corrosion under initial hot, dry conditions. The high-lime concrete or d lumina liner will provide an alkaline, passivating environment for the metallic liner materials. In case of water ingress to the repository during the time when containment if the isotopes is necessary, the cathodically protected inner barrier should be very resistant. to corrosion under moist conditions.

MATERIALS SELECTION

Review of corrosion lesting work carried ut for the NRC (Beavers s Durr, 1991) and materials pertormance assessments conducted by lawrence Livermore National habs, showed 1825 to be very resistant to all forms of corrosion attack. CDA 715 was the most resistant copper-based 11 loy tested but showed pitting in active corrosion environments. Sacrificial anodos may improve the performance of canister materials in these active environments.

Cathodic protection literature was reviewed to locate suitable candidate alloys for sacrificial anodes that vould meet the twin criteria of low corrosion rate and sufficientl $\%$ low potential (less than $-0.6 \mathrm{~V}$ SCE) to put the canister shell materials into the immune region of their pourbaix diagrams. Candidate anode materials are maqnesium alloy $A 231 \mathrm{C}$, aluminum, $\therefore$ inc, and mild steel alloy $1: 1010$.

\section{DESIGN AND ANALYSIS}

Thermal expansion and contraction calculations wero conducted for candidate materials using thermal analysis ut multi-barrier canister conducted by skaqgs, at al, 1991. Results indicated small dimensional changes in canister shell diameters for axpected temperature changes in the canister-repository system. 
Sacriticial anodes were initially sized isind corrosion tate lata for the most severe conditions found in literature, and inultipl $\because$ ind by a tactor of safet $\because$ of 2 , resulting in an estimated $45 \mathrm{~kg}$ mass for a c1010 anode interacting with the canister shell. corrosion rate results for :inc, aluminum and maqnesium vill be required betore anodes made ot these materials can be sized.

With a $5-10 \mathrm{~cm}$ air gap from the outer shell to the borehole wall, a $1.635 \mathrm{~cm}$ wall thickness tor the Incoloy 825 unter shell. 5 cm concrete liner thickness, and $.635 \mathrm{~cm}$ tor the inner DA 715 shell, riticality calculations using kENO $v$ showed a ketfective of $0.196 \div 0.002$ tor the multibarrier desian, compared to keff of $0.204 \div 9.001$ for the single barrier borehole canister desian.

Calculation of several indices used to estimate corrosivity of waters rerified previous experimental evidence of the relatively non-aggressive nature of $\mathrm{J}-13$ we 11 water. Langelier index values at $25^{\circ}$ and $30^{\circ} \mathrm{C}$, were slightly positive, indicating mild depositing

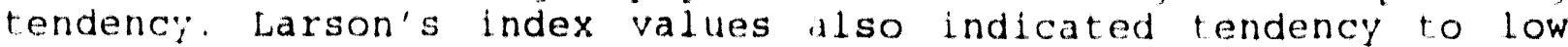
corrosion rates. Equilibrium calculation of chemical speciation of any aqueous medium should be conducted to determine which dissolved species are most likely to be present in aqueous media in the repository.

\section{FABRICATION}

Concrete casting methods used for making concrete-1.ined pipe are proposed for bonding of the inner concrete liner to the outer shell. Concrete lining will also improve structural strength of the outer shell, making it more resistant to compressive loads from backtill or trom collapse of wall of borehole.

\section{AREAS NEEDING EXPERIMENTATION}

Since Hoxeng and prutton, 1949, Hoxeng, 1950, and subsequent workers have observed potential reversal in inc-steel galvanic couples for certain solution compositions and temperatures, corrosion testing is recommended tor any proposed sacrificial anode - cathodic shell galvanic couple. It is planed to report results of the corrosion test proaram at the conterence.

\section{ACKNOWLEDGEMEN'T}

The authors thank paige zelinski and william culbreth, INLV civil Endincering tor the KENO $V$ criticality calculations and results.

\section{REFERENCES}

Beavers, J.A., and C.L. Durr, "Immersion studies on randidate Container .lloys for the iuft Reposicor" NUREG/CR-5598. Cortest Columbus Technoloqies, us Nuclear Requlatory Commission, office of Nuclear Regulator $\because$ Research, Washington DC. 108pp. (1991).

Hoxeng, R. and C. Prutton, "Electrochemical Behavior of :inc and Steel in Aqueous Media," Corrosion, $\because .5, p p, 330-338$ (1949).

Hoxend, P., "Flectrochemical Behavior of "inc and steel in Aqueous Media-Part II," Corrosion, $\because 6$, pp.308-\$12 (1950).

Skagqs, R., S.loujaes, Y.Lei, V.V. Gopal, "Thermal and Metalluraical considerations of a Novel vesian tor the Nuclear Waste canister," proceeding Nuclear waste Packaging focus 1 , ANS, ASCE Dublication, Ju19 1991, Pp. 153-159(1992). 
Thermal Simulation of lligh Level Nuclear vaste canister Emplacement

Task 2.A

prepared by:

Samir Moujaes, Associate professor

Yao Lei, Graduate student, ME Dept.

Akshay Bhargava, Graduate Student, ME Dept. 
8lmulation of Heat Transior Around a canister placed Horizontally in a Drift

Dr.Samir Moujaes Ph.D, P.E Associate Professor
Akshay Bhargava Graduate student University of Nevada, Las Vegas
Nevada

The Yucca Mountain Site Characterization Project is investigating the feasibility of locating a high level radioactive nuclear waste repository at Yucca Mountain, Nevada. The bore hole and in-drift waste emplacement schemes are under evaluation as potential repository drift geometries. This paper presents a two dimensional finite element thermal analysis of the nuclear waste container placed horizontally in a drift. The purpose of the simulation is to evaluate the relative effects of free convection and radiation on the resultant temperature and velocity flelds and to determine the temperatures on the drift walls as well as inside the waste package.

The computational domain of the chermal model is shown in Fig.1. All the thermal calculations are performed using the FIDAP finite element code. The thermal model extends vertically $300 \mathrm{~m}$ above the center of the drift (ground surface) and $300 \mathrm{~m}$ below the center of the drift (water table). The top horizontal boundary is kept at a constant temperature of 25 degc and the bottom horizontal surface is set at 35 degc. Adlabatic conditions are used at the symmetry planes between the drifts and at the center line of the drift. The entities in the computational domain are rock, air and nuclear waste. They have been deined by quadrilateral elements. Radiation elements are composed of the drift walls and the surface of nuclear waste container. The individual waste 
containers are placed end to end in the drifts and are collectively modelled as infinitely long drift with a circular cross section. The waste package is modeled as a single material.

The repository drifts are $6.7 \mathrm{~m}$ in diameter and spaced $44.5 \mathrm{~m}$ center to center. Each waste package is $1.67 \mathrm{~m}$ in diameter and $4.45 \mathrm{~m}$ in length and contains $30 \mathrm{~kW}$ of heat. The waste package has been considered as a heat source and is a part of the solution field. The rock is modelled as a continuum with average properties. The thermal conductivity of the rock mass is taken as a constant $(2.1 \mathrm{~W} \cdot \mathrm{m}-\mathrm{k})$. The surface emmissivities used for radiative heat transfer are 0.6 for the waste packages and 0.75 for the drift walls. The conductivities for the rock, air and nuclear waste are taken as constants.

FIDAP provides advanced capabilities for the modeling of radiation. The radiative heat transfer depends on the fourth power of the temperature where as for convection or conduction the transfer of heat depends on a temperature gradient only. Due to the dependence on $T$ the radiative heat transfer increases significantly as the absolute temperature increases and becomes a major mode of heat transfer. The drift emplacement removes heat from the waste package more effectively as the radiation heat transier to the large area drift walls is very effective.

In the problem, the method of successive substitution is employed with a relaxation factor equal to 0.9 . Due to the high non- linearity of the radiation exchange equation, the use of relaxacion factor is almost mandatory when performing a simulation involving grey body internal exchange radiation. The value of 
relaxation factor is more tied to the radiation number and less to Rayleigh number. In general, this relaxation is required for the temperature and the heat flux values rather than the velocities.

The flow is assumed to be strongly coupled i.e. buoyancy forces are dominant. The value of the initial guess plays an important role in the convergence behaviour of the simulation. The problem is first solved using the steady state energy equation without any heat source. This generated an initial guess for the temperature field. The problem is then run for transient state to determine the temperature and velocity fields for 1000 years. 


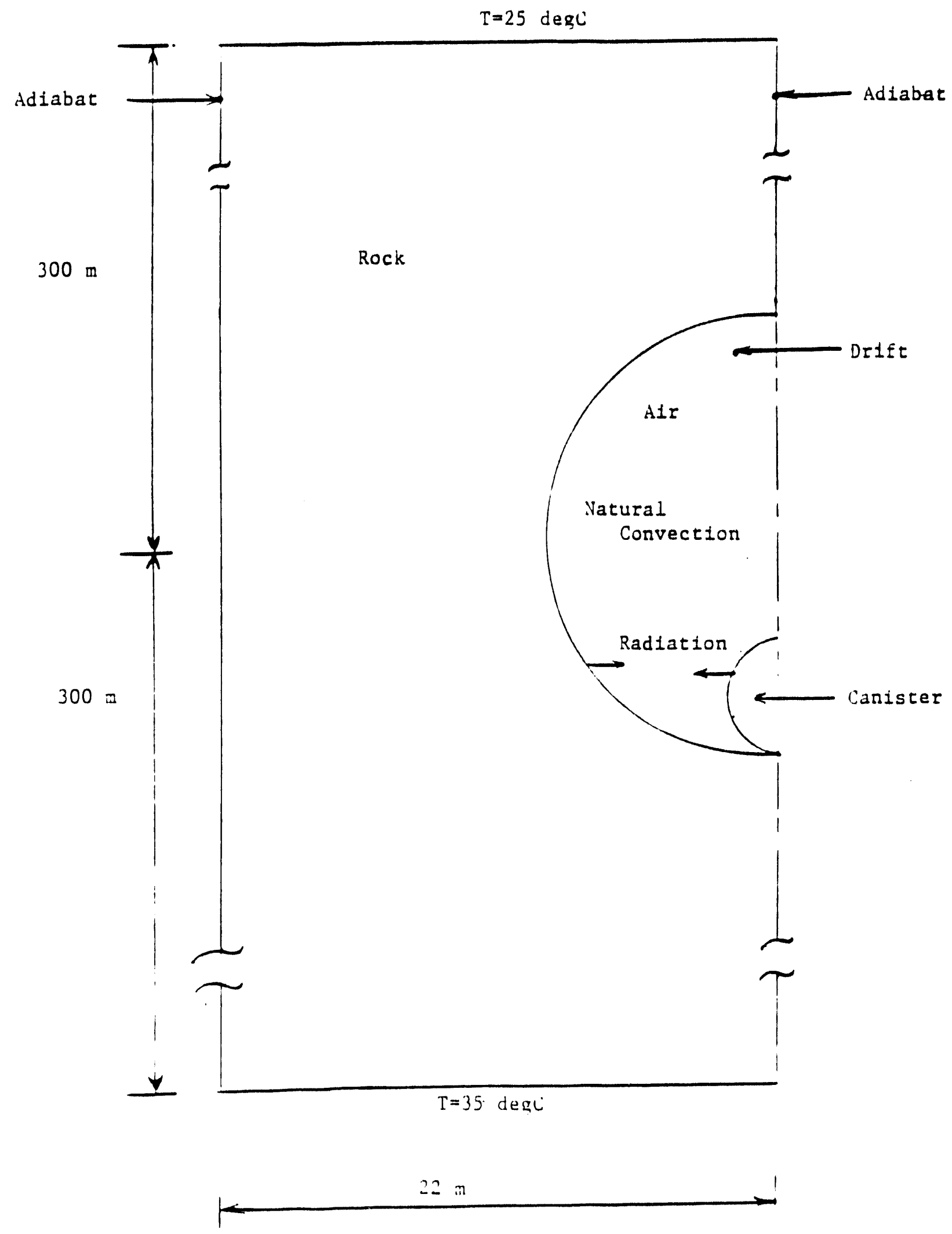

Figure 
SUMONARY:

Samir Moujaes, ME Dept., Yao Le1, graduate student

One of the important aspect for the high level nuclear waste container design is its thermal performance. This thermal performance will directly affect the container material selection, structural design, and the maximum allowable nuclear waste load per each container. For a vertically emplaced container, there is a thin air gap in between the outer container wall and the borehole rock wall. This air gap acts as a thermal barrier which will be a main factor to determine the maximum temperature inside the waste package. The limitation of this maximum temperature is the maximum allowable cladding temperature which is $350^{\circ} \mathrm{C}$. So solve the air gap problem is necessary for predicting the maximum temperature inside the high level nuclear vaste package.

A detailed numerical investigation has been performed on an vertical annulus air gap geometry to determine the temperature profile in the air gap and at the outer surface of the nuclear waste container. FIDAP was used for this axis-symmetric study. The problem is solved as a nonlinear axis-symmetric steady state problem with strongly coupled flows. The full set of the following equations are solved by FIDAP.

continuity equation:

$$
\frac{1}{r} \frac{\partial}{\partial r}\left(\rho r u_{z}\right)+\frac{\partial}{\partial z}\left(\rho u_{z}\right)=0
$$

momentum equations: 


$$
\begin{aligned}
& \rho\left(\frac{\partial u_{z}}{\partial t}+u_{z} \frac{\partial u_{z}}{\partial r}+u_{z} \frac{\partial u_{z}}{\partial z}\right) \\
= & \frac{1}{r} \frac{\partial}{\partial r}\left(r \sigma_{z I}\right)-\frac{1}{r} \sigma_{3 \theta}+\frac{\partial \sigma_{z z}}{\partial z}
\end{aligned}
$$

$$
\begin{aligned}
& \rho\left(\frac{\partial u_{z}}{\partial t}+u_{z} \frac{\partial u_{z}}{\partial r}+u_{z} \frac{\partial u_{z}}{\partial z}\right) \\
& =\frac{1}{r} \frac{\partial}{\partial r}\left(r \sigma_{z z}\right)+\frac{\partial \sigma_{z z}}{\partial z}
\end{aligned}
$$

$$
\begin{aligned}
& \sigma_{z z}=-p+2 \mu \frac{\partial u_{z}}{\partial r} \\
& \sigma_{\theta \theta}=-\rho+2 \mu \frac{u_{z}}{r} \\
& \sigma_{z z}=\mu\left(\frac{\partial u_{z}}{\partial z}+\frac{\partial u_{z}}{\partial r}\right) \\
& \sigma_{z z}=-p+2 \mu \frac{\partial u_{z}}{\partial z}
\end{aligned}
$$

energy equation:

$$
\begin{aligned}
& \rho c_{p}\left(u=\frac{\partial T}{\partial r}+u=\frac{\partial T}{\partial z}\right) \\
& \left.=\frac{1}{\Sigma} \frac{\partial}{\partial r} ; \therefore r \frac{\partial T}{\partial r}\right)+\frac{\partial}{\partial z}\left(k \frac{\partial T}{\partial z} ;-G^{\prime \prime \prime}\right.
\end{aligned}
$$


where $p$ is the density, $c_{p}$ is the specific heat of, $k$ is the heat conductivity, $u_{r}$ and $u_{\text {: }}$ are the fluid velocity components, $\sigma_{1 j}$ is the stress tensor, $\beta$ is the volume expansion coefficient, $T$ is the temperature.

The temperature history on the rock over a thousand years after emplacement has been obtained (see flgure 1. The time history plot). It was used to solve the air gap problem. In this study, the problem was set-up as a set of vertically placed concentric cylinders which the inner one had the boundary condition of imposed constant heat flux, the outer one had a boundary condition of uniform temperature, and both ends of the gap are adiabats. The vertical aspect ratio of this problem is 80 (the high to the width) and a no-slip condition was applied to all walls. There are two kinds of simulations can be done on this problem, one is simulating the heat convection as the only heat transfer mechanism, the other one is to run the problem combining the heat convection and radiation. The intent here is to show the relative magnitude and hence importance of the tivo mechanisms in controlling the temperature of the core material. Hence air gap temperature profiles with only heat convection as the heat transfer mechanism, will be compared to the result of both heat convection and radiation as the heat transier mechanisms to show the relevant effects. The temperature history at the outer waste container wall is then used to predict the maximum temperature at the center of the container for the purposes of determining how that will affect the container design. This will be done by making the assumption that transient changes in the container will be much faster than 
those in the rock and hence a simplified steady state analysis of the temperature distribution inside the canister will be made assuming that the process is that of a uniform volumetric heat generation inside the canister. Also on the air side its thermal inertia is considered much lower than the rock, therefore the thin air gap will reaches its steady state instantaneously compare to the rock mass. Hence fifteen time intervals were used to cover the span of a thousand years are good enough to show the change of temperature profile in the air gap as well as the air flow fleld profile.

Because the Rayleigh number is the main factor which controls the solution convergence the solutions have to be built from low Rayleigh number. So the air gap problem was solved from the end of a thousand years after emplacement of the nuclear waste container, then backward to get solution for the beginning of the emplacement. For the result of the air flow pattern, it could be a single cell flow or a multi cellular flow inside of the air gap. Both cases have been seen in the different runs of the simulation (see figure 2, and 3. The streamline contour plots).

since the problem is still in progress, the results will be presented as they become available. 


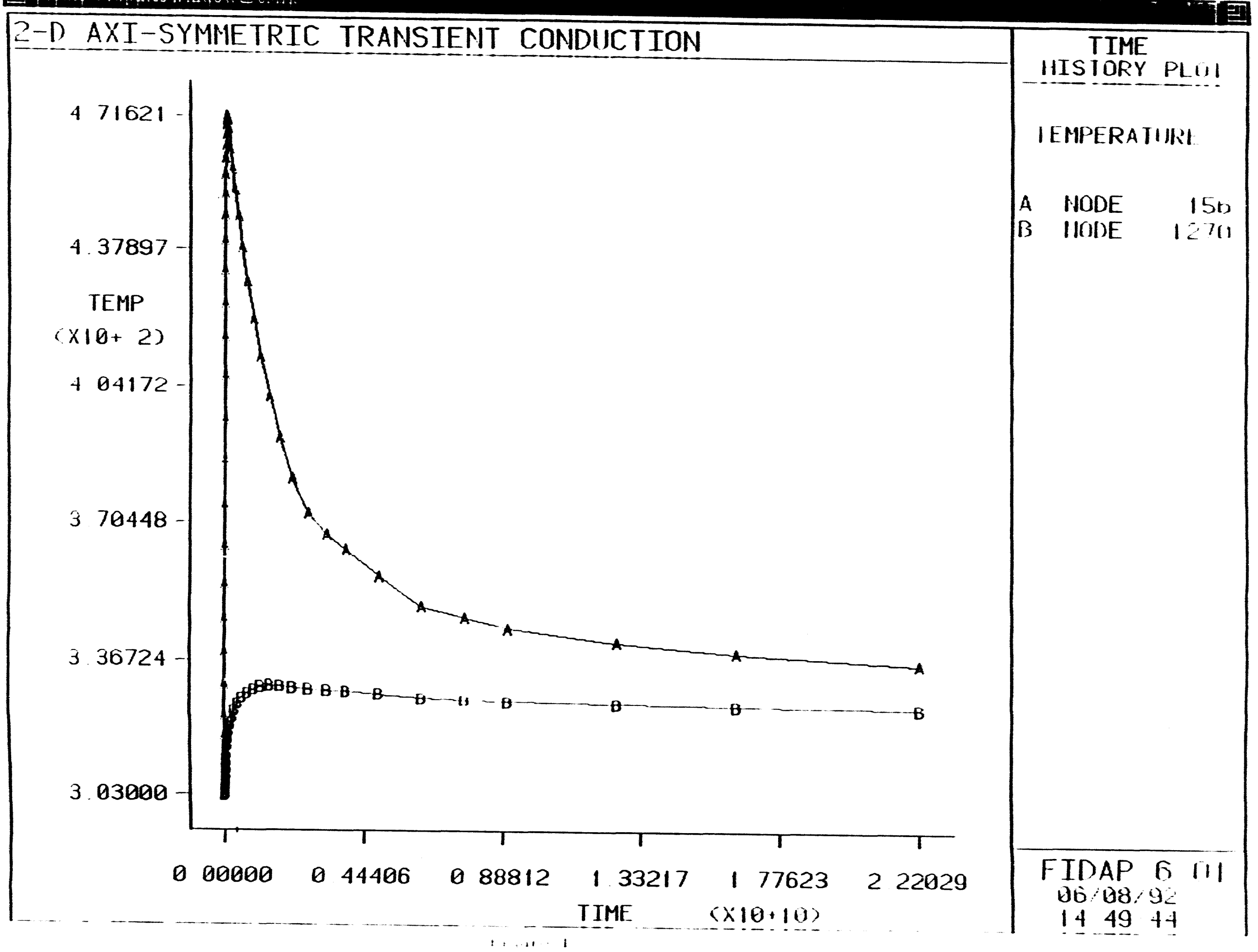




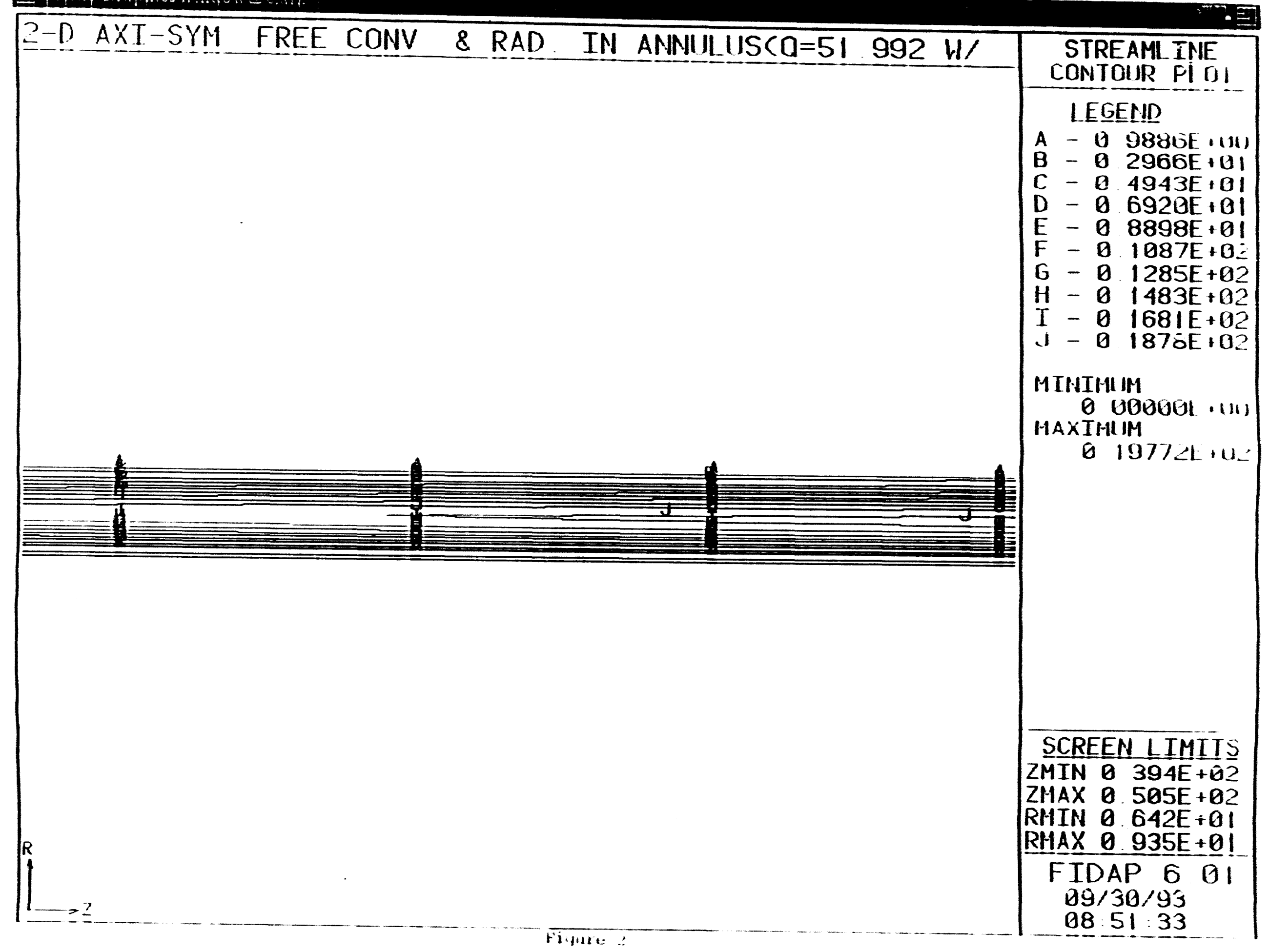




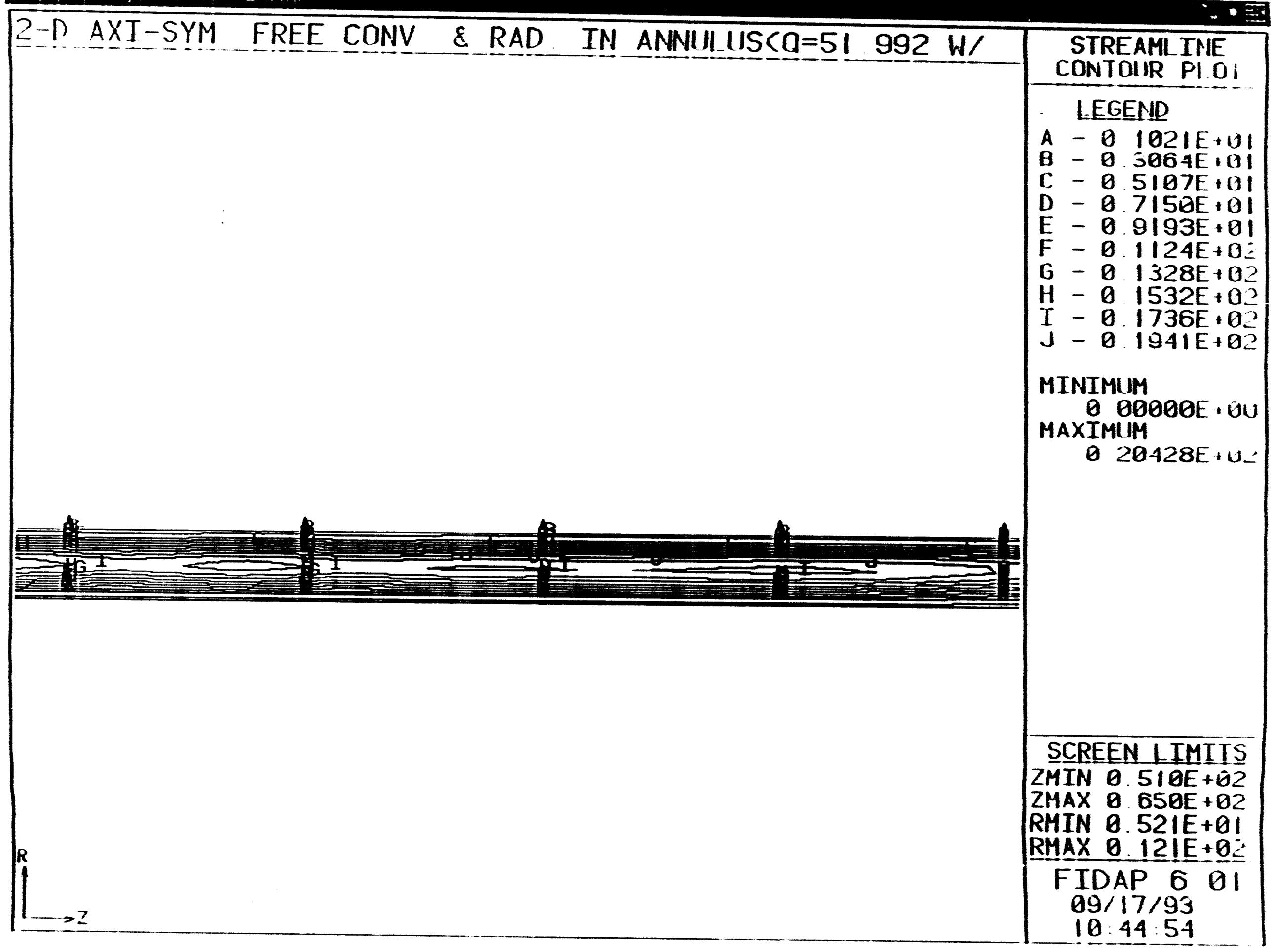




\section{Task B.1.1 -- structural Analyole and Design of Nuolear wate paokage candster}

Dr. Bamaan Ladkany, P.E. professor of Civil anvironmental angineering Rajkumar Rajagopalan, Graduate Btudont 


\section{Task B.1.1. Btruotural Analysis and Design of waste Package}

canieter

Faculty Researcher: Dr. Samaan Ladkany

Title: Professor of Civil Engineering and Director, DOE Waste Package Project, University of Nevada, Las Vegas

Student Assistant: Rajkumar Rajagopalan

\section{B.1.1.1. Introduction}

Using data, provided by Doering, Bahney et.al' of the B\&W Fuel Co., concerning the proposed design of a Multipurpose Canister (MPC), the critical stresses in the eyebolts, flat outer iffing lid, inner lid, shield plug, the cylindrical shell and weldments of a high level nuclear waste MPC are evaluated under a variety of static and dynamic loading conditions resulting from normal handling. Axisymmetric, linear and nonlinear thick and thin shell elements are used to model the MPC shell. Results are compared to theoretical analysis whenever possible. The MPC shell, shown in Figure 1, will be used for the storage and transportation of high level nuclear waste (HLNW) to the site of a repository. The shell of the spent fuel rods will be placed inside an inner barrier container then an outer barrier container' for long term storage in geological formations.

The MPC shell is designed to hold 21 PWR assembly and weighs 125 tons. The shell is $0.0254 \mathrm{~m}$ ( 1 in) thick, $4.9 \mathrm{~m}$ (193 in) long and $1.532 \mathrm{~m}(60.3 \mathrm{in})$ in diameter. The MPC shell design is also provided with outer and inner lids. The outer lifting lid which is welded to the shell is $0.07 \mathrm{~m}(2.75 \mathrm{in})$ thick and is provided in the design with $0.051 \mathrm{~m}$ ( 2 in) size removable eyebolts, having a yield stress of $490 \mathrm{MPa}(70,000 \mathrm{psi})$ and a tensile strength of $665 \mathrm{MPa}$ $(95,000 \mathrm{psi})$. The eyebolts are designed to be screw installed into the outer IId and be used for canister lifting purposos. The $0.051 \mathrm{~m}(2 \mathrm{in})$ thick inner $11 \mathrm{~d}$ is also welded to the shell with a $0.025 \mathrm{~m}$ ( 1 in) effective throat weld. The two 1 ids are separated with a $0.025 \mathrm{~m}$ (1 in) thick steel honeycomb spacer. The MPC is provided in the design with a shield plug of $0.051 \mathrm{~m}$ ( 2 in) Depleted Uranium (du) clad in $0.012 \mathrm{~m}(0.5 \mathrm{in})$ steel on top and sides, and $0.057 \mathrm{~m}(2.25 \mathrm{in}) 316 \mathrm{~L}$ stainless steel on bottom.

Two materials are candidates for the shell, the primary candidate is $316 \mathrm{~L}$ stainless steel having $22 \mathrm{MPa}(32,000 \mathrm{psi})$ yield stress, an ultimate strength of $586 \mathrm{MPa}(85,000 \mathrm{psi})$ and high resistance to crack initiation. The secondary candidate for the design of the shell is Alloy 825 . 
The MPC shell is designed to house an al/boron basket sandwiched between stainless steel containing 21 square tubes, $4.11 \mathrm{~m}$ (162 in) long and $0.254 \mathrm{~m}(9.99 \mathrm{in})$ wide.

\section{B.1.1.2. Deecription of Actual work}

In our previous publications, 19.6 two of which"s were presented at the HLNW conference held at Las Vegas, in 1992 and 1993, we analyzed the structural performance of the previously proposed ${ }^{7, x}$ $0.0095 \mathrm{~m}(0.375 \mathrm{in})$ thick canister, having either a $0.0051 \mathrm{~m}$ ( 2 in) thick top plate with a pintle or an ASME flanged and dished shaped tophead. The analysis proved that this thin canister would not adequately resist the forces that may develop during various lifting, transportation and accident scenarios'. Stress levels that exceeded the yleld strength of the $304 \mathrm{~L}$ stainless steel would develop in the canister leading to the potential of stress corrosion cracking early in the life of the permanently stored HLNW canister. It was for this purpose that we recommended' that a robust nuclear waste container be designed.

In this paper, we present stress analysis performed on the MPC shell, that is similar in type to the analysis presented in our earlier work ${ }^{156}$.

\section{B.1.1.2.1. Finite Element Models} she 11:

We have developed three finite element models for the MPC

1. Axisymmetric thin shell element model.

2. Linear/Nonlinear four node thin shell elements capable of large structural deformations.

3. Linear/Nonlinear four node thick shell elements, capable of elasto-plastic material behavior and large structural deformations.

The axisymmetric shell element model is used in providing stress level checks in the elastic ranges and to compare results with the other 3D shell models. Examples of the finite element shell models for the MPC shell are shown in Figure 2 .

\section{B.1.1.2.2 woldment}

In the axisymmetric shell element model and in the four node thin/thick shell element models, the weld is represented as the frustra of a hyperboloid shell of revolution. This technique was used in our earlier work and yielded excelient results when compared to 2D axisymmetric analysis' of the weldment and to theory". 


\section{B.1.1.2.3 Loading Conditions}

In the analysis, the nuclear canister models are subjected to the type of loading that would result from normal handing conditions. Critical stresses and displacements in the canister models are evaluated due to the following loading conditions:

A. Dynamic lifting of canister shell in the vertical position.

B. Dynamic lifting of canister shell from a horizontal position.

C. Accidental slippage of crane cable carrying loaded canister shell.

D. Accidental drop of one canister shell onto another.

VI. STRESS ANALYSIS OF THE WASTE CONTAINER

Preliminary analysis"' indicates that the maximum axial and circumferential stresses in the bottom plate under the 125 ton loading are in the neighborhood of $105 \mathrm{MPa}(15,000 \mathrm{psi})$. This stress does not include stresses due to accident scenarios or lifting crane accelerations.

The $0.025 \mathrm{~m}(1 \mathrm{in})$ weldments have an ultimate strength of approximately $20.7 \mathrm{MN} / \mathrm{m}(18,000 \mathrm{lb} / \mathrm{in})$ which is quite conservative for the design of the MPC shell. The eyebolts each have a simple tensile carrying capacity of $0.63 \mathrm{MN}(139,0001 \mathrm{~b})$, a shear capacity of $0.39 \mathrm{MN}(87,000 \mathrm{Ib})$ and a capacity of $0.39 \mathrm{MN}(87,000$ 1b) under combined tension and shear, a loading condition which may occur at $45^{\circ}$ when the canister shell is being lifted from a horizontal position".

Detailed finite element studies 11.12 are performed in the analysis, results are compared with theory $y^{910}$ whenever applicable. Figure 3 shows elasto-plastic analysis indicating progressive ylelding of the canister shell under radial loading conditions which may result from accidental drop of one canister onto another.

If a Canister is lifted suddenly, the equivalent dynamic load is twice the weight of the Canister. The deflected pattern (exaggerated) of the canister is shown in Figure 4. The maximum von Mises stress in the bottom weld (weld between the bottom plate and the MPC shell) due to such a loading is $62.975 \mathrm{MPa}(91,600 \mathrm{psi})$ and is shown in Figure 5. The bottom weld was assumed to be $0.0095 \mathrm{~m}$ $(0.375$ in) fillet weld, a design adopted from the previous canisters. Since the stress in the bottom weld is too high, a thicker weld will be designed for this connection. The maximum radial and circumferential stress in the bottom plate under this loading is $20.9 \mathrm{MPa}(30,500 \mathrm{psi})$ as shown in Figure 6 and is less than the yield stress of $22 \mathrm{MPa}(32,000 \mathrm{psi})$. The results were verifled with theory ${ }^{10}$ and were found to be exact. 


\section{B.1.1.3 Conclusions}

dies of the structural performance of an MPC shell under normal handling conditions are performed using nonlinear finite element analysis and theoretical analysis. Stresses that may lead to crack initiation, under normal handling or accidental loading conditions are discussed.

\section{Acknowledgement}

This research work was done under a grant by U.S. Department of Energy \#DE-FC08-90NV10872.

\section{References}

1. T. Doering, R. Bahney et al., "Private Communication," B \& W Fuel Co., Management and operating Contractor, Civilian Radioactive Waste Management System, Las Vegas, NV, September (1993).

2. US DOE Office of Civilian Radioactive Waste Management, "MPC Conceptual Design Report," DOW/CRWMS M\&O Document Identifier : A0000001-01717-5705-SSSSB September (1993).

3. S.G. Ladkany and B.R. Kniss " Critical stresses in pintle, weldment and tophead of nuclear waste container", High Level Radioacilive Waste Management, Proceedings of the $3^{\text {rd }}$ International Conference, Las Vegas, Nevada (1992).

4. Nuclear Regulatory Commission, "Packing of Radioactive Material for Transport and Transportation of Radioactive Material Under Certain Conditions," 10CFR part 71, Federal Regulations, (1982).

5. S.G. Ladkany, P. Gan and R. Rajagopalan, "Critical Stresses in Nuclear Waste Container Under Normal Handling Conditions," Proceedings of the HLNW Management Conference, Las Vegas, Nevada, April (1993).

6. S.G. Ladkany and R. Rajagopalan, "On the structural stability of Large Steel Spent Nuclear Fuel Canisters", Structural stability Research Council, Proceedings of the Annual Technical session, Milwaukee, Wisconsin, April (1993).

7. L. B. Ballou, "Current Status of Waste Package Project Designs for the Yucca Mountain Project," UCID-100790, Lawrence Livermore National Laboratories, July (1989).

8. D.W. Gregg and W.C. O'Neal, "Initial Specifications for Nuclear Waste Package External Dimensions and Materials," UCID19926, Lawrence Livermore National Laboratory, September (1983).

9. C.G. Salmon and J.E. Johnson, Steel Structures, Third Edition, Harper and Row, New York (1990). 


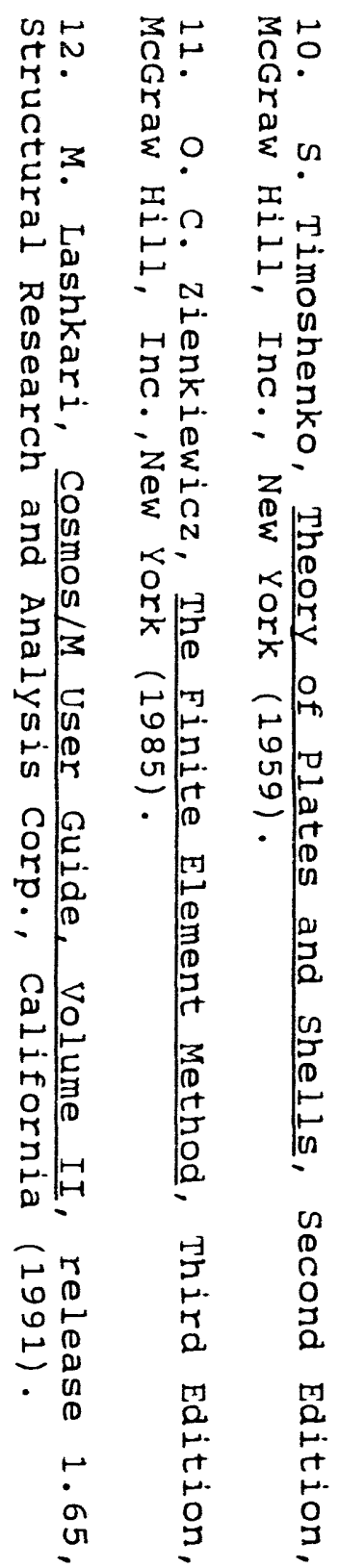




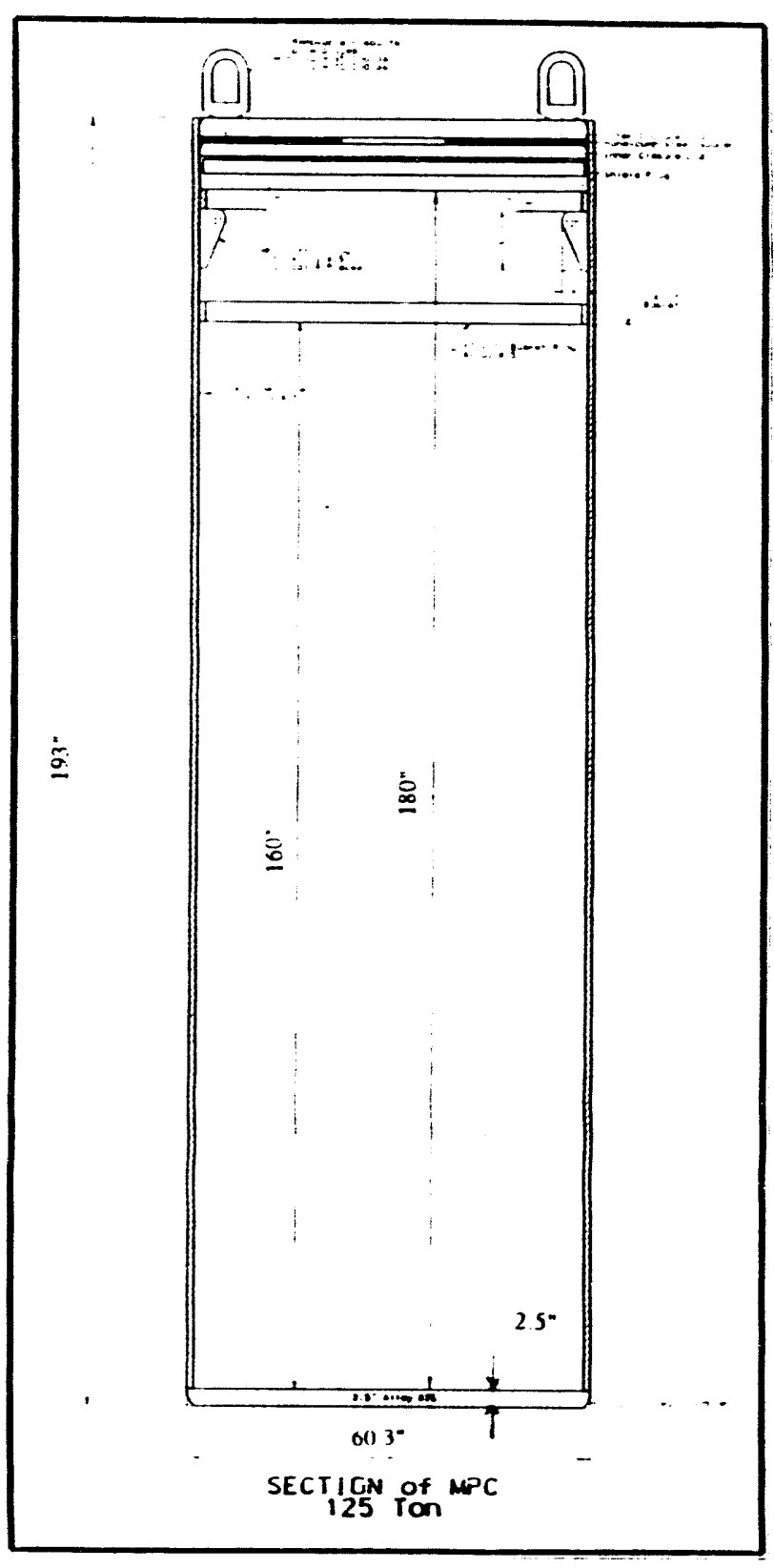

Figure 1a. Cross-section of 125 Ton MPC. (From Reference 1)

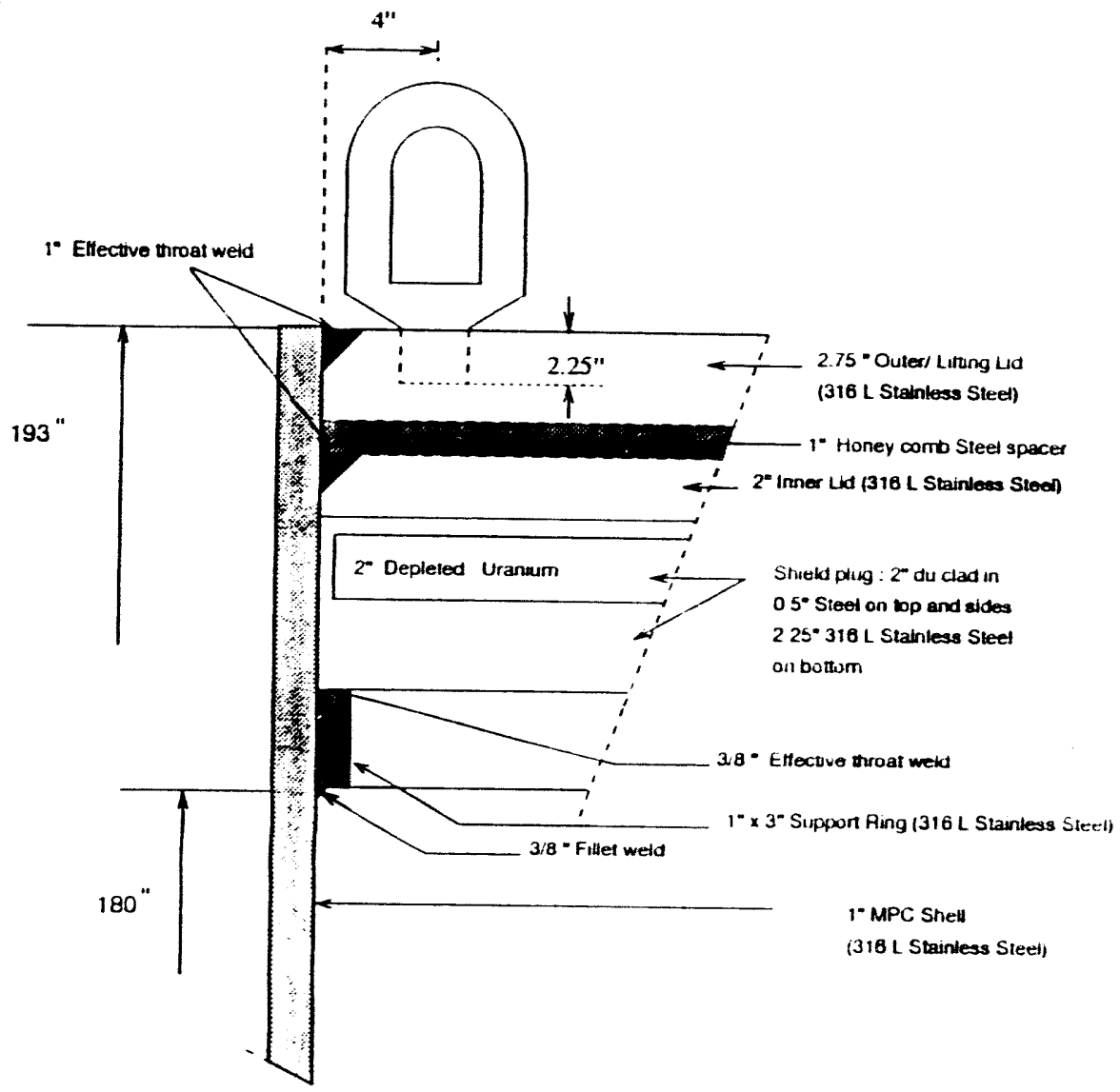

Figure 1b. Cross-section Showing Details of Outer Lid, Inner Lid, Eyebolts and Shield Plug. (From Reference 1) 


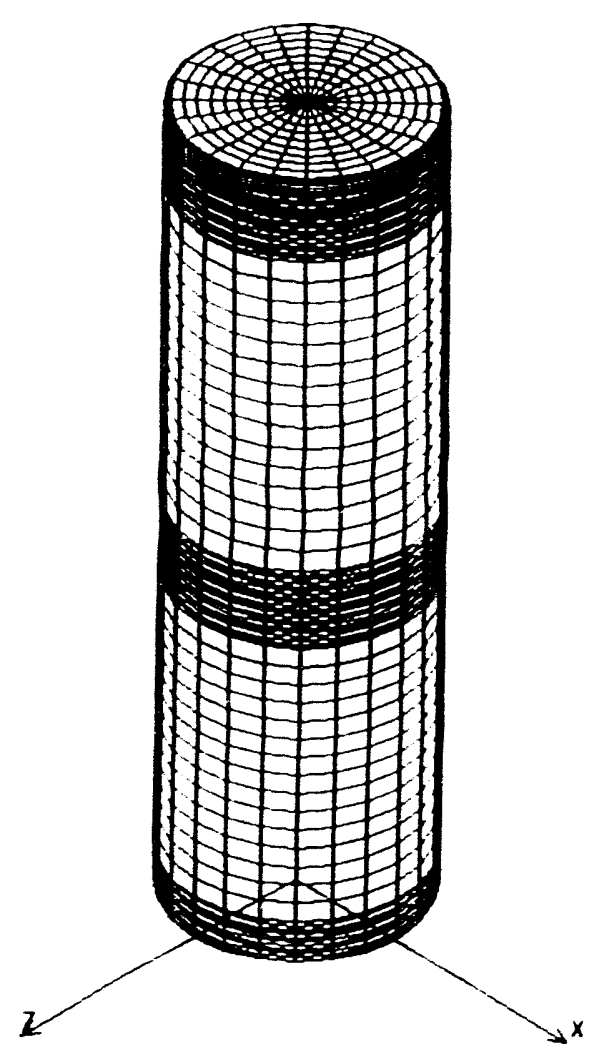

Figure 2a. Four Node Thin/Thick Shell

Elements Represeting MPC Shell. Bottom Plate, Inner and Outer Lids.

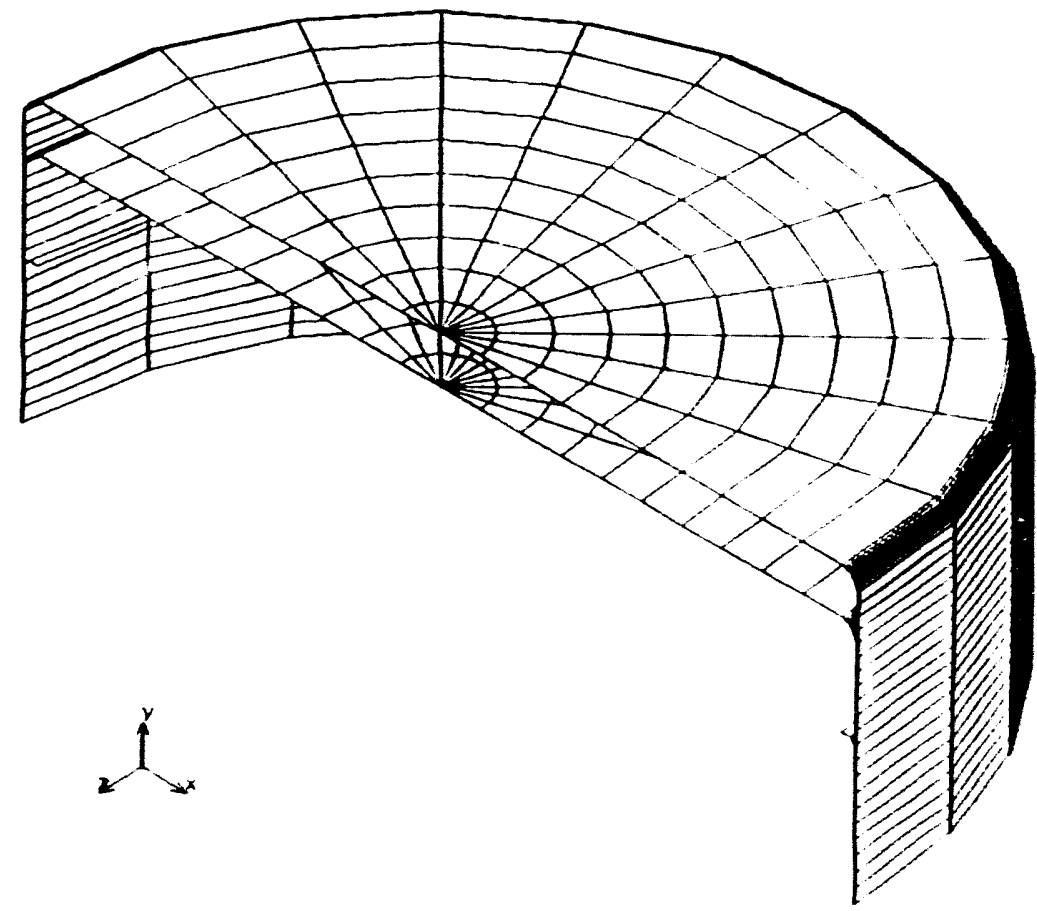

Figure 2b. Four Node Thin/Thick Shell Elements Showing Details of Weld, Inner and outer Lids. 
speot I eiped patIddy xapun IIays xazstuej

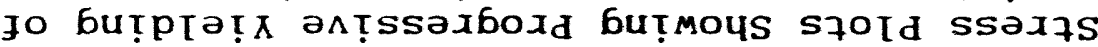

$\varepsilon \operatorname{axn6ta}$
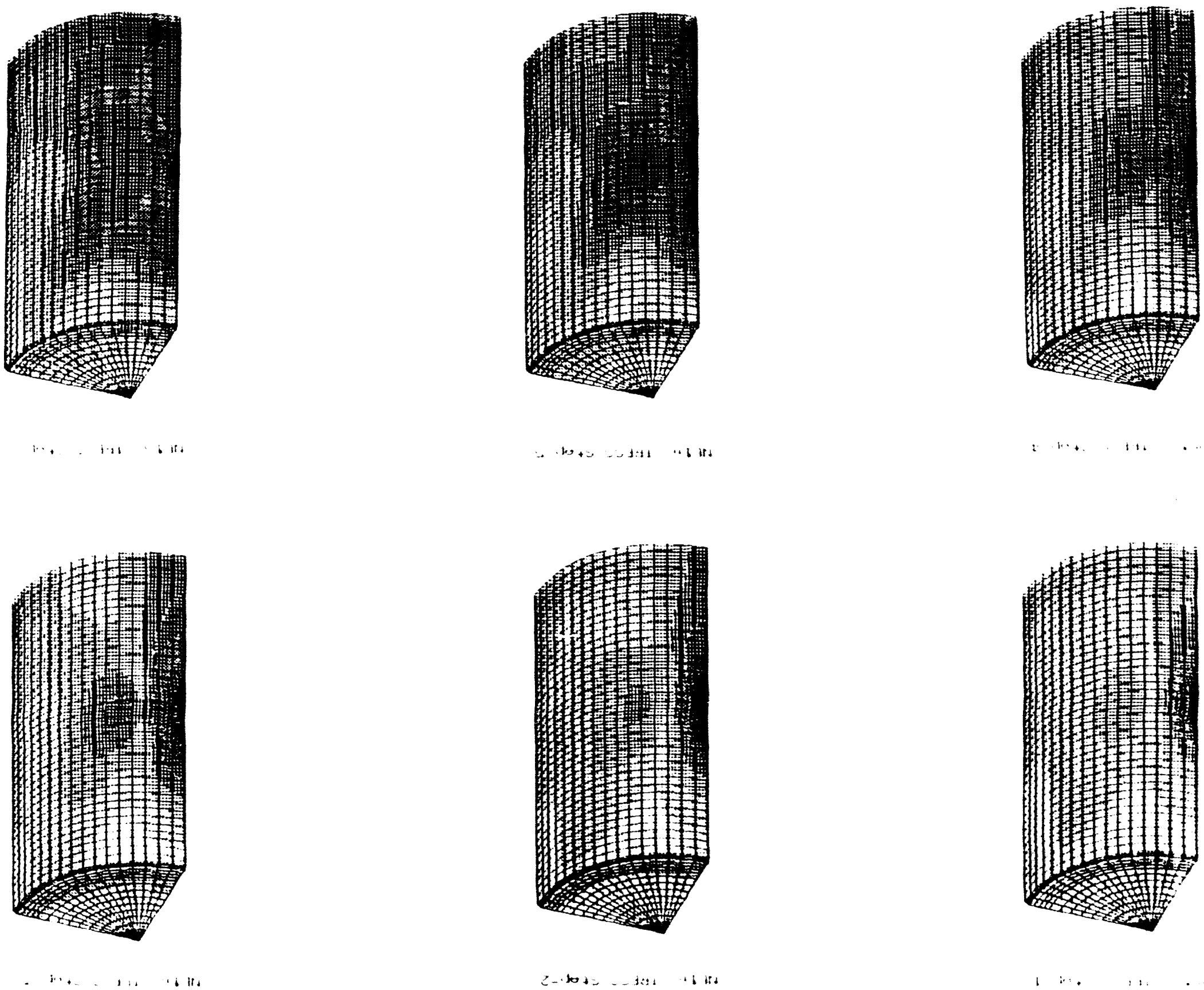


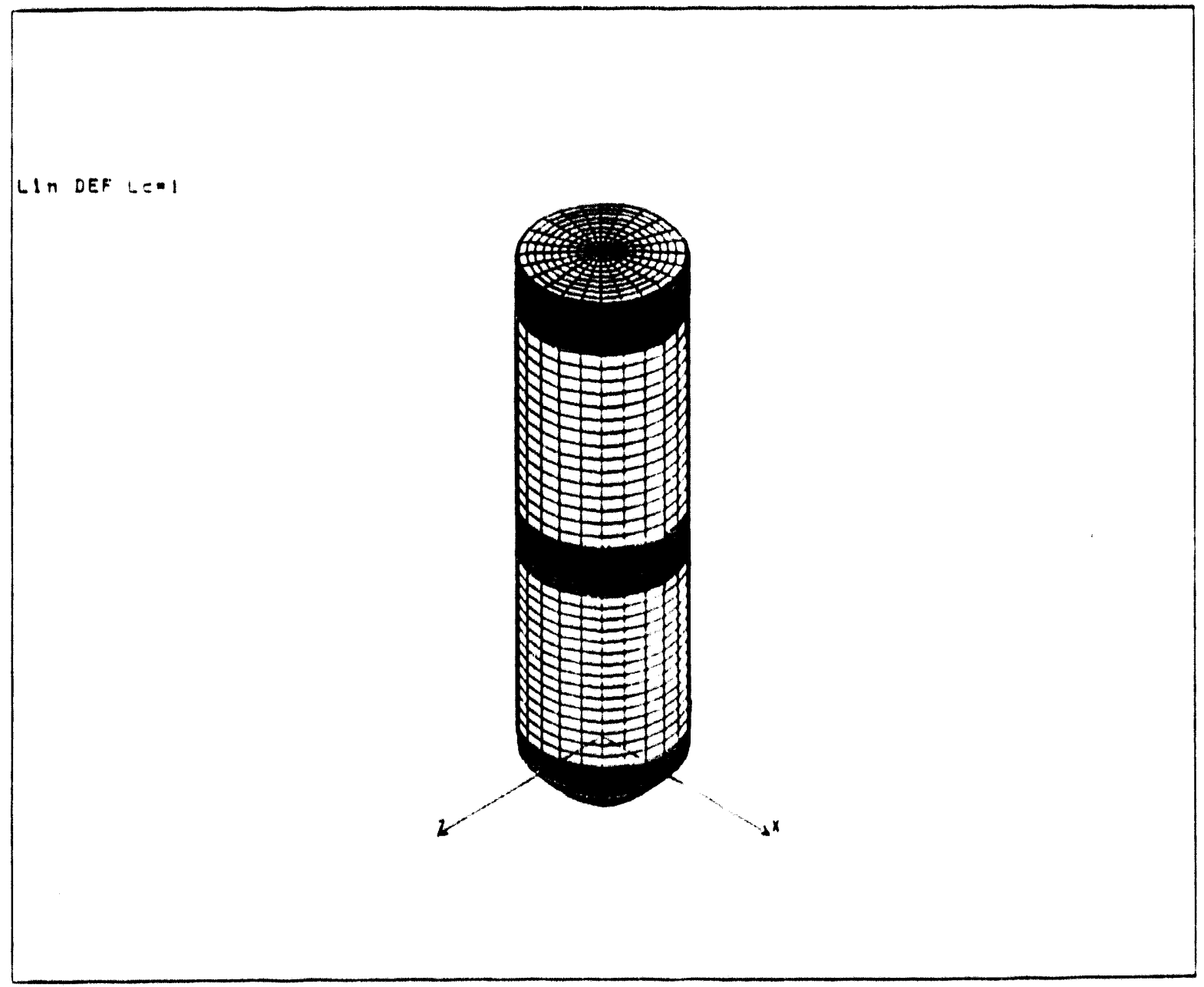

Figure 4. Deflection pattern (Exaggerated 200 times) of the MPC, due to dynamic lifting of MPC from a vertical position. 
LIN STRESS LE $=1$

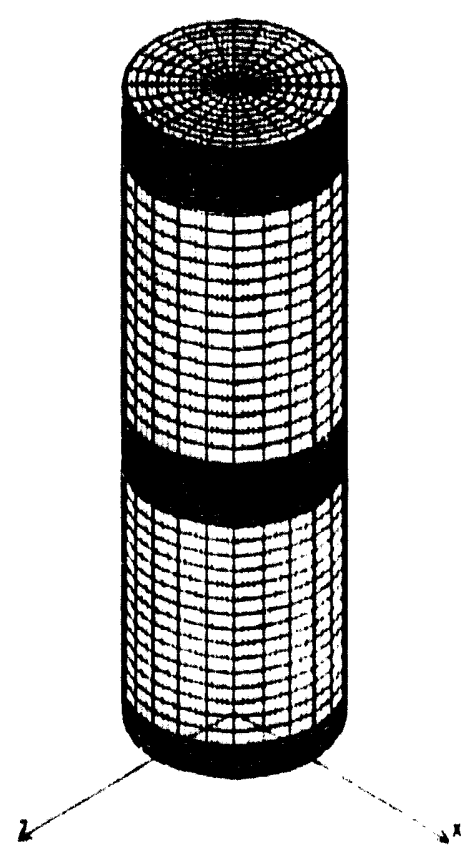

Figure 5. Von Mises stress pattern in MPC shell due to dynamic lifting of MPC from a vertical position. The highest stress is in the bottom weld. 


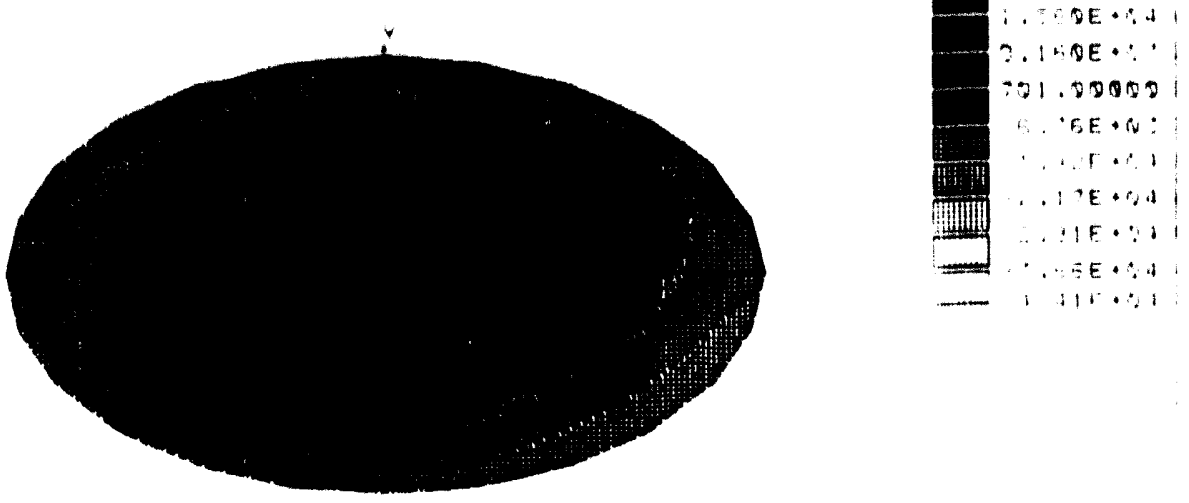

Figure 6. Stress distribution (Global $x$-direction) in the bottom plate of MPC due to dynamic lifting of MPC from a vertical position. 
Task B.1.2 --- Robotio Kanipulation of the Nuolear Waste Container

Dr. Mohamed Trabia

Aseoclate profeseor of

Mechanical Engineering

Mlobael Nal1ey

Graduate student
Dr. Bamaan Ladkany, P.E.

Profeseor of civil a

Environmental Engineering

Bhashi Channarayapatna

Graduate student 
Task B.1.b: Manipulation of the Nuclear Waste Container Facult: Researcher: Dr. Mohamed B. Trabia

ritle: Associate protessor of lechanical linaineerina

Student issistants: Iichael Nalley

Sarath Abayweera

\section{swinging control of Nuclear waste container}

We are still studyind swing-tree control of overhead cranes. currentl $\%$, a tuzzy-logic controller of an overhead crane is established. We are in the process of testind the robustness ot this controller under "arious payloads, canister length, and wire rope length.

\section{study of Nuclear waste container Integrity in Accidents}

study of the impact effects on the nuclear waste container is underway. In the proposed scenario, the container is carried by overhead crane through a wire rope. A finite element model of the overhead crane carryind the container using iosmos/m is formulated. This model allows nonlinear lynamic analysis ot the container motion. A model for elastic plastic impact ot solids is under development. This model shows rlose correlation with

experimental results ot wher researchers. This research resulted in a paper presented at the 1993 ASME besiun lechnical conference (included). The elastic plastic model will be incorporated with the finite element program to study the iffects of impact on the nuclear waste ranister.

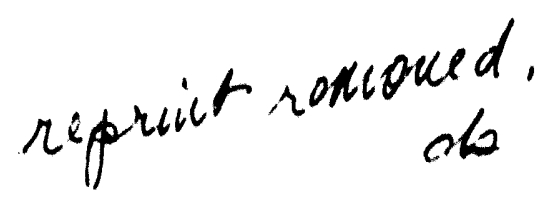


Taak B.2.28 Experimental studies of the Dynamio Reaponse of a Three Link Hydraulioaliy Aotivated Robotio Meohaniam

Faculty Researcher: Dr. Samaan G. Ladkany

T1tle: Professor of Civil Engineering

student Assistants: Shashidhar Channarayapatna

The research described in this section is presently NOT supported by DOE funding through the waste Package Project, however, due to the relevance of the research to the loading and manipulation of waste package containers, a brief description of the work in progress is included in this report.

The three link hydraulically activated robotic mechanism was completely financed under grant by the U.S. Army Research office. The robot is a steel structure, capable of carrying a canister model load of $100 \mathrm{lb}$. The robot was constructed of steel tubling and resembles a construction crane, or an earth moving equipment with articulated movement capability in the vertical plane and the ablilty to rotate around its vertical axis. The robot was outfitted with twelve pairs of strain gauges and four pairs of strain rosettes, along its two extended links.

At present laboratory measurements of the response of the robot under movement, controlled by computer commands, are being accumulated by measuring the dynamic traces of the loaded end effector of the robot. The corresponding strain gauge readings are recorded through a dynamic strain acquisition apparatus and an $A / D$ board. 
The strain gauge measurements are integrated to predict the dynamic mode shape of the robot in an effort to control it.s response by computer. Figure 1 shows a schematic view of the three-ilinked robot, figure 2 and 3 show two out-of-plane first modes, for two different conflgurations of the unloaded robot, as predicted by finite element analysis. On-line automatic feed back routines are used to generate commands that control the two hydraulic actuators in the vertical plane and an actuator in the horizontal plane. Feedback is ueed to dampen the dynamic oscillations of the end effect. 


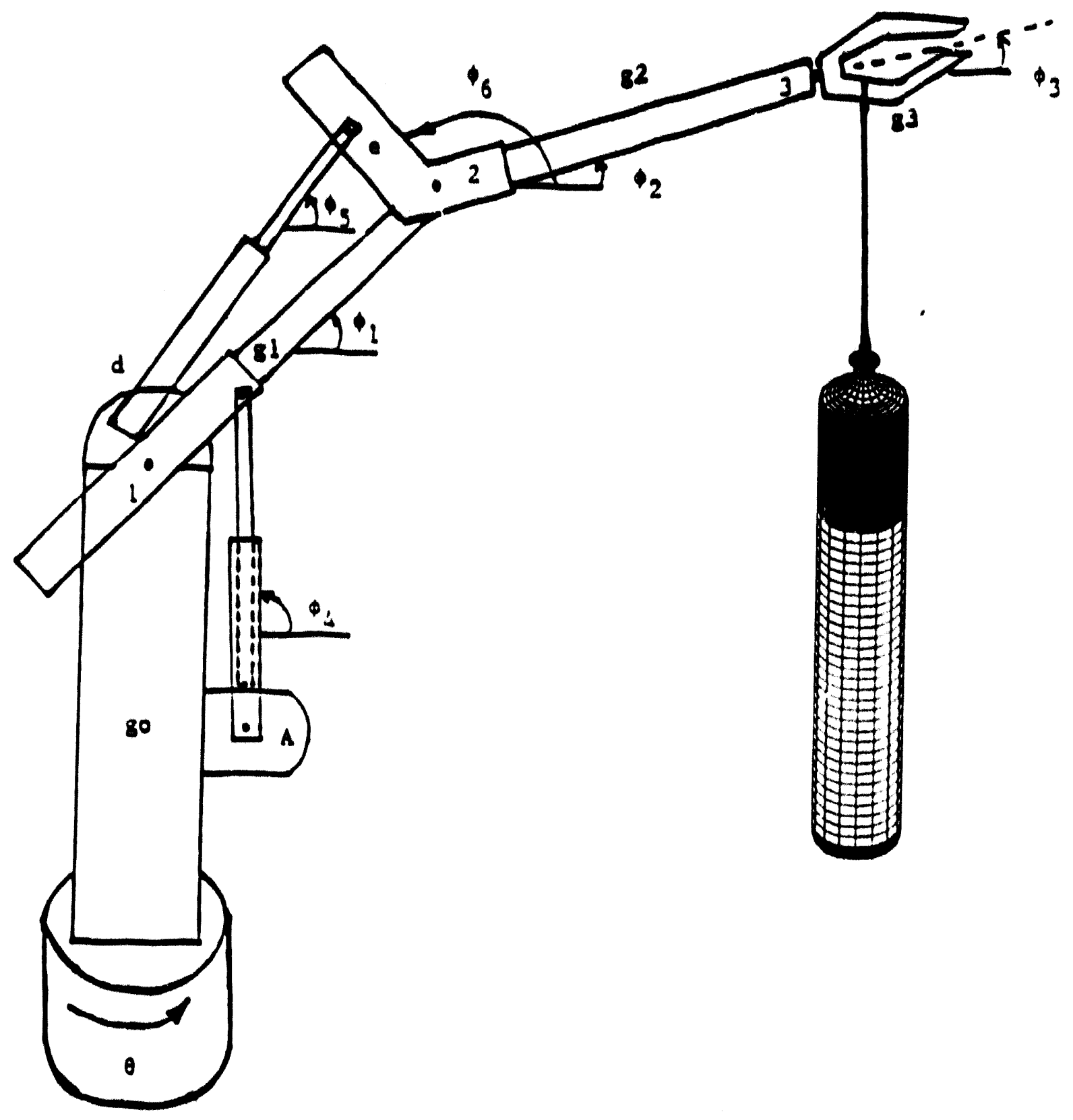

Flgure (1). A Schematic Plc sure of a 3-1lak robot1c mechanter atcached to a rotating rigid base and anipulated by two hydraulic aceuacors. 


\section{MODII-- 5,388II+8CCPS}
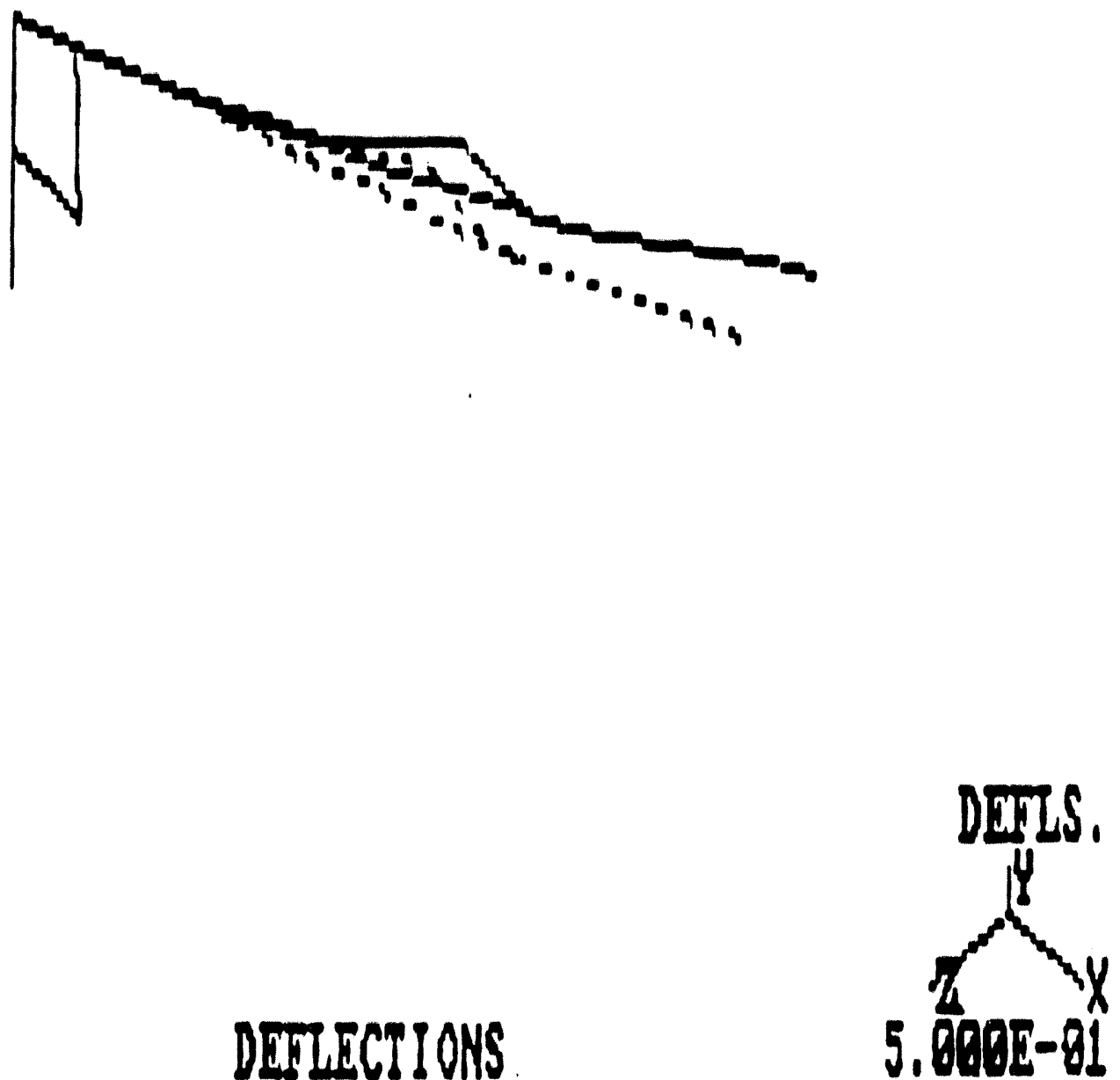

$$
\begin{aligned}
& \text { FIGURE (2) FIRST MODE (5.38 CPS), OUT-OF-PLANE } \\
& \text { VIBRATIONS, NITH THE SECOND AND THIRD } \\
& \text { Links of the jobot at thejR Maximum } \\
& \text { ELEYATION. }
\end{aligned}
$$



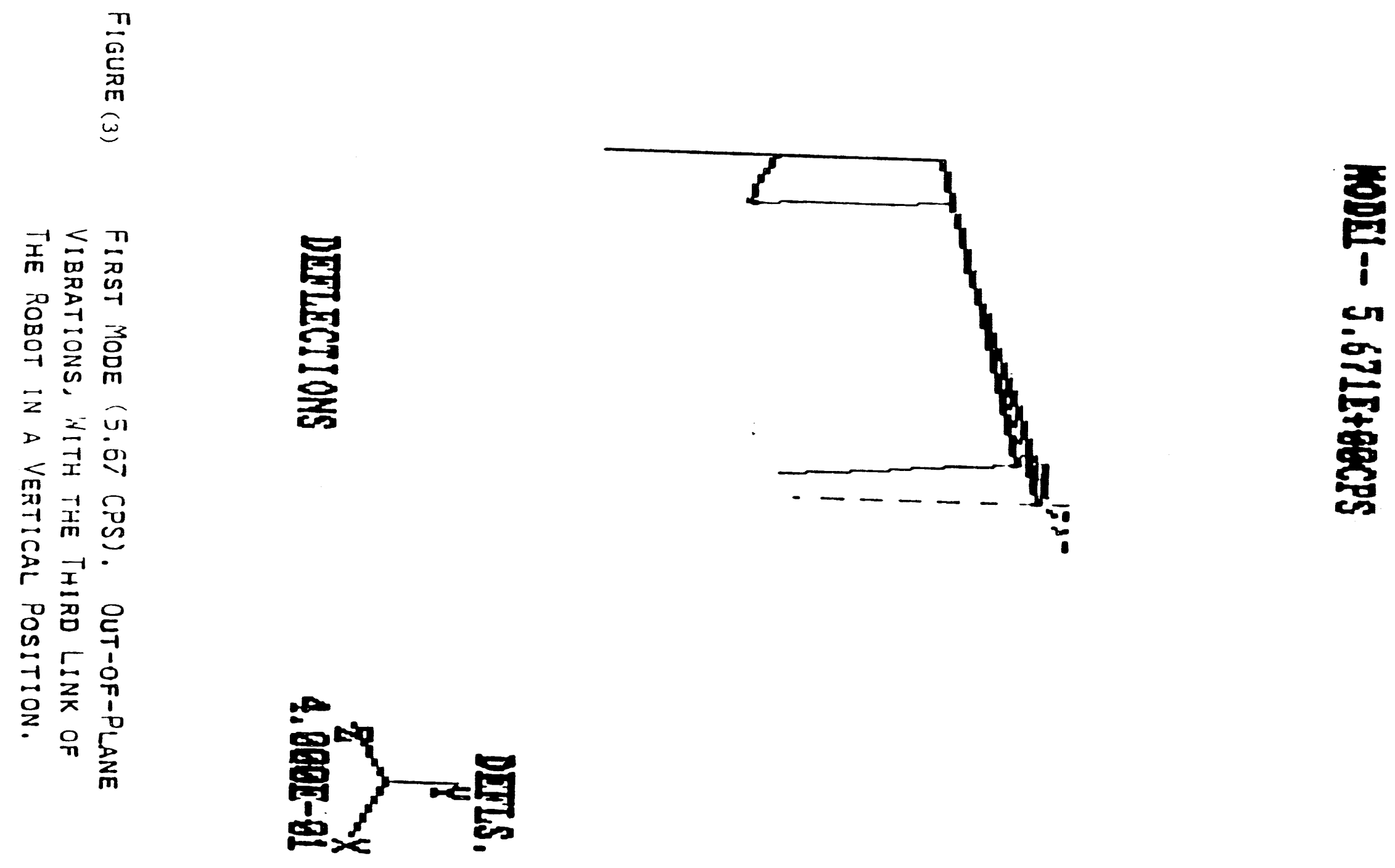
Task B.2.1 --- Investigation of stress in a Circular Tunnel Due to Overburden \& Thermal Loading of Horizontally Placed 2 IPWR Multi-Purpose Canisters

Dr. Richard Wyman, P.E.

Professor Emeritus of Civil \& Environmental Engineering

Nadia Randalaft-Ladkany, M.S.E.

Project Associate

$\therefore$ 
TA8R B.2- Design Requirement of Various Rock Tunnel shapes for Long Term storage for High Level Nuclear waste

RICHARD V. WYMAN, PhD, PE, Professor Emeritus of Civil Engineering NADIA KANDALAFT-LADKANY, MSCE, Project Associate

INVESTIGATION OF STRESB IN A CIRCULAR TUNNEL DUE TO OVERBURDEN AND THERKAL LOADING OF HORIZONTALLY PLACED 21 PWR MULTI-PURPOSE CANISTERS

\section{B.2.1 INTRODUCTION}

Stress analysis due to overburden, gravity and thermal loading of horizontally placed 21PWR Multi-Purpose Canisters (MPC) with inner and outer barriers. In this analysis the MPC are horizontally placed end-to-end inn the drifts of the High Level Nuclear Waste repository (HLNWR) in tuff. This end-to-end emplacement of the MPC's allows for a $2-D$ temperature distribution and hence stress analysis using the finite element method.

our previous studies ${ }^{1,2}$, the canisters were placed in a vertical emplacement mode with the vertical holes spaced $20 \mathrm{~m}$, center to center and the parallel circular drifts $38 \mathrm{~m}$ apart. Both the 2-D and the 3-D finite element models showed high thermal stress concentrations and local collapses around the sides of the vertical emplacement holes and in some areas of the circular tunnel walls.

\section{B.2.2. ACTOAL WORR}

\section{TWO DIMENSIONAL TEMPERATURE DISTRIBUTION}

The two dimensional temperature distribution, used in this paper to establish the thermal loading was provide by Doering, $T$. and Bahney, $R^{3}$. et al., of the CRWMS M\&O Group, thus the stress distribution in the tunnel wall and a vertical section of the repository will be analyzed. The temperature distribution over a half quadrant including half of the tunnel is shown in Figure 1. Maximum temperatures in the drift walls were reached at 10 years after the start of the horizontal emplacement. Thermal data obtained from Reference 3 showed a heat load of $515.4 \mathrm{~W}$ per assembly and temperature of $224^{\circ} \mathrm{C}$ at the MPC side, $210.52^{\circ} \mathrm{C}$ at the waste package side, $172.08^{\circ} \mathrm{C}$ at the drift wall and $102.18^{\circ} \mathrm{C} 1 \mathrm{~m}$ into the rock tunnel walls.

Finite element modeling was used ${ }^{3}$ to obtain the temperature distributions in the MPC and into the rock. Figure 1 , shows the temperature to decrease horizontally from $172.08^{\circ} \mathrm{C}$, at the drift wall to $49.8^{\circ} \mathrm{C}$, at the center line between two drifts; and to decrease vertically upward to $24^{\circ} \mathrm{C}$ at $100 \mathrm{~m}$ above the tunnel and to $37^{\circ} \mathrm{C}$ at $100 \mathrm{~m}$ below the tunnel. 


\section{FINITE ELEMENT MODEL}

The finite element mesh uses triangular plane strain elements having two degrees of freedom per node. The exact tunnel shape and the emplacement of the MPC waste package are shown in the Figure 2 . a closely and increases the sizes of the element gradually away from the waste package (WP); with the smallest triangular elements having sides of approximately $0.17 \mathrm{~m}$ and heights of $0.09 \mathrm{~m}$ to $0.15 \mathrm{~m}$ adjacent to the WP. Similarly elements adjacent to the sides of the tunnel have sides of approximately $0.3 \mathrm{~m}$ and heights of $0.10 \mathrm{~m}$ to $0.25 \mathrm{~m}$. Figure $2 . \mathrm{b}$. shows the triangular element mesh representing the concrete seat of the MPC waste Package, the engineered material, backfill, and sides of the $7.8 \mathrm{~m}$ diameter rock tunnel with depth of $13 \mathrm{~m}$ to the center line between two tunnels. Figure $3 . \mathrm{a}$ shows the element gradation in a mesh covering an area $100 \mathrm{~m}$ above and below the center of the tunnel. The finite element model presented has a total of 4936 nodes, 9496 elements and 9852 degrees of freedom.

\section{TEMPERATURE LOADING}

Thermal loading is applied to the nodes of the elements by specifying continuously varying temperature values specified at circular surfaces having the waste package at their center. These surfaces are shown in Figure $3 . b$.

\section{MATERIAL CONSIDERATIONS}

The material properties used in the analysis of the concretes seat under the WP are : Young's Modulus, $E_{c}=18.3 \mathrm{GPa} ;$ Poisons' Ratio, $\mathrm{Nu}=0.26 ;$ Density, $\mathrm{Rho}=2.24 \mathrm{~g} / \mathrm{cm}^{3}$; and the thermal expansion coefficient Alpha $=1.1 \times 10^{-6} / \mathrm{C}^{\prime \prime}$ at temperature, $\mathrm{T}=96^{\circ} \mathrm{C}$. The engineered material ${ }^{6}$ properties used for the tunnel backfill, under the MPC seat, are Young's Modulus, $E_{c}=6.89 \mathrm{GPa}$; Poisons' Ratio, $N u=0.2$; Density, Rho $=2.32 \mathrm{~g} / \mathrm{cm}^{3}$; and the thermal expansion coefficient Alpha $=12.6 \times 10^{-6} / \mathrm{C}^{\circ}$. The tuff TSW2 Rock ${ }^{8}$ properties used in the model are Young's Modulus, $E_{\mathrm{c}}=15.2 \mathrm{GPa}$; Poisons' Ratio, Nu=0.22 ; Density, Rho $=2.32 \mathrm{~g} / \mathrm{cm}^{3}$; and the thermal expansion coefficient for $\mathrm{T}<200^{\circ} \mathrm{C}$ Alpha $=8.8 \times 10^{-6} / \mathrm{C}^{\circ}$ and for $\mathrm{T}>200^{\circ} \mathrm{C} \mathrm{ALPHA}=24 \times 10^{-6} / \mathrm{C}^{\circ}$.

\section{ANALYSIS}

our previous analysis 1.2 of the vertical emplacement mode showed rock failure and collapse in the vertical boreholes and some areas of tunnel walls. The present study will determine the adequacy of horizontal emplacement of 125 Ton, 21 PWR MPC/WP producing a thermal loading of $57 \mathrm{w} /$ acre. Other waste package assemblies and/or different spacing distances' between Mpc's may have to be considered. Similarly, a parametric study of the engineered material backfill, under the canisters, is in progress, to determine a suitable material that produces thermal stress compatibility with the tunnel concrete lining, if it is deemed necessary, and the rock tunnel walls. 
Preliminary results for the temperature loading only without the overburden load and the weight of the MPC, indicates that the stresses are within the allowable limit for the tuff TSW2. Principle stresses in the rock around the tunnel opening are shown in Figure 4 and 5. Figure 6 shows the magnitude of the displacement resultant around the the tunnel opening while Figure 7 . shows a graphically exaggerated displacement pattern and the deformed tunnel shape due to temperature loading alone. Previous reports mentioned that the allowable stress for rock mass of the TSW2 is $75 \mathrm{MPa}$ in ambient temperature. The maximum compressive stress did not exeed $37 \mathrm{MPa}$ and the tensile stresses around the tunnel are also below the allowable stresses in tension for the TSW2.

\section{ACKNOWLEDGEMENT}

This research work was done under a grant by U.S. Department of Energy \#DE-FCO8-90NV10872. 


\section{REFERENCES}

1. N. Kandalaft-Ladkany, R.V. Wyman, "Design Management and Stress Analysis of a Circular Rock Tunnel and Emplacement Holes for Storage of Spent Nuclear Fuel," High Level Radioactive Waste Management, Proceedings of the $3^{\text {rd }}$ International Conference, Las Vegas, Nevada, (1992).

2. N. Kandalaft-Ladkany, R.V. Wyman and S.G. Ladkany, "Investigation in 3D of stress Distribution in a Circular Tunnel and Vertical Emplacement Holes due to Thermal and overburden Loading in Tuff," High Level Radioactive Waste Management, Proceedings of the $4^{\text {th }}$ International Conference, Las Vegas, Nevada, (1993).

3. T. Doering and R. Bahney," Mined Geologic Disposal system Multipurpose Canister - Design Considerations Report," TRW Environmental Safety systems - Civilian Radioactive waste Management system - Management and operating contractor, Preliminary Draft, B00000000-01717, August (1993).

4. M. Lashkari, Cosmos/M User Guide, Volume II, release 1.65 , Structural Research and Analysis Corp., California (1991).

5. American Concrete Institute, "Behavior of Concrete Under Temperature Extremes", ACI Publication SP - 39, (1973).

6. J.A. Fernandez, J.B. Case and J.R. Tyburski,"Initial Field Testing Definition of Subsurface Sealing and Backfilling Tests in Unsaturated Tuff," SANDIA REPORT SAND92-0960, May (1993).

7. S.P. Clark, Jr. "Handbook of Physical Constants," Geological Society of America, Memoit 97, 570 pp., (1966).

8. L.S. Costin and S.J. Bauer,"Thermal and Mechanical Codes; Part I : Thermal Analysis," SANDIA REPORT SAN88 - 1221 UC 814. 


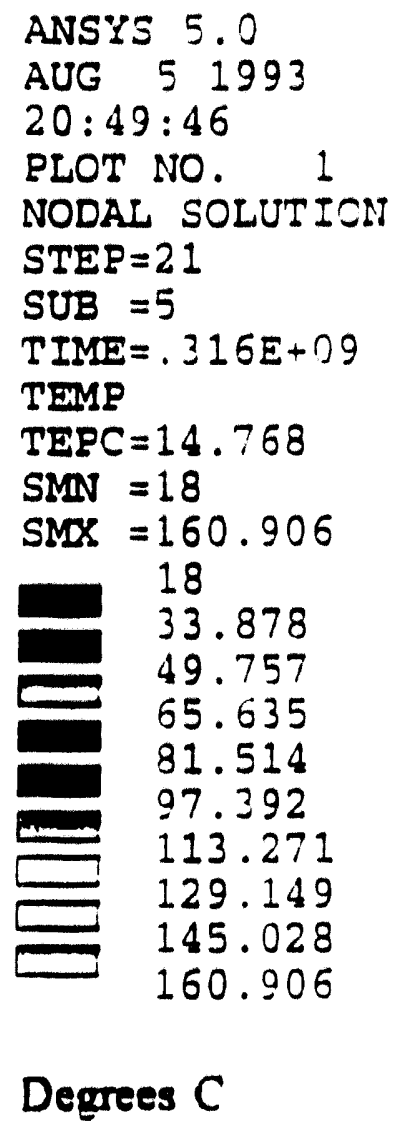

Degrees C

Drif Emotaced 21 PWR MPC/Wan Packene

\section{$57 \mathrm{~kW} / \mathrm{acre}$}

10 yeurs Post-Emoiecernom

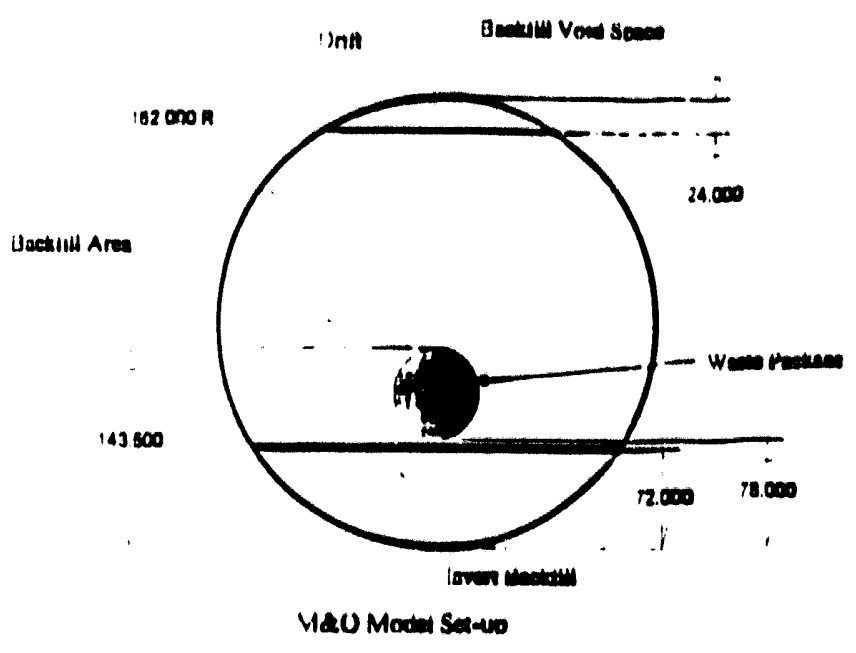

Figure 2.a Schematic view of a Tunnel \& Canister

Figure 1. Temperature Distribution in 2-D for Horizontal emplacement of 125 BWR MPC's. From reference 3. 


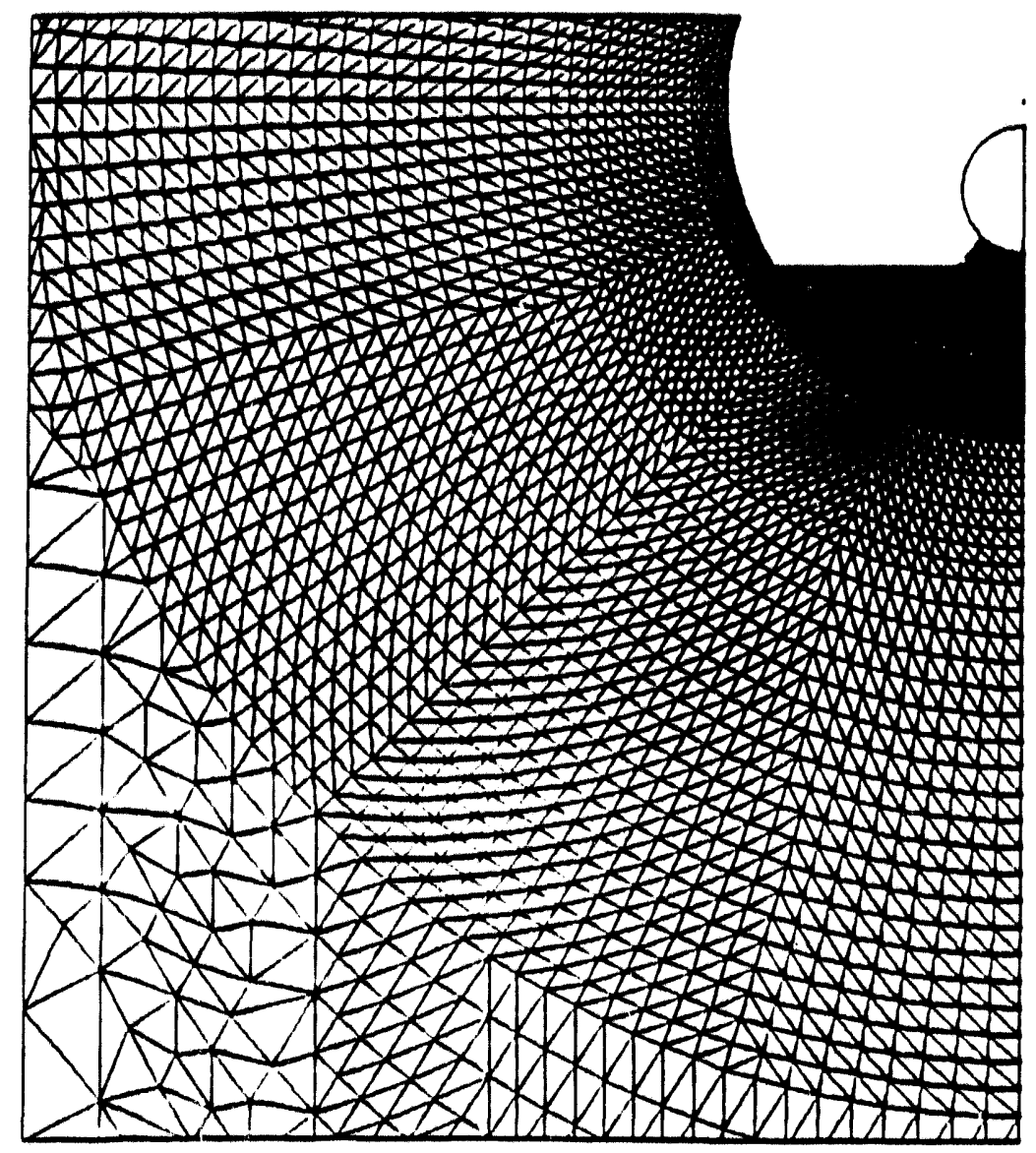

Figure 2.b Finite element Mesh of rock tunnel and backfill 

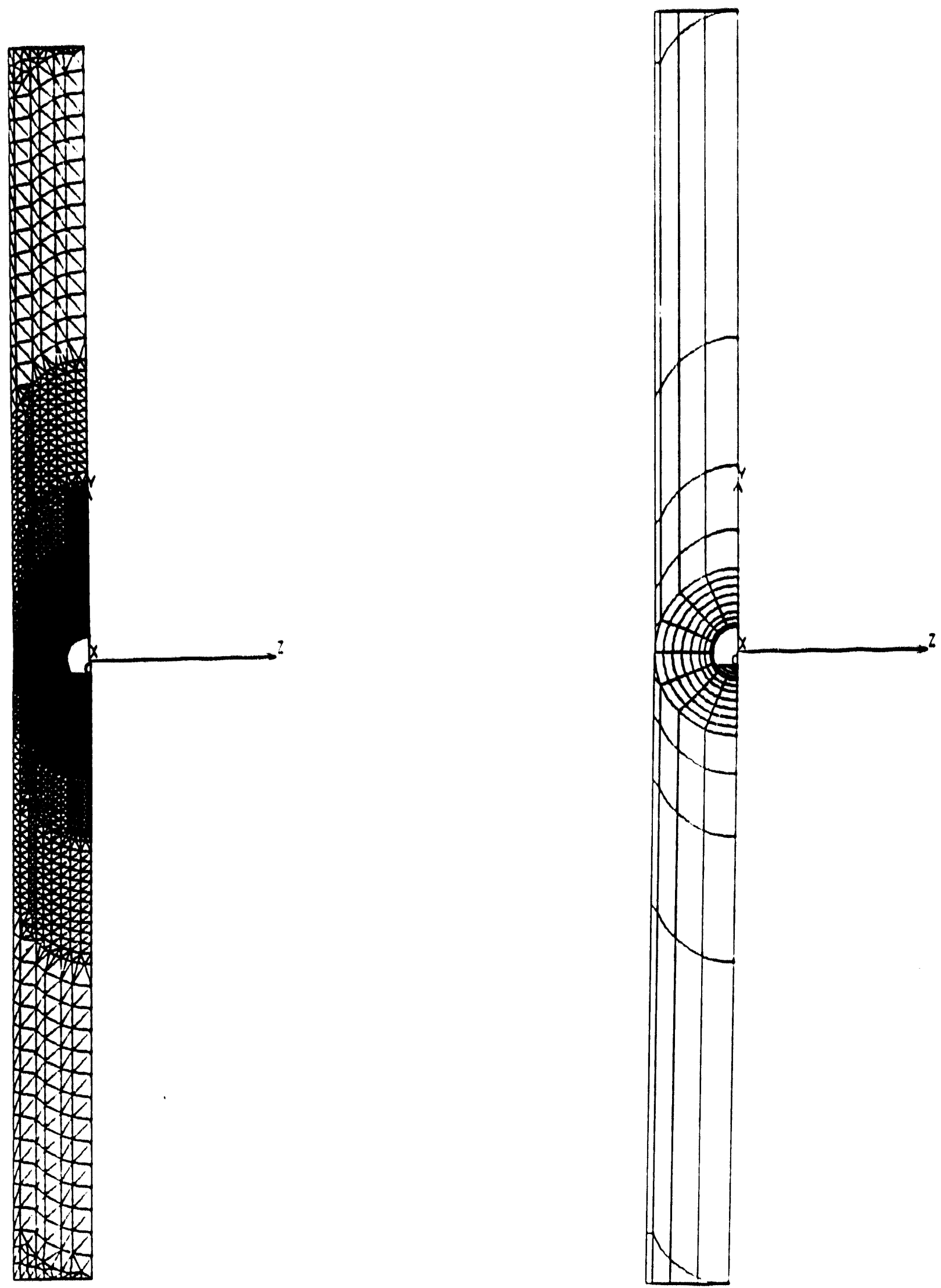

Figure $3 . a$

Figure $3 \cdot b$

Figure 3.a,b Finite element mesh representation of element grid for the model, $3 . a$ and concentric surfaces used in thermal loading, $2 . b$. 


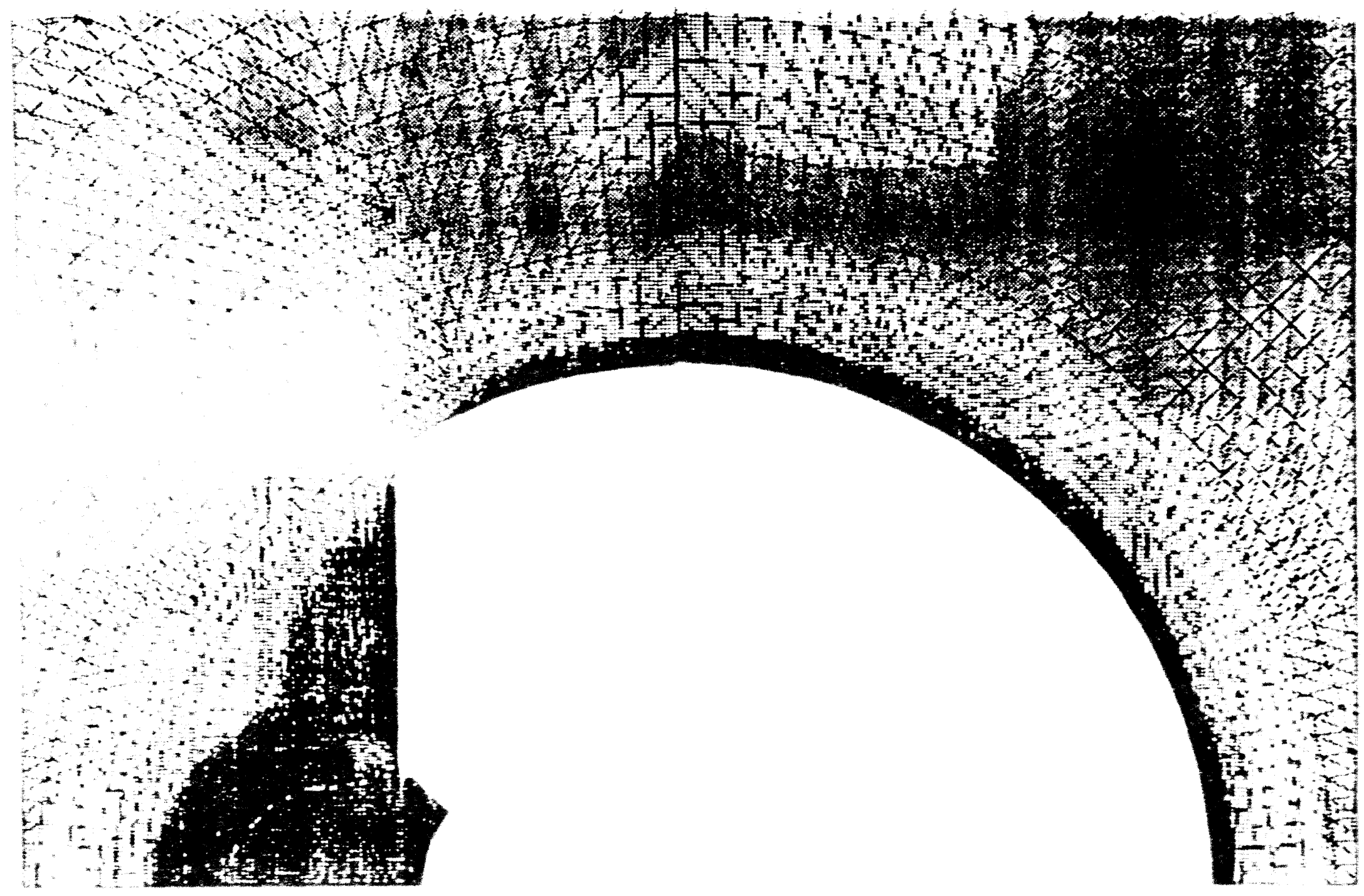

- 논 


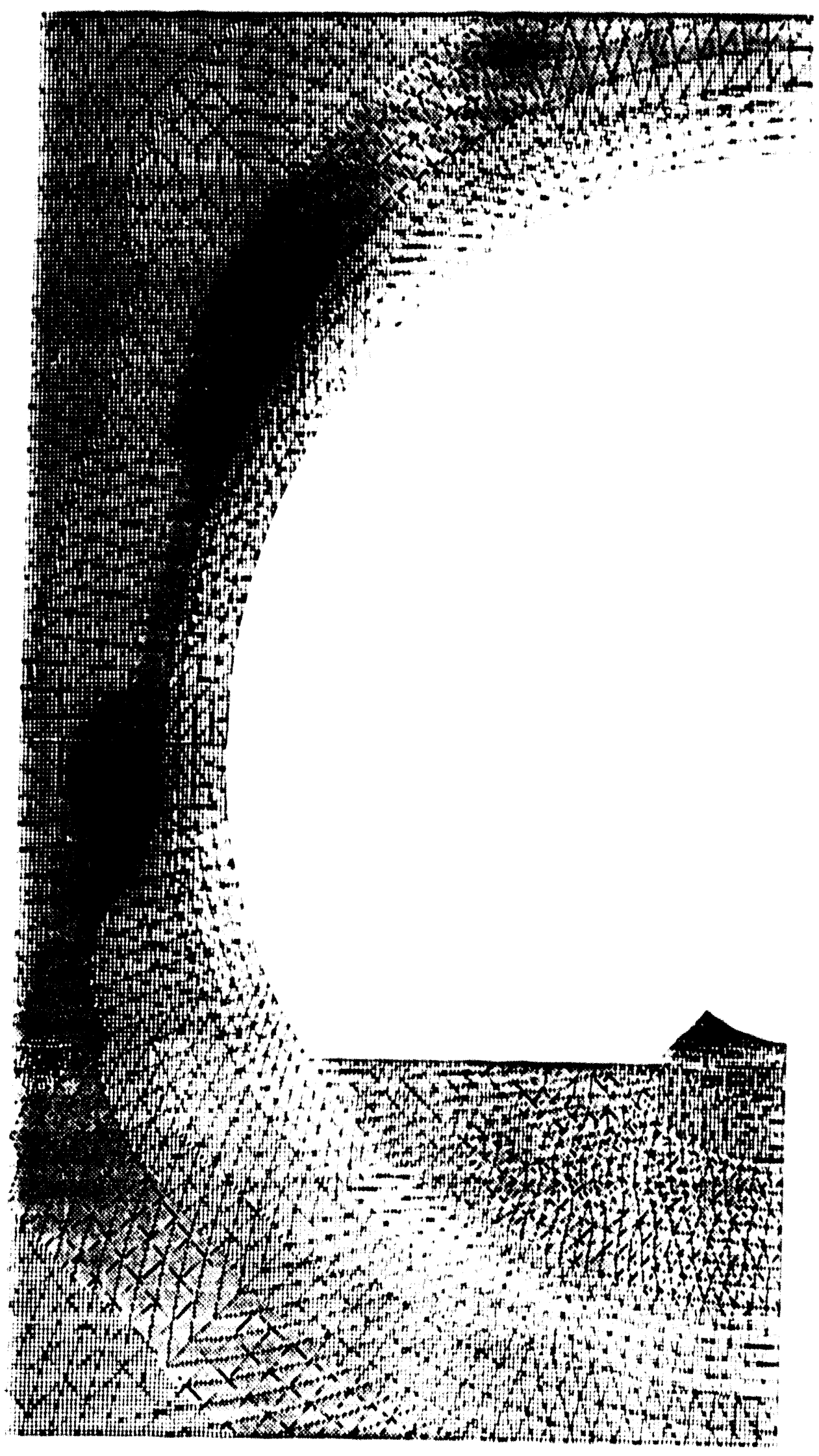



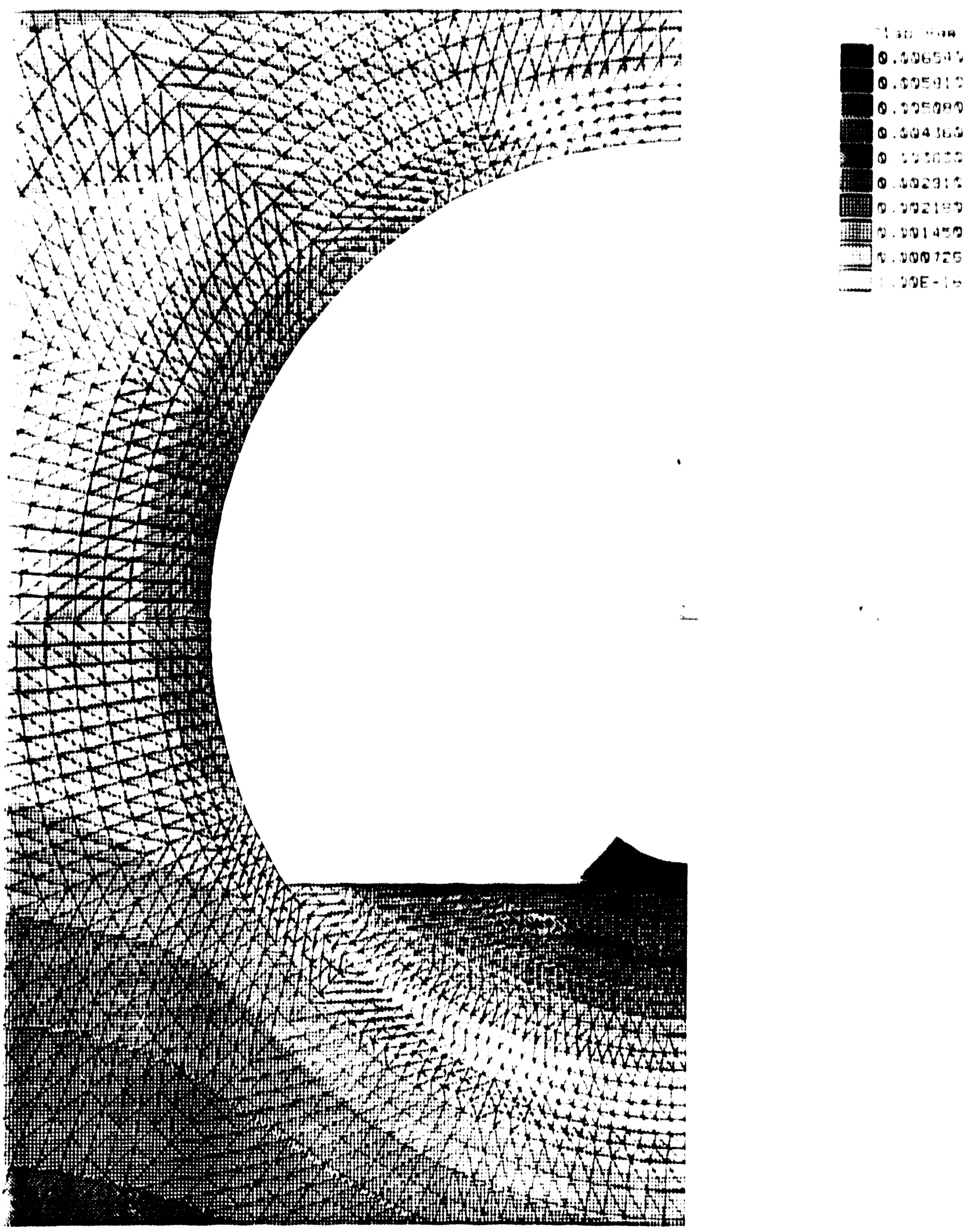


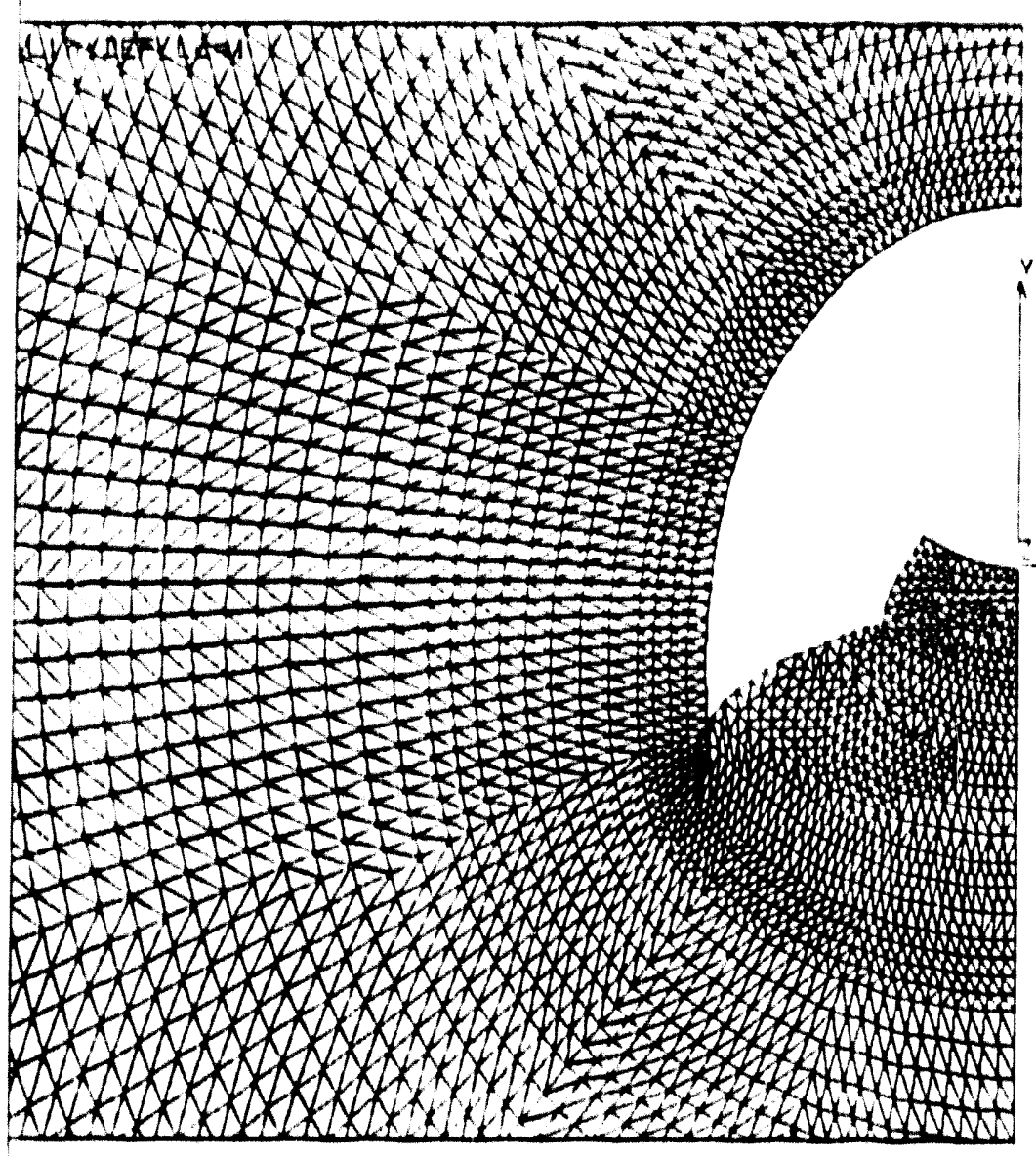

FIGURE 7: DEFORMED TUNNEL SHAPE DUE TO TEMPERATURE

LOADING ONLX (DISPLACEMENTS ARE GRAPHICALL $\because$ EXAGGERATED) 
Task B.2.2 -.- Investigation of raulted Tunnel Models by Combined Photoelasteity and Finite Element Analysio

Dr. Samaan Ladkany, P.E.

Profeseor of Civil Eavironmental Engineering

Yuping Huang, Oraduate student 


\title{
INVESTIGATION OF FAULTED TUNNEL MODELS BY COMBINED
} PHOTOELASTICITY AND FINITE ELEMENT ANALYSIS

\author{
Samaan G. Ladkany', Ph.D, P.E. \\ Yuping Huang', \\ Department of Civil and \\ Environmental Engineering, \\ University of Nevada, Las Vegas, \\ 4505 Maryland Parkway, \\ Las Vegas, NV 89154 \\ (702) $895-4328$
}

I. INTRODUCTION

Critical stresses in a model of faulted adjacent rock tunnels are studied using a photoelastic plexiglass model of the tunnels and concurrent simulation by numerical finite element of the same plexiglass model using 2-D plane stress elements. The analysis is intended for the study of stress concentration factors due to a fault that crosses the path of an underground tunnel system, such as, the Ghost Dancel Fault, that penetrates the tunnels of a proposed High Level Nuclear Waste Repository. Results from the plexiglass photoelastic model and the concurrent finite element simulation of the same photoelastic model are compared with each other to verify the accuracy of both test procedures and to set the stage for a full scale finite element analysis of the region in the rock tunnel that will penetrate through the inclined plane of the Ghost Dancel Fault.

In our previous work $\mathrm{k}^{2.3}$, we investigated the stress patterns in the rock tunnel walls of a proposed High Level Nuclear Waste (HLNW) repository. Two dimensional studies and 3-D studies ${ }^{3}$, using finite element models of the rock tunnels, were evaluated due to overburden loads and due to the thermal loading, 10 years after emplacement, of the HLNW Canisters in vertical emplacement holes. These studies did not include the effect of an existing rock fault that cuts through the tunnels.

The plexiglass photoelastic and numerical finite element models represent two adjacent square tunnels having rounded corners, as seen in Figure 1 , and two adjacent circular tunnels, having diameters equal to the diagonals of the tunnels and are not shown in this abstract.

\footnotetext{
'Professor and Director

US DOE Waste Package Project

'Graduate student
} 
The fault in the rock is depicted as a crack in the models, having the same angle of incidence with the tunnels as that of the Ghost Dancel Fault.

The introduction of a tunnel through the inclined plane of a major fault plane in the rock introduces stress concentrations around the tunnel opening, in the vicinity of the fault, and in the fault plane itself as to lead to local failure in the rock or global failure over a considerable length in the tunnel adjacent to the fault plane.

In the models, two compressive loading conditions are introduced in the vertical and horizontal directions. A crack is initiated, cutting through the top ad bottom of one of the two tunnel models. The stress concentrations at the tip of the crack, as it is made progressively longer, are measured and recorded. Changes in the stress field at specific points around both tunnels are also recorded.

\section{DESCRIPTION OF MODELS}

The Photoelastic model shown in Figure 1 , which is exactly duplicated in the finite element model, consists of a $0.00953 \mathrm{~m}$ $(0.375 \mathrm{in}$ ) thick and $0.25609 \mathrm{~m}$ (10.25 in) sides, plexiglass square plate. The two identical square tunnel openings in this model start at $0.04849 \mathrm{~m}$ ( $1.9375 \mathrm{in})$ below the top surface of the plate and have sides of length $0.05795 \mathrm{~m}$ ( $2.28125 \mathrm{in})$. The clear distance between the two openings is $0.04603 \mathrm{~m}(1.8125 \mathrm{in})$ and the square openings are $0.04921 \mathrm{~m}$ ( $1.9375 \mathrm{in}$ ) each away from the plate sides.

The model tunnels have rounded corners with fillet radil of $0.002 \mathrm{~m}(0.07875 \mathrm{in})$. The square holes were not placed at the center of the plate in order to determine the local effects of the boundary conditions by comparing the stress patterns in the upper side, which is close to the top surface of the plate to those in the lower side of the opening, which is three times farther away from the lower surface of the plate. The same differences in the stress patterns are also observed in the finite element model.

\section{MATERIAL PROPERTIES OF MODEL}

The plexiglass plate has a photoelastic constant, $c=40$ psi/fringe/in, a Young's modulus, $E=2660 \mathrm{MPa}\left(3.8 \times 10^{5} \mathrm{psi}\right)$ and a Poison's ratio, $\nu=0.3$.

\section{TEST EQUIPMENT}

Figure $2 a, b$ shows the $0.407 \mathrm{~m}$ (16 in) diameter 060 series Transmission Polariscopet, having a model 067, articulated compensator, used in the fine measurement of fringe orders and model 163, oblique incidence prism adaptor, used in the direct 
measurements of principal stresses, and a model 065 telemicroscope, used in the close identification of the Isoclinic and Isochromatic patterns.

\section{EXPERIMENTAL MEASUREMENTS}

Both photoelasticity and finite element have been widely used in stress measurements. Photoelasticity plays a major role in the measurement of stress distribution patterns and stress concentration factors around circulars, rectangular and other shaped holes. Photoelastic measurements have also been used in crack propagation studies and in the identification of the static and dynamic stress intensity factors ${ }^{6}$, at the tip of a propagating crack, using high speed photography for dynamic measurements.

In our research, a load of $2269 \mathrm{~N}(500 \mathrm{lb})$ is applied to the plexiglass plate in its vertical direction. Stress patterns are recorded at points around the openings and at specific points along the line where a crack is to be initiated and slowly propagated through progressive cutting. The plate is then turned $90^{\circ}$ in its plane and the same load is now applied in its horizontal direction. Stress patterns are measured and recorded at exactly the same points, under both loading conditions.

\section{FINITE ELEMENT ANALYSIS}

The finite element grid, part of which are seen in figure $3 a, b$ and $4 a, b$ is made up of 2598 triangular plane stress elements, 1426 nodes producing 2807 equations. A fine mesh is generated around the square openings. Figure $3 a, b$ shows global $Y$-direction (Vertical) and $x$-direction (Horizontal) stress patterns due to vertical load of $500 \mathrm{lb}$ in the plane of the specimen. Figure $4 \mathrm{a}, \mathrm{b}$ shows $Y$-direction and $X$-direction stress patterns due to $a$ horizontal load of $500 \mathrm{lb}$ in the plane of the specimen.

The crack will be modeled using Gap elements which accept compressive stresses and account for coulomb friction factors between surfaces using nonlinear iterative procedures. Stress intensity factors along the crack path using Gap elements will be compared to those obtained by photoelastic measurements.

\section{RESULTS}

Stress comparison between photoelastic measurements and finite element analysis show excellent correlation. The photoelastically measured stresses are consistently higher in intensity by about $10 \%$ and with maximum differences between techniques in measured stress varying between $1 \%$ and $20 \%$ the latter being at rounded corners. 
VIII. CONCIUSIONS

The experimental/numerical techniques described in the paper will be used to establish the validity of the stress analysis of inclined faults passing through a tunnel opening and in the eventual full scale modeling of the Ghost Dance fault which passes through the tunnel walls in Tuff.

\section{ACKNOWLEDGEMENT}

This research work was done under a grant by U.S. Department of Energy \#DE-FC08-90NV10872.

\section{REFERENCES}

1. R.W. Elayer,"Private Communications," Morrison Knudsen Corp., Management and operation Contractors to the US DOE, Las Vegas, Nevada, (1993).

2. N. Kandalaft-Ladkany, R.V. Wyman, "Design Management and Stress Analysis of a Circular Rock Tunnel and Emplacement Holes for Storage of spent Nuclear Fuel," High Level Radioactive Waste Management, Proceedings of the $3^{\text {rd }}$ International Conference, Las Vegas, Nevada, (1992).

3. N. Kandalaft-Ladkany, R.V. Wyman and S.G. Ladkany, "Investigation in 3-D of Stress Distribution in a Circular Tunnel and Vertical Emplacement Holes due to Thermal and Overburden Loading in Tuff," Hiah Level Radioactive Waste Management, Proceedings of the $4^{\text {th }}$ International Conference, Las Vegas, Nevada, (1993).

4. Measurements Group, Photoelastic Division, Raleigh, N.C., USA

5. S.A. Meguid and S.X. Gong,"Stress Concentration Around Interacting Circular Holes: A Comparison Between Theory and Experiments," Journal of Engineering Fracture Mechanics, Vol. 44., No.2, pp. 247-256, (1993).

6. C. Toudou, and K. Ravi-Chandar, "Experimental Determination of the Dynamic Stress-intensity Factor Using Caustics and Photoelasticity," Journal of Experimental Mechanics, Vol. 32, pp. 203-210, (1992).

7. 0. C. Zienkiewicz, The Finite Element Method, Third Edition, McGraw Hill, Inc., New York (1985).

3. M. Lashkari, Cosmos/M User Guide, Volume II, release 1.65, Structural Research and Analysis Corp., California (1991). 


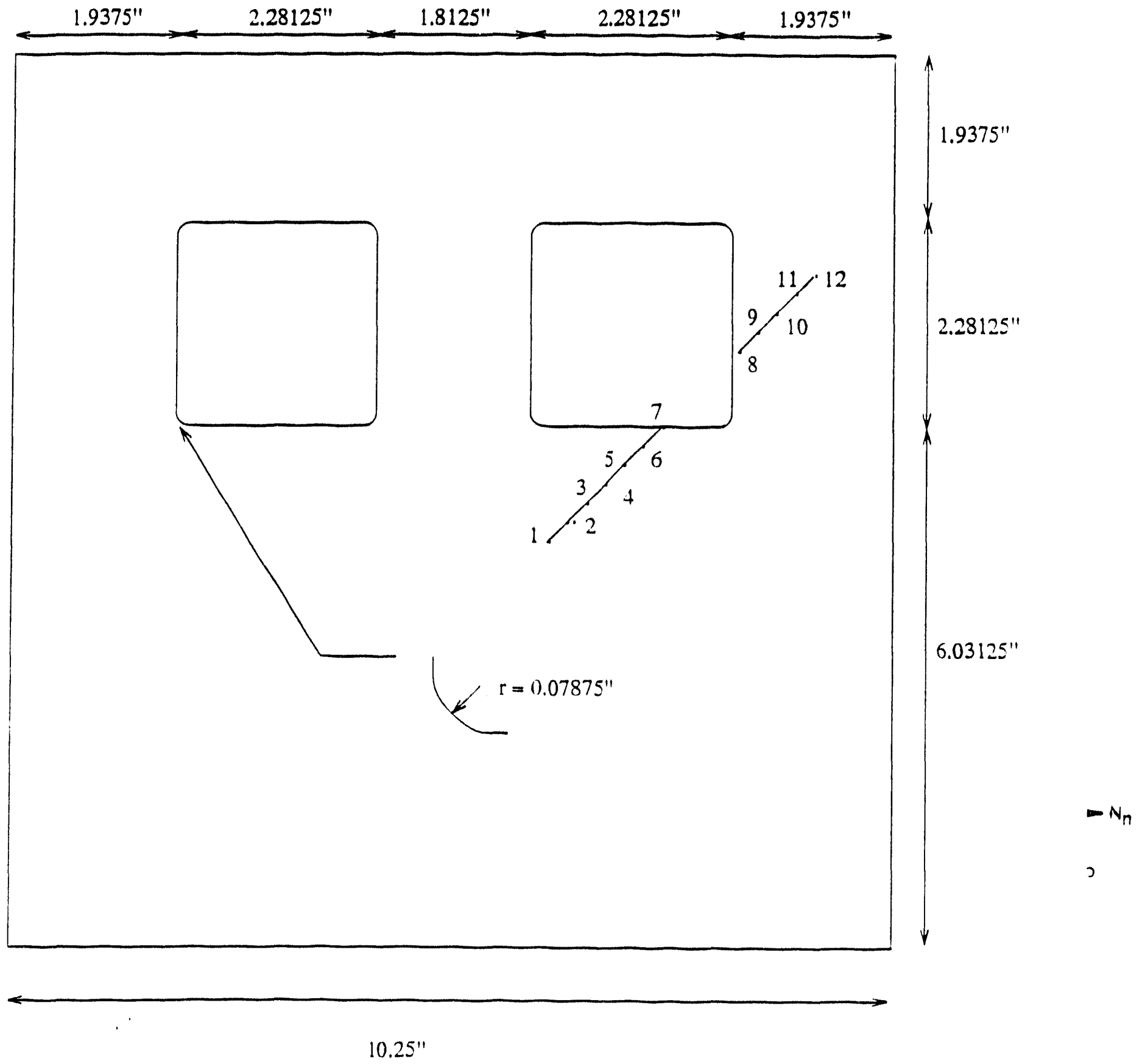

Pigure 1. Dimension of The Plexiglass $0.0095 \mathrm{~m}(0.375 \mathrm{in})$ Thick Photoelastic Model of Two Adjacent Tunnels. 


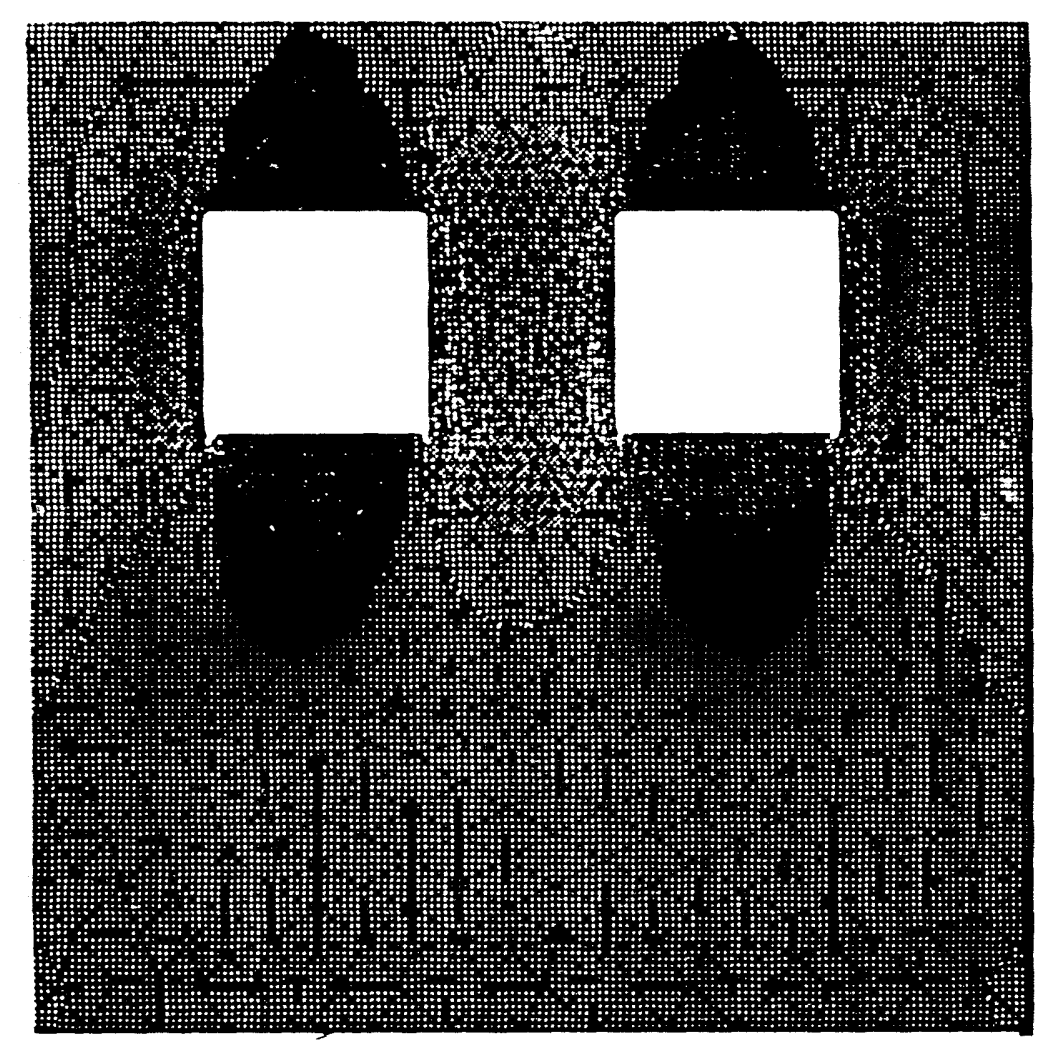

(d)

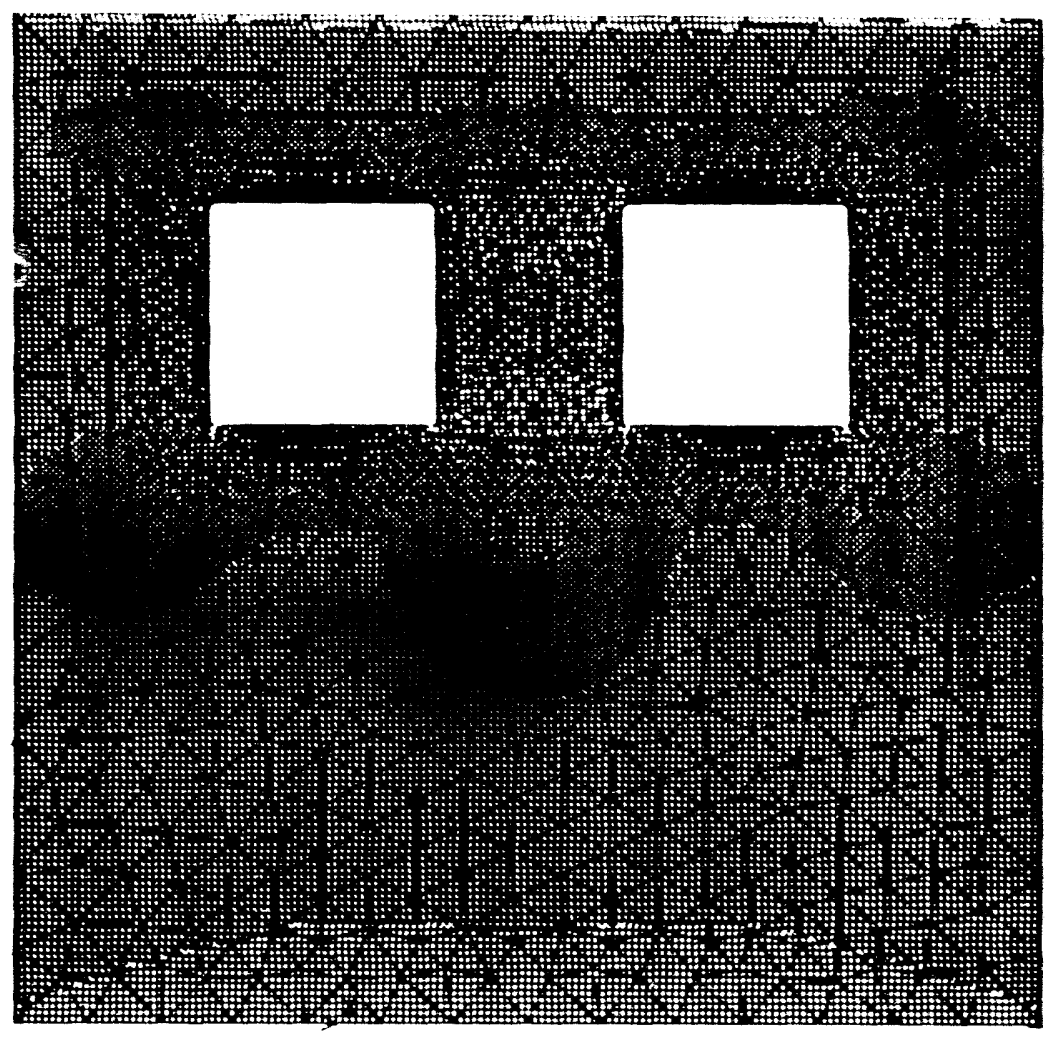

(b)

F. gure 3a,b. Vertical o. And Horizontal o, Stresses vue to a vertical loding of $500 \mathrm{lb}$ on the sides of the Model. 


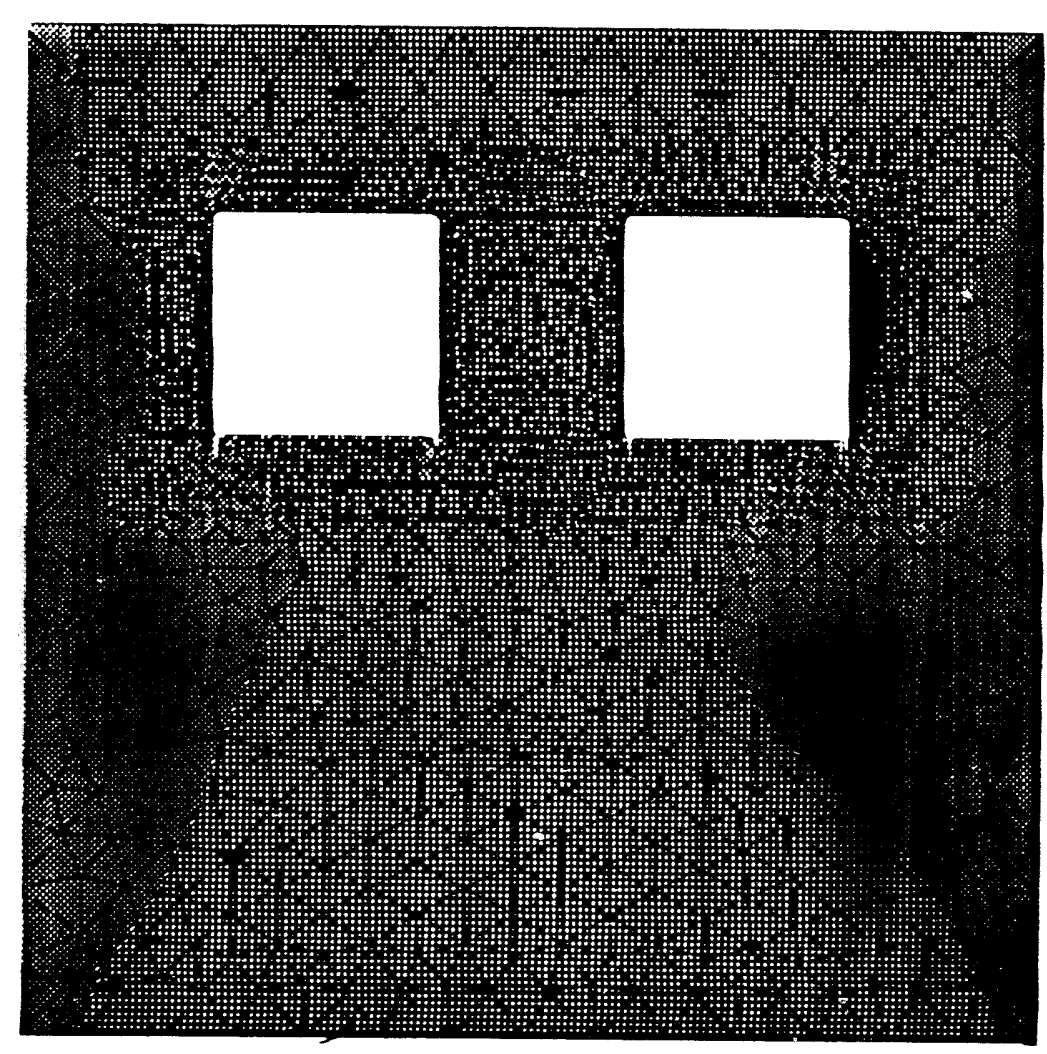

(a)

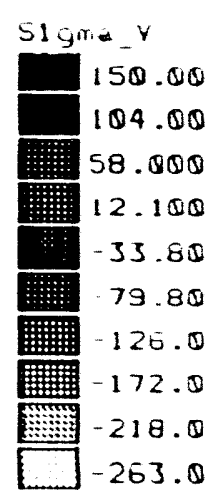

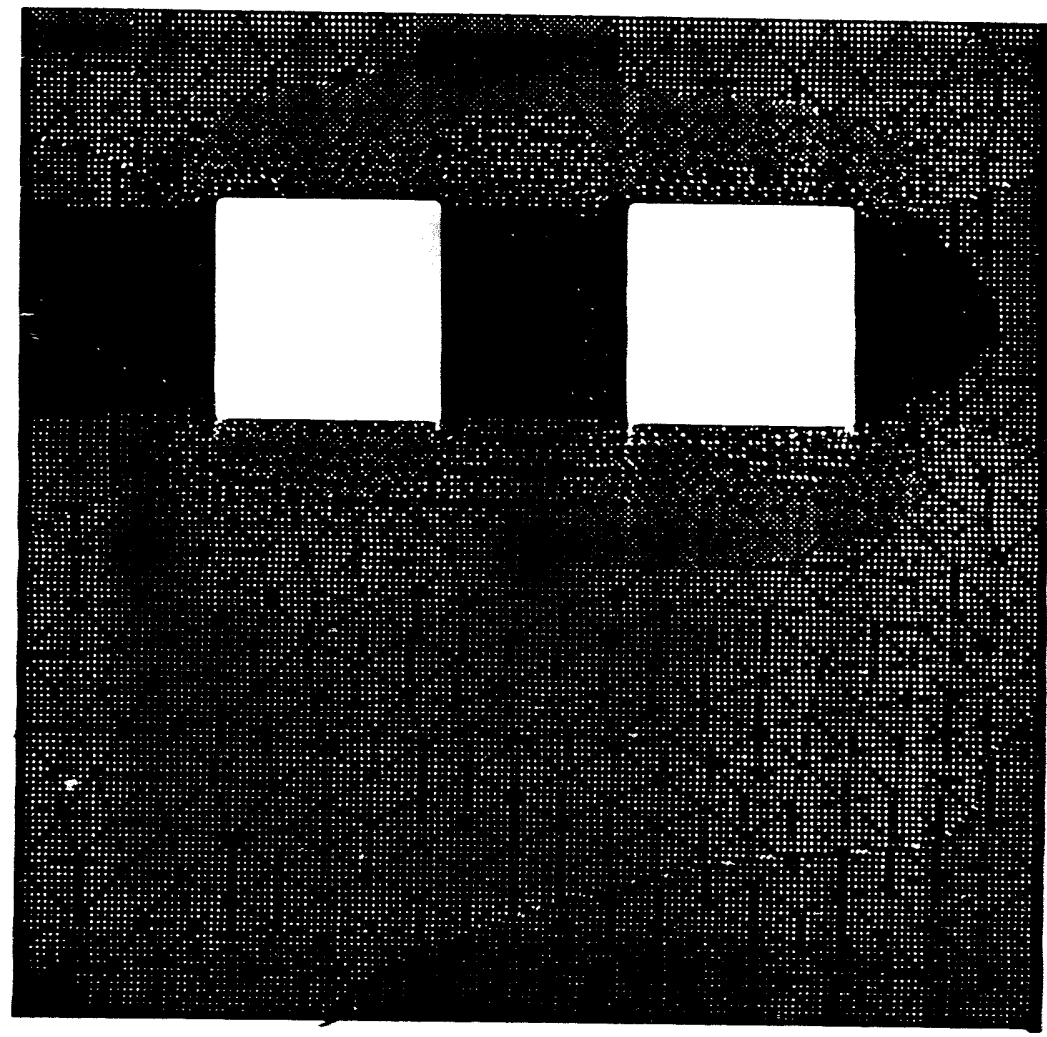

(b)

Figure 4a,b. Vertical $\sigma_{y}$ and Horizontal $\sigma_{x}$ stresses Due to a Horizontal Loading of $500 \mathrm{lb}$ on the sides of the Model. 
Task B.3 -- Transport Phenomena in the Near Field

Dr. James Cardle

Associate Professor of Civil Environmental Engineering

Xia wu, Graduate student 


\section{Task II}

Supplemental task B - 3. Transport Phenomena in the Near Field

Personnel

Dr. J. Cardle

Ms. Xia Wu

1. Work during the last period has involved the completion of a joumal publication on a finite element technique for the solution of transport equations with both convective and diffusive terms. The numerical technique is explicit in time and allows for accurate modeling of convection diffusion problems where the convective effects are large in comparison to the diffusion effects and or the initial conditions are characterized by sharp discontinuities. A variety of phenomena associated with a high level nuclear waste repository such as thermal transport and material transport can be described by such convection diffusion equations. A copy of this submitted paper is attached to this report.

2. Ms. Xia Wu, a graduate student, has joined this project as of the start of fall semester and will be involved in some transport modeling work.

3. A proposal on criticality analysis of drift emplaced containers has been developed as submitted to the DOE along with Dr. Culbreth. The purpose of this proposal is to analyze the movement of and the resulting concentrations of fissile materials and neutron poisons in the backfill matcrial in order to verify that a critical mixture of fissile material and moderator (water) will not occur. 


\title{
A Modification of the Petrove(Galerkin Method \\ For The Transient Convection - Diffusion Equation
}

\author{
James A. Cardle \\ Dept. of Civil \& Environmental Enginecring \\ University of Nevada, Las Vegas \\ Las Vegas, Nv. 89154
}

(702) 4583941

July 21,1993

\begin{abstract}
A variation of the Petrov-Galerkin method of solution of a partial differential equation is presented in which the weight function applied to the time derivative term of the transient convection-diffusion equation is different from the weight function applied to the spacial derivatives. This allows for the formulation of th order explicit and centered difference schemes. Comparison with analytic solutions show that these methods are able to capture steep wave fronts. The ability of the explicit method to capture wave fronts increases as the amount of convective transport increases.
\end{abstract}




\section{Introduction}

A variety of transport phenomena can be described by transient convecton-diffusion cquations. Linder certain circumstances, the convecuon terms can be large in comparıson to the diffusion terms. Examples range trom solute transport in a homogeneous porous media to the highly complex thermally driven movement of moisture and associated contaminants in the fractured porous media surrounding waste packages containing spent nuclear reactor fuel. The former can be described by one linear convection diffusion equation, the latter requires a complex system of nonlinear equations. Initial conditions can be characterized by sharp discontinuitics. Due to its ability to generate computational meshes which conform to complex geometries, the finite element method is a natural method for these problems.

Unless a shock fitting approach is used wherein a discontinuity in the flow is tracked and the discontinuous form of the conservation equations (e.g. Rankine Hugoniot equations) is then applied across the discontinuity, spurious oscillation are generated in the numerical solution, and the discontinuity becomes "smeared" across many mesh points as time progresses. These phenomena result from the attempt to fit a linite number of basis functions to a solution containing a discontinuity. There is always a certain amount of overshoot or undershoot at the point of the discontinuity, which then appears as a short wavelength signal. These short wavelength components or signals are then propagated at the wrong velocity by the numerical scheme and appear as spurious oscillations in the numerical results. A number of techniques have been developed which introduce damping only at high wave numbers in order to eliminate these spurious oscillations. A survey of these methods as developed for finite difference inethods in hyperbolic equations can be found in Sod [1978]. Corresponding techniques for finite element methods using artificial diffusion have been developed by van Genuchten and Gray [1978], Iluvakorn and Nilkuha [1979], and Baker and Soliman (1981). Leisman and Frind [1989) demonstrated the importance of the time weighting of the various equation terms. These methods are all tend to be implicit. The method of $\gamma^{\prime} u$ and /leinrich $|1987|$ is finite 
clement in tume and is also always implicit. Selmin et. al. $|1985|$ developed a finite element version of the LaxWendroff method. Morion |1985| developed a method based upon method of characteristics. These are more applicable to the pure convection or hyperbolic cquation than to the convection diffusion equatuon which is parabolic.

The purpose of this paper is to introduce a modification of the Galerkin method which can capture disconunuities and can be calculated in an efficient fashion. The method is finite element in space - finite difference in time. The advantage of the method is that all of the spacial terms are calculated at the known time level. The unknown parameters only appear in the time derivative terms. II will be shown that this method can be applied to both the convection diffusion and the pure convection equations.

\section{The Galerkin Method}

The equation

$$
\left.\iint \frac{\partial \hat{u}}{\partial x} w_{1}+\left(a \frac{\partial \bar{u}}{\partial x} \cdot D \frac{\partial^{2} \tilde{u}}{\partial x^{2}}\right) w_{1_{1}}\right) d x=0
$$

is an approximation to the variational statement for the one-dimensional unsteady convection-diffusion cquation

$$
\frac{\partial u}{\partial t}+a \frac{\partial u}{\partial x} \cdot D \frac{\partial^{2} u}{\partial x^{2}}=0
$$

where $a$ is the propagation speed. $D$ is the diffusion coefficient, and $t$ and $x$ are the temporal and spacial dimensions.

The function $u=u(x, t)$ and is approximated by $\bar{u}=\sum U_{j}(t) \phi_{j}(x)$ in the usual manner, $U_{j}(l)$ being the nodal values 
of the approximating function $\hat{u}$ and $\Phi_{j}(x)$ the basis functions. Linear basis functions are used which are dofined in local coordinates $-1 \leq \eta \leq 1$ over each element as $\phi_{1}=\frac{1}{2}\left(1 \cdot \eta\right.$ )and $\phi_{2}=\frac{1}{2}(1+\eta)$. Note that the weight function $w_{1}$ applied to the time derivative is allowed to be different from the weight function $w_{s_{1}}$ applied to the spacial derivatives. In the following. two cases are examined, the standard method wherein both weight functuons are the same, and the Differently Weighted Method which, as the name implies, uses different weight functions on the temporal and spacial terms.

\section{Analytic Solution}

Substitution of the perturbation $u=\mathrm{e}^{\prime}\left\langle\lambda_{n} x+()_{n} 1\right\rangle$ where $\lambda_{n}$ is the wave number and $\omega_{n}$ is the frequency into the convection-diffusion cquation, cquation (2), laads to the dispersion relation $\frac{\omega_{n}}{\lambda_{n}}=i D \lambda_{n}$. a. In one time step $h$, the change in $u(x, t)$ is the damping wave:

$$
\xi_{1}=\frac{u(x, t+h)}{u(x, t)}=c^{\cdot D \lambda_{n}^{2} h} e^{\cdot 1 \cdot \lambda_{n} h}=c^{\cdot c_{2}\left(\lambda_{n} k\right)^{2}} e^{\cdot i c_{1} \lambda_{n} k}
$$

with Taylor series expansion

$$
=1 \cdot c_{1} i \lambda_{n} k-\left(\frac{1}{2} c_{1}^{2}+c_{2}\right)\left(\lambda_{n} k\right)^{2}+\left(c_{1} c_{2}+\frac{1}{6} c_{1}^{3}\right) i\left(\lambda_{n} k\right)^{3}+\cdots
$$

so that the amplification factor for the analytical solution is the decaying exponential function $\left|\xi_{1}\right|=e^{\cdot c_{2}\left(\lambda_{n} k\right)^{2}}$ and the phase angle is $\Phi_{1}=c_{1} \lambda_{n} k$. The parameter $k$ is the spacial grid sizc, $c_{1}=a h / k$ is the Courant number and $c_{2}$ $=\mathrm{Dh} / \mathrm{k}^{2}$ is the diffusion number. 


\section{A Standard Petrove(ialerkin Solution}

In the standard Petrov. (Galerkin technique, the weight function applied to the tume derivative is the same as the weight function applied to the spacial derivatives, i.c. $w_{t_{i}}=w_{s_{i}}$ Cubic polynomial weighting functions developed by Dick $|1983|$ are used:

$$
w_{1}=\varphi_{1}-r-g
$$

and

$$
w_{2}=\varphi_{2}+f+g
$$

where

$$
f=3 \alpha \varphi_{1} \varphi_{2} \text { and } g=\frac{5}{2} \beta \eta \phi_{1} \varphi_{2}
$$

Westerink and Shea $|1989|$ noted that use of polynomial weighting functions two degrees greater than the basis functions allow for the development of more accurate solutions through climination of truncation error terms. Since the basis functions are linear, the weight functions are cubic. Application of the lincar basis functions plus the weight functions defined in equations (5) and (6) to the approximation to the variational stitement for the onedimensional convection-diffusion equation (1) plus using Green's theorem to eliminate second derivatives yicids at interior points the ordinary differential equation:

$$
\begin{gathered}
\left(\frac{1}{6}+\frac{\alpha}{4}+\frac{\beta}{24}\right) \frac{d U_{j-1}}{d t}+\left(\frac{2}{3}-\frac{\beta}{12}\right) \frac{d U_{j}}{d t}+\left(\frac{1}{6}-\frac{\alpha}{4}+\frac{\beta}{24}\right) \frac{d U_{j+1}}{d t} \\
+\frac{a}{2 k}\left(U_{j+1}-U_{j-1}\right) \cdot \frac{a}{k}\left(\frac{\alpha}{2}+\frac{1}{P c}\right)\left(U_{j+1}-2 U_{j}+U_{j-1}\right)=0
\end{gathered}
$$




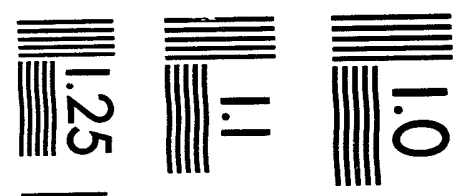

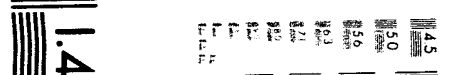

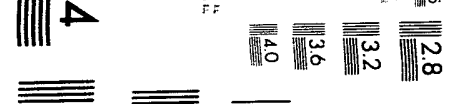

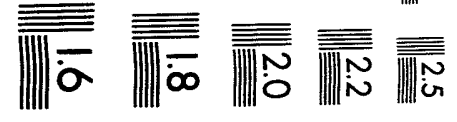



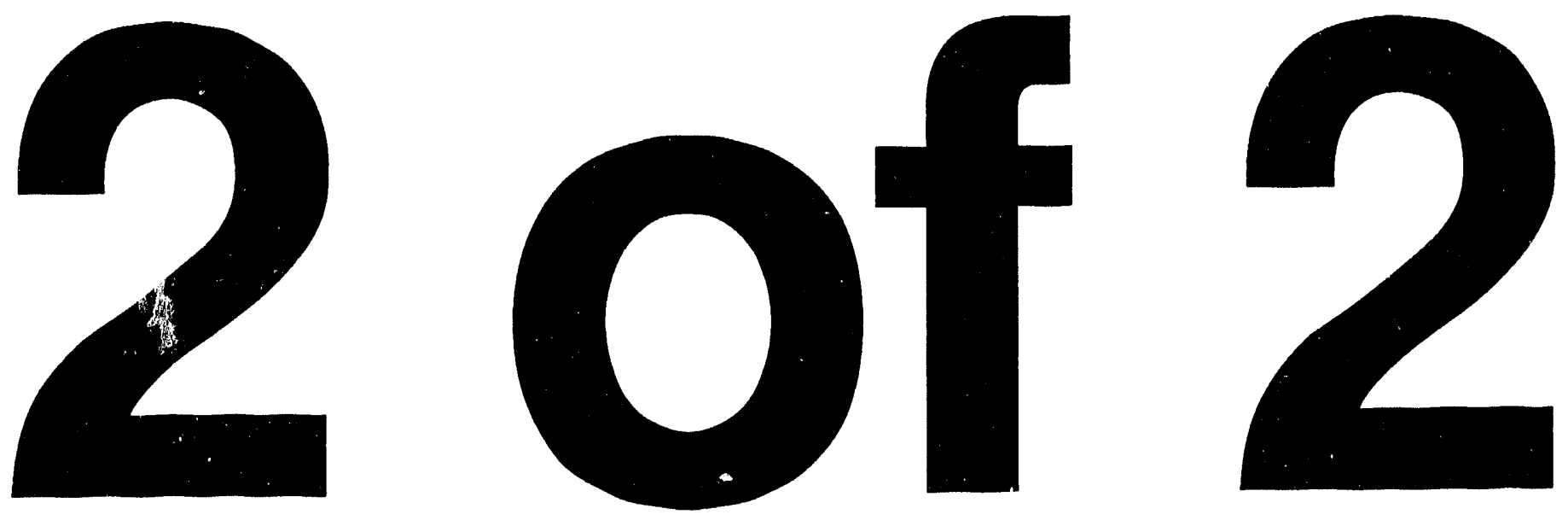
where $\mathrm{k}$ is the distance step and $\mathrm{Pe}=\mathrm{ak} / \mathrm{D}$ is the grid Peclet number. A simple "box" discretization of equation (7) in time leads to:

$$
\begin{gathered}
\left(\frac{1}{6}+\frac{\alpha}{4}+\frac{\beta}{24}\right)\left(U_{j-1}^{r+1}-U_{j-1}^{r}\right)+\left(\frac{2}{3}-\frac{\beta}{12}\right)\left(U_{j}^{r+1}-U_{j}^{r}\right)+\left(\frac{1}{6}-\frac{\alpha}{4}+\frac{\beta}{24}\right)\left(U_{j+1}^{r+1}-U_{j+1}^{r}\right) \\
+\theta\left[\frac{1}{2} c_{1}\left(U_{j+1}^{r+1}-U_{j-1}^{r+1}\right)-\left(\frac{1}{2} \alpha c_{1}+c_{2}\right)\left(U_{j+1}^{r+1}-2 U_{j}^{r+1}+U_{j-1}^{r+1}\right)\right] \\
+(1-\theta)\left[\frac{1}{2} c_{1}\left(U_{j+1}^{r}-U_{j-1}^{r}\right)-\left(\frac{1}{2} \alpha c_{1}+c_{2}\right)\left(U_{j+1}^{r}-2 U_{j}^{r}+U_{j-1}^{r}\right)\right]=0
\end{gathered}
$$

where the superscript $r$ indicates the time level and $\theta$ is the weight given the convection and diffusion terms at time level $r+1$.

Substitution of the perturbation $u=e^{i\left(h_{n} x+\left(c_{h} t\right)\right.}$ into cquation (8) shows that for the standard Petrov-Galerkin method the change over one time step is:

$$
\xi_{\mathrm{P}-\mathrm{O}}=\frac{1-\left(\frac{2}{3}+\frac{\beta}{6}+(1-\theta)\left(2 \alpha c_{1}+4 c_{2}\right)\right) \sin ^{2}\left(\frac{1}{2} \lambda_{n} k\right)-i\left(\frac{1}{2} \alpha+(1-\theta) c_{1}\right) \sin \left(\lambda_{n} k\right)}{1-\left(\frac{2}{3}+\frac{\beta}{6}-\theta\left(2 \alpha c_{1}+4 c_{2}\right)\right) \sin ^{2}\left(\frac{1}{2} \lambda_{n} k\right)-i\left(\frac{1}{2} \alpha-\theta c_{1}\right) \sin \left(\lambda_{n} k\right)}
$$

which expands in Taylor series as

$$
\xi_{P-0}=1-c_{1} i \lambda_{n} k-\left(c_{2}+c_{1}^{2} \theta\right)\left(\lambda_{n} k\right)^{2}+\left(2 c_{1} c_{2} \theta+c_{1}^{3} \theta^{2}-\frac{1}{2} c_{2} \alpha-\frac{1}{24} c_{1} \beta\right)\left(i\left(\lambda_{n} k\right)^{3}+O\left(\lambda_{n} k\right)^{4}\right.
$$

Comparison of this series expansion in (10) with the scries expansion of the analytic solution in (4) gives a basis for the adjustment of the parameters $\alpha$ and $\beta$. Using $\theta=1 / 2$ and setting $\alpha=0$ and $\beta=2 c_{1}{ }^{2}$ reduces the error 
to at least $\mathrm{O}\left(\mathrm{k}^{4}\right)$, a result also derived by Westerlink and Shea $|1989|$ using truncation crror analysis. Note that the adjustable parameters $\alpha$ and $\beta$ appear only in the dispersion terms (odd powered terms), so that only the centered or Crank-Nicholson form with $\theta=1 / 2$ allows for a potential match of the $\mathrm{O}\left(\mathrm{k}^{2}\right)$ terms.

The explicit form, $\theta=0$, has a truncation error of $\mathrm{O}\left(\mathrm{k}^{2}\right)$. As the flow becomes purely convective $\left(\mathrm{c}_{2}=0\right)$, the second order damping term disappears so that this method is unstable.

The backward implicit form, $\theta=1$, although stable is always restricted to a truncation error of $\mathrm{O}\left(\mathrm{k}^{2}\right)$.

\section{Development of the Differently Weighted Scheme}

The sccond case to be examined is the non-standard case in which the weight function $w_{1}$ applied to the time derivative is different from the weight function $w_{s_{i}}$ applied to the spacial derivatives. This represents a departure from the usual Petrov-Galerkin scheme and is motivated by observing that the non-symmetrical weighting of the time derivative terms in the standard Petrov-Galerkin method leads to unstable explicit schemes. This was recognized by Huyakorn and Nilkuha [1979] who produced a stable explicit scheme by weighting the time derivative terms with the linear basis functions and only applying the "upwinded functions" as weights to the spacial terms.

The weight functions for the time derivative terms are derived by adding a suitable polynomial $p(\eta)$ to the basis functions. In order to produce a symmetrical weighting of the time derivative terms, the polynomial $p(\eta)$ must satisfy three conditions, $p(\eta)=0$ at $\eta= \pm 1$ and $\int_{-1}^{1} p(\eta) d \eta=0$, so that a cubic equation allows for one free parameter $\beta$. Therefore the cubic polynomial $\mathrm{g}$ defined in equation (6) is used so that the weight functions for the time derivative are:

$$
\begin{aligned}
& w_{t_{1}}=\phi_{1}-g \\
& w_{t_{2}}=\phi_{2}+g
\end{aligned}
$$


The spacial derivatives are upwinded using the quadratic polynomial $f$ defined in equation (6) with free parameter $\alpha$. The weight functions for the spacial terms are thus:

$$
\begin{aligned}
& w_{s_{1}}=\phi_{1}-f \\
& w_{s_{2}}=\phi_{2}+f
\end{aligned}
$$

Again, the application of the linear basis functions plus the weight functions defined in equations (11) and (12) to the approximation to the variational statement for the one-dimensional convection-diffusion cquation, equation (1), plus using Green's theorem to eliminate second derivatives yields at interior points the ordinary differential equation:

$$
\begin{gathered}
\frac{1}{6}(1-\beta)\left[\frac{d U_{j-1}}{d t}+\frac{d U_{j+1}}{d t}\right]+\frac{1}{3}(2+\beta) \frac{d U_{j}}{d t} \\
+\frac{a}{2 k}\left(U_{j+1}-U_{j-1}\right) \cdot\left(\frac{\alpha a}{k}+\frac{b}{k^{2}}\right)\left(U_{j+1}-2 U_{j}+U_{j-1}\right)=0
\end{gathered}
$$


Again, a simple "box" discretization of equation (13) yields:

$$
\begin{gathered}
\frac{1}{6}(1-\beta)\left[\left(U_{j+1}^{r+1}-U_{j+1}^{r}\right)+\left(U_{j-1}^{r+1}-U_{j-1}^{r}\right)\right]+\frac{1}{3}(2+\beta)\left(U_{j}^{r+1}-U_{j}^{r}\right) \\
+\theta\left[\frac{1}{2} c_{1}\left(U_{j+1}^{r+1}-U_{j-1}^{r+1}\right)-\left(\frac{1}{2} \alpha c_{1}+c_{2}\right)\left(U_{j+1}^{r+1}-2 U_{j}^{r+1}+U_{j-1}^{r+1}\right)\right] \\
+(1-\theta)\left[\frac{1}{2} c_{1}\left(U_{j+1}^{r}-U_{j-1}^{r}\right)-\left(\frac{1}{2} \alpha c_{1}+c_{2}\right)\left(U_{j+1}^{r}-2 U_{j}^{r}+U_{j-1}^{r}\right)\right]=0
\end{gathered}
$$

For this Differently Weighted Scheme, the change over one time step is:

$$
\xi_{\text {D-w }}=\frac{1-\left(\frac{2}{3}(1-\beta)+2(1-\theta)\left(\alpha c_{1}+2 c_{2}\right)\right) \sin ^{2}\left(\frac{1}{2} \lambda_{n} k\right)-i(1-\theta) c_{1} \sin \left(\lambda_{n} k\right)}{1-\left(\frac{2}{3}(1-\beta)-2 \theta\left(\alpha c_{1}+2 c_{2}\right)\right) \sin ^{2}\left(\frac{1}{2} \lambda_{n} k\right)+i \theta c_{1} \sin \left(\lambda_{n} k\right)}
$$

which expands in Taylor series as:

$$
\xi_{D-W}=1-c_{1} i \lambda_{n} k-\left(\theta c_{1}^{2}+\frac{1}{2} \alpha c_{1}+c_{2}\left(\lambda_{n} k\right)^{2}+\left(\frac{1}{6} \beta c_{1}+2 \theta c_{1} c_{2}+\theta \alpha c_{1}^{2}+\theta^{2} c_{1}^{3}\right) i\left(\lambda_{n} k\right)^{3}+\left(\alpha\left(\lambda_{n} k\right)^{4}\right.\right.
$$

It is important to observe that in contrast to the example standard Petrov-Galerkin scheme, the adjustable parameters $\alpha$ and $\beta$ appear in both the damping (even powered) and dispersion (odd powered) terms so that both of these terms can be adjusted to conform to the series expansion of the analytical solution. 


\section{Differently Weighted Scheme - Forward Difference}

Comparison of this series for the explicit form, $\theta=0$, with the series expansion of the analytic solution shows that setting $\alpha=c_{1}$ and $\beta=c_{1}{ }^{2}+\left(c_{2}\right.$ leads to a local truncation error of $O\left(k^{4}\right)$. The method is stable, unlike the explicit form of the standard Petrov-Galerkin method for the pure convection problem. The amplification factor becomes:

$$
\left|F_{D-w}\right|=\left|\frac{1-\frac{2}{3}\left(1+2 c_{1}^{2}\right) \sin ^{2}\left(\frac{1}{2} \lambda_{n} k\right)-1 c_{1} \sin \left(\lambda_{n} k\right)}{1+\frac{2}{3}\left(c_{1}^{2}+6 c_{2}-1\right) \sin ^{2}\left(\frac{1}{2} \lambda_{n} k\right)}\right|
$$

which has a maximum value at $\lambda k=\pi$ so that the stability criterion is

$$
c_{1} \leq \frac{3}{\mathrm{Pe}}+\sqrt{1+\frac{9}{\mathrm{Pe}^{2}}}
$$

In the case of pure convection $\left(c_{2}=0\right)$ and constant coefficients, the method becomes identical to the TaylorGalerkin method of Selmin et al [1985] and stability requires that $c_{1} \leq 1$. The ratio of the amplitude of the numerical scheme to the amplitude of the analytic solution $\left|\frac{\xi_{\mathrm{D}-w}}{\xi_{\mathrm{a}}}\right|$ and the ratio of the phase angle of the numerical scheme to the analytic solution $\frac{\Phi_{D-w}}{\Phi_{a}}$ are plotted in Figure 1 for the optimal choices of $\alpha$ and $\beta$. The amplitude ratio is greater than one at high wave number for the low Pe case, which shows that the numerical scheme is slightly underdamped. Large phase angle errors also occur at high wave number. As the Peciet number is increased, the underdamping and the region of phase error both diminish. In the case of pure convection, the amplitude ratio and the phase angle ratio are both one, indicating a good match between the analytic and numeric solutions. 


\section{Differently Weighted Scheme - Centered Difference}

The local truncation error can also be minimized to at least $\mathrm{O}\left(\mathrm{k}^{4}\right)$ for the centered or Crank-Nicholson form $1 \theta=$ 1/2) by setting $\alpha=0$ and $\beta=-\frac{1}{2} c_{1}^{2}$. The amplification factor is then:

$$
\left|\xi_{\mathrm{D}-\mathrm{w}}\right|=\left|\frac{1-\left(\frac{2}{3}(1-\beta)+\left(\alpha c_{1}+2 c_{2}\right)\right) \sin ^{2}\left(\frac{1}{2} \lambda k\right)-i \frac{1}{2} c_{1} \sin (\lambda k)}{1-\left(\frac{2}{3}(1-\beta)-\left(\alpha c_{1}+2 c_{2}\right)\right) \sin ^{2}\left(\frac{1}{2} \lambda k\right)+i \frac{1}{2} c_{1} \sin (\lambda k)}\right|
$$

which also has a maximum value at $\lambda k=\pi$ leading to the stability restrictions $\alpha \geq-2 \frac{c_{2}}{c_{1}}$ and $\beta \geq-\frac{1}{2}$. This means that the truncation error can only be minimized to $\mathrm{O}\left(\mathrm{k}^{4}\right)$ for $\mathrm{c}_{1} \leq 1$, otherwise the method is $\mathrm{O}\left(\mathrm{k}^{3}\right)$ indicating dispersion error.

However, setting $\alpha=0$ for the pure convection problem ( $\left.c_{2}=0\right)$ or hyperbolic problem results in the amplification factor:

$$
\left|\xi_{D-w}\right|=\left|\frac{1-\frac{2}{3}(1-\beta) \sin ^{2}\left(\frac{1}{2} \lambda_{n} k\right)-i \frac{1}{2} c_{1} \sin \left(\lambda_{n} k\right)}{1-\frac{2}{3}(1-\beta) \sin ^{2}\left(\frac{1}{2} \lambda_{n} k\right)+i \frac{1}{2} c_{1} \sin \left(\lambda_{n} k\right)}\right|=\left|\frac{\bar{z}}{2}\right|=1
$$

which is stable for any Courant number $c_{1}$ and any choice of $\beta$, so that the truncation error can be minimized to $\mathrm{O}\left(\mathrm{k}^{4}\right)$ for any choice of $c_{1}$.

The amplitude and phase angle ratios as a function of wave number for the optimal choices of $\alpha$ and $\beta$ are shown in Figure 2. These plots indicates that the centered difference scheme is also underdamped but the phase angle error is smaller than in the forward difference case. Again, a good match of amplitude and phase angle is achieved for the pure convective case. 
In Figure 3, the weight functions applied to the time derivative for the forward and centered difference schemes are shown. Note that the functions are symmetric and that the amplitude of the weight function is decreased in the centered difference scheme.

\section{Differently Weighted Scheme - Backward Difference}

The implicit or backward difference form is obtained by setting $\theta=1$. As above, $\alpha$ and $\beta$ can be chosen so as to minimize the truncation error, but unfortunately the most desirable choice has stability problems. The crror can be minimized to $O\left(k^{4}\right)$ by setting the weighting factors to $x=-c_{1}$ and $\beta=c_{1}{ }^{2}-\left(x_{2}\right.$ but these values are constrained by $\frac{1}{2} \alpha c_{1}+c_{2}>0$ in order to keep the "diffusion term" in equation (13) positive. This leads to the stability constraint $\mathrm{c}_{1} \leq \frac{2}{\mathrm{Pe}}$ so that $\mathrm{c}_{1} \rightarrow 0$ as $\mathrm{Pe} \rightarrow \infty$.

Other possible choices are setting $\alpha=0$ and $\beta=1 / 2-3 c_{2}$ or increasing the damping and diffusion by using the values $\alpha=+c_{1}$ and $\beta=1 / 2-3 c_{2}$. Either of these two choices lead to an error of $O\left(k^{2}\right)$ when $c_{1}$ is large, which is the same order of magnitude as the backward implicit finite difference method, and to $O\left(\mathrm{k}^{6}\right)$ as $\mathrm{c}_{1}$ becomes negligible, and are stable for all $c_{1}$.

\section{Numerical Results}

An example problem is provided by Avdonin 11964]. As described in Updegraff [1989], this is an injection problem in which cold water is injected into a semi-infinite hot water aquifer. In order to simplify the modeling of this problem, the effects of the overburden and the underburden are eliminated by prescribing adiabatic conditions wong these boundaries. The conservation of energy equation is then reduced to the one-dimensional convection- 
diffusion cquation:

$$
\frac{\partial u}{\partial t}+v_{w} \frac{\rho_{w} c_{w}}{\rho_{m} c_{m}} \frac{\partial u}{\partial x} \cdot \frac{K_{m}}{\rho_{m} c_{m}} \frac{\partial^{2} u}{\partial x^{2}}=0
$$

where the variable $u(x, l)$ represents the temperature, $v_{w}$ is the Darcy velocity, $\rho_{w}$ is the density of water, $c_{w}$ is the heat capacity of water, $c_{m}$ is the heat capacity of the saturated matrix, $K_{m}$ is the thermal conductivity of the saturated matrix, and $\rho_{m}$ is the density of the matrix. This has analytic solution $u(x, t)$ :

$$
\frac{u(x, t)-u(x, 0)}{u(0, t)-u(x, 0)}=\frac{1}{2}\left(\operatorname{erfc}\left(\frac{x-a t}{\sqrt{4 D t}}\right)+\exp \left(\frac{a x}{D}\right) \operatorname{erfc}\left(\frac{x+a t}{\sqrt{4 D t}}\right)\right)
$$

where the convection is $a=v_{w} \frac{\rho_{w} c_{w}}{\rho_{m} c_{m}}$ and the thermal diffusion is $D=\frac{K_{m}}{\rho_{m} c_{m}}$. Three different cases corresponding to low Peclet number, high Peclet number, and pure convection were examined. The parameter values used were porosity $n=0.20, \rho_{w}=919 \mathrm{~kg} / \mathrm{m}^{3}, c_{w}=4185 \mathrm{~J} / \mathrm{kg}^{\circ} \mathrm{C}, c_{\mathrm{m}}=898.9 \mathrm{~J} / \mathrm{kg}^{\circ} \mathrm{C}, \mathrm{K}_{\mathrm{m}}=18.3 \mathrm{w} / \mathrm{m}{ }^{\circ} \mathrm{C}$, and $\rho_{m}=2450 \mathrm{~kg} / \mathrm{m}^{3}$. An aquifer thickness of $100 \mathrm{~m}$ was specified. The temperature is held fixed at $\left.\mathrm{T}_{\mathrm{a}}=160\right)^{\circ} \mathrm{C}$ at $\mathrm{x}$ $=0$, while the initial aquifer temperature was set at $170^{\circ} \mathrm{C}$ and the far boundary, denoted by $\mathrm{T}_{\mathrm{b}}$, was maintained at this temperature.

Case 1. A length of $50 \mathrm{~m}$ of aquifer was simulated with an injection rate of $10 \mathrm{~kg} / \mathrm{s}$. This leads to a Darcy velocity of $v_{w}=1.088 \times 10^{-4} \mathrm{~m} / \mathrm{s}$, convection $\mathrm{a}=1.9 \times 10^{-4} \mathrm{~m} / \mathrm{s}$ and thermal diffusion $\mathrm{D}=8.33 \times 10^{-6} \mathrm{~m}^{2} / \mathrm{s} . A$ distance step $k=1 \mathrm{~m}$ gives a grid Peclet number $\mathrm{Pc}=\frac{\mathrm{ak}}{\mathrm{D}}=22.8$. 
For the explicit method, stability requires that $\mathrm{c}_{1} \leq \frac{3}{\mathrm{Pe}}+\sqrt{1+\frac{9}{\mathrm{Pe}^{2}}}$ which leads to a Courant number $\mathrm{c}_{1}=$ 1.14 so that the time step is then $h=6000 \mathrm{~s}$ and the optimal $\alpha=1.14$ and $\beta=1.6$. Results for this simulation after 26 time steps and the analytical solution are shown in Figure 4. Note that the steep wave front is captured by this method but that some spurious oscillations are also produced behind the wave front. This is not surprising as the the amplification factor ratio plot in Figure 1 indicates that this method is underdamped and the phase error is large at high wave numbers.

Results for the centered scheme for the same conditions after 26 time steps are plotted in Figure 5. A Courant number $c_{1}=1$ is used so that the optimal weighting parameters are $\alpha=0$ and $\beta=-\frac{1}{2}$. Although the error is the same order of magnitude as in the explicit case, the amplitude and phase properties are better so that a close fit of the wave front is obtained without the spurious oscillation present in the explicit case.

Also shown in this plot are results for the centered scheme using $c_{1}=2$ after 13 time steps. Stability requires that $\beta=-\frac{1}{2}$ which is no longer optimal and the error drops to $\mathrm{O}\left(\mathrm{k}^{3}\right)$ which is dispersive. Spurious oscillations and a more diffuse wave front are indicative of the dispersion error.

Case 2. The thermal conductivity was reduced to $\mathrm{K}_{\mathrm{m}}=4.18 \mathrm{w} / \mathrm{m}{ }^{\circ} \mathrm{C}$ while maintaining all of the other conditions the same as in case 1 . The diffusion decreased to $D=1.9 \times 10^{-6}$ thercby increasing the Peclet number to $\mathrm{Pe}=100$.

The maximum stable Courant number for the explicit scheme is then $c_{1}=1.03$ so that the time step $h=5423 \mathrm{~s}$ and the optimal weighting parameters are $\alpha=1,03$ and $\beta=1.1237$. As in the low Peclet number case, a good fit at the front is obtained with some spurious oscillation. It is interesting to observe that this spurious oscillation is somewhat larger in magnitude but the overall amount of spurious oscillation is reduced from the low Peclet number case. As the effect of diffusion diminishes the spurious oscillation in the explicit scheme diminishes. This result is 
expected because the amplitude and phase angle plots show a better match at higher Peclet numbers.

As in the low Peclet number case, the centered scheme with $c_{1}=1$ and optimal weighting parameters are $\alpha=0$ and $\beta=-\frac{1}{2}$ gives a good fit to the front without the spurious oscillation as demonstrated in Figure 7 . Increasing the Courant number to $c_{l}=2$ again gives dispersion crror.

Case 3. The thermal conductivity was entircly climinated by setting $\mathrm{K}_{\mathrm{m}}=0$ so that equation (21) is reduced to the purely convective or hyperbolic form. The solution is then a discontinuity moving left to right at speed a = $1.9 \times 10^{-4} \mathrm{~m} / \mathrm{s}$. Analytic and numerical results for the explicit form are shown in Figure 8 . The numerical results exactly match the moving discontinuous front without any spurious oscillation, overshoot, or undershoot. As shown in Figure 9, the centered difference method gives a similar good match for $c_{1}=1$. Increasing the Courant number to $c_{1}=2$ and using $\alpha=0$ and $\beta=-\frac{1}{2}$ results in a large degree of oscillation and dispersion. According to the theoretical discussion, $\beta$ is unrestricted so that the optimal values $\alpha=0$ and $\beta=-2$ could be used. In fact, if these optimal values are used, oscillations develop which quickly swamp the solution. These oscillations are due to the absence of any damping in the numerical scheme. In other words, the method fails for the same reason that the plain Galerkin method fails in the presence of a steep front or discontinuity.

These three cases were also simulated using the backward implicit form. The most accurate values of the weighting parameters were found to be $\beta=\frac{1}{2} \cdot 3 c_{2}$ and $\alpha=0$, which are also the optimal values for the pure diffusion equation. The addition of this damping does not effect the accuracy in the strongly convective case as much as in the more weakly convective case. If $\alpha \neq 0$, the amount of dispersion is increased, and the accuracy of the numerical solution is decreased. Again, this decrease in accuracy diminishes as the Peclet number becomes larger. 


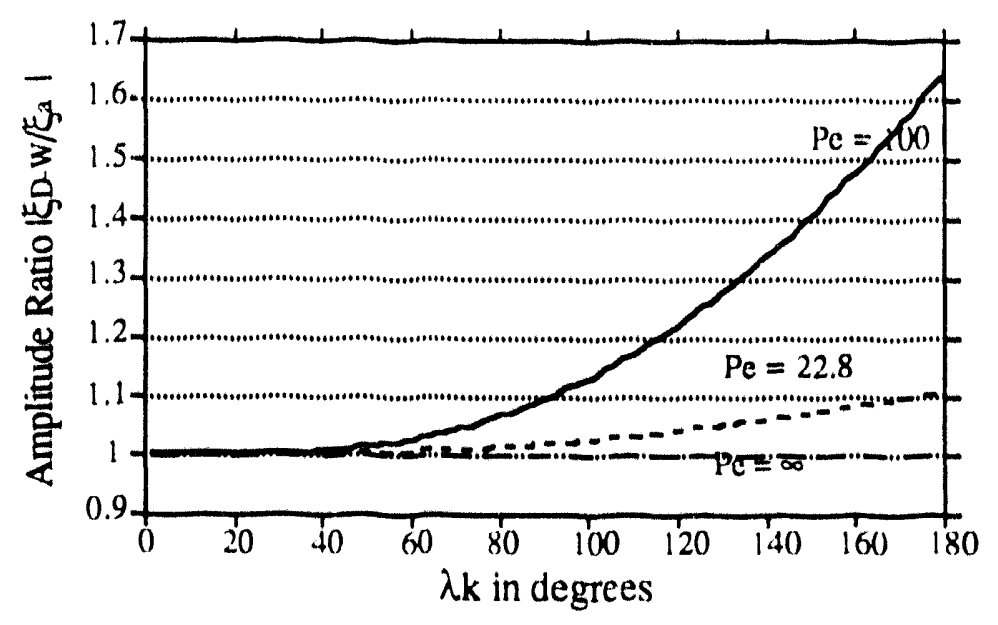

a) amplitude ratio diagram for the explicit method

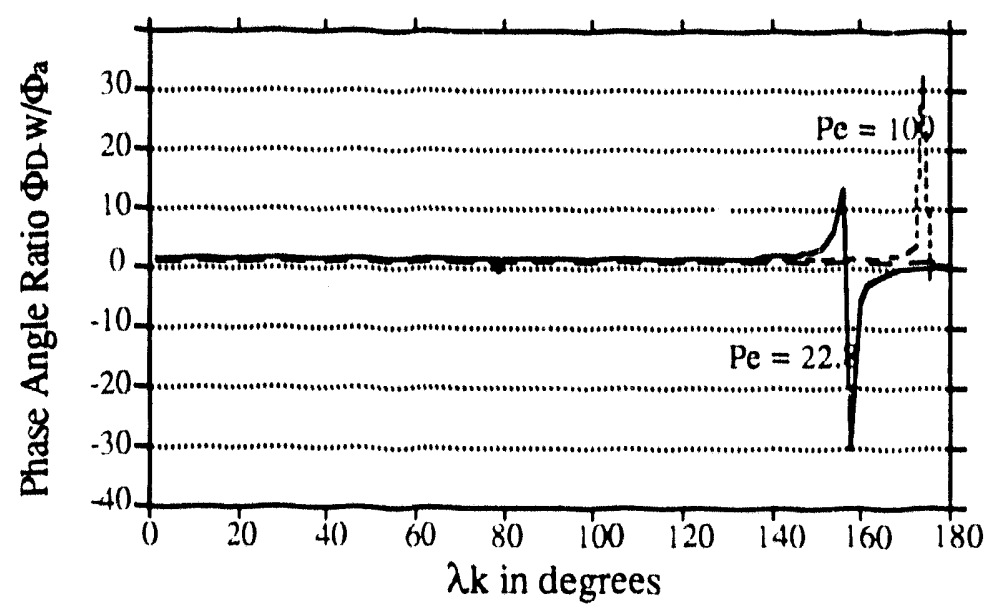

b) phase angle ratio diagram for the explicit method

Figure 1 Amplitude and phase angle diagrams for the explicit for of the differentially weighted Galerkin method. 


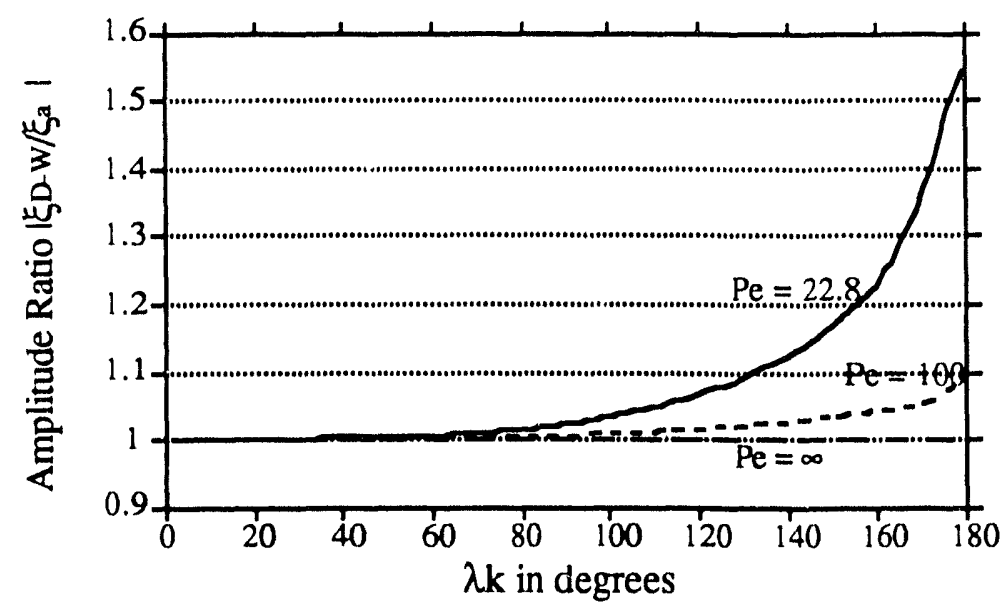

a) amplitude ratio for centered difference method

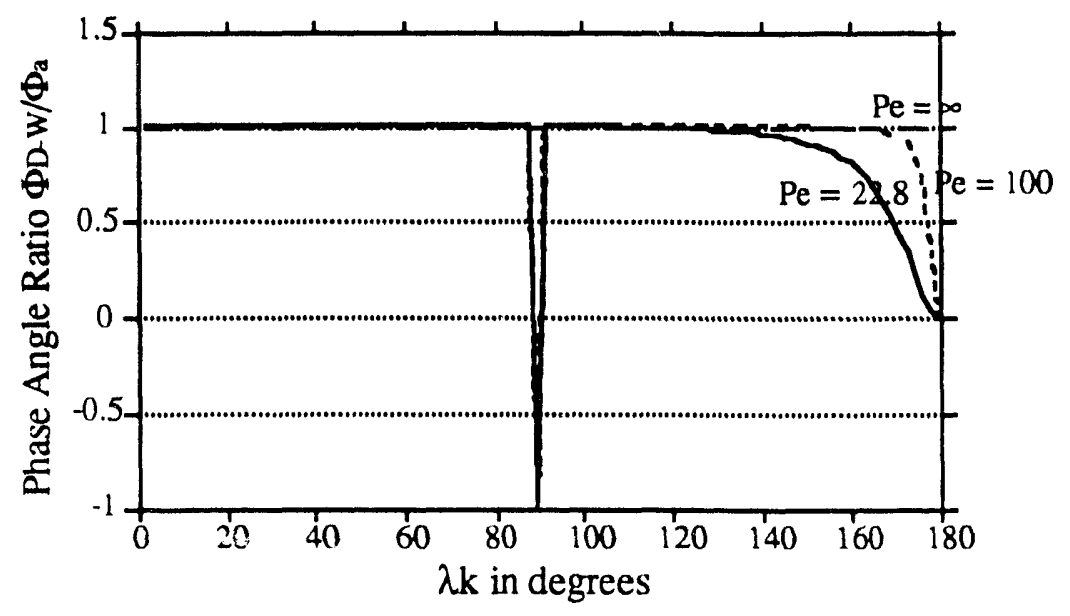

b) phase angic ratio for centered difference method

Figure 2. Amplitude and phase angle ratio diagrams for the centered difference form of the differentially weighted Galerkin method. 


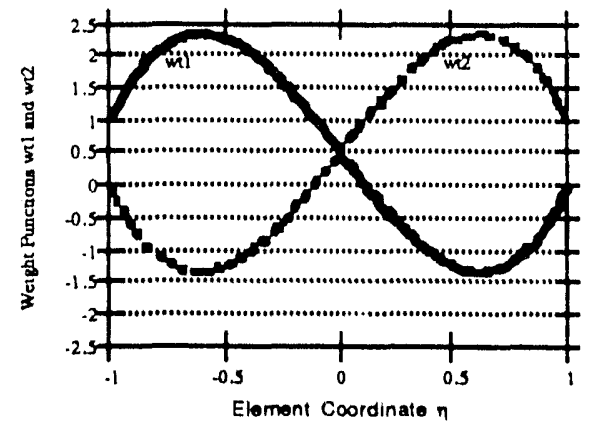

explicit

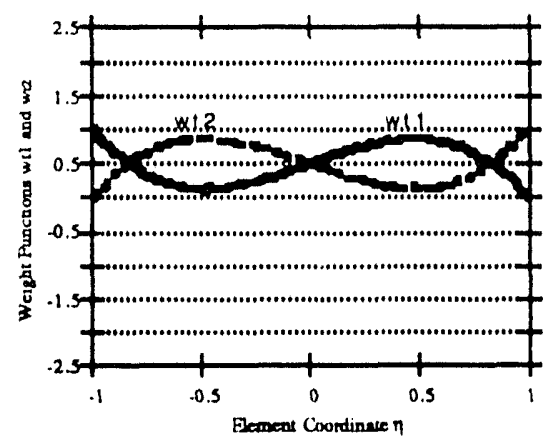

centered difference

Figure 3. Weight functions applied to the time derivative terms at optimal value of $\alpha$ and $\beta$ for the explicit method and for the centered difference method.

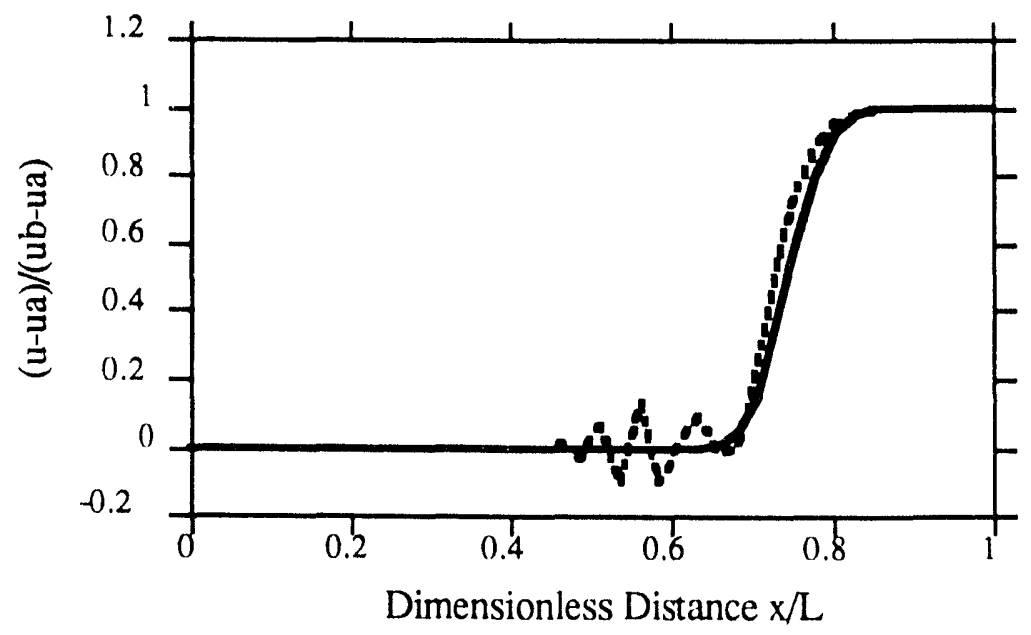

Figure 4. Comparison of the results of the explicit method using optimal values of $\alpha$ and $\beta$ with the analytic solution for $\mathrm{Pe}=22.8$ 


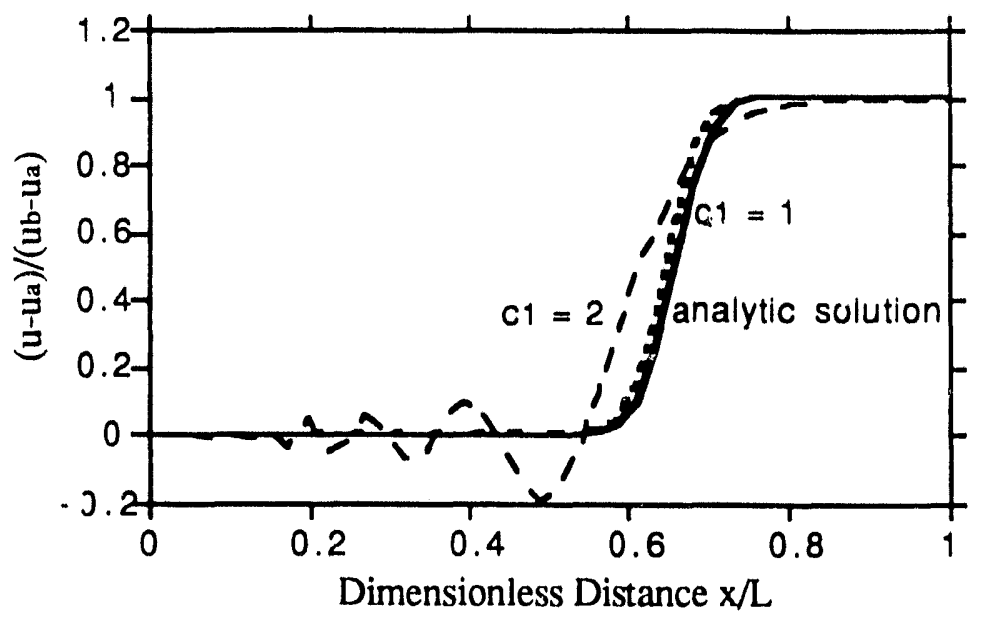

Figure 5. Comparison of the results of the centered difference method with the analytic results. This is the strongly diffused case where $\mathrm{Pe}=22.8$

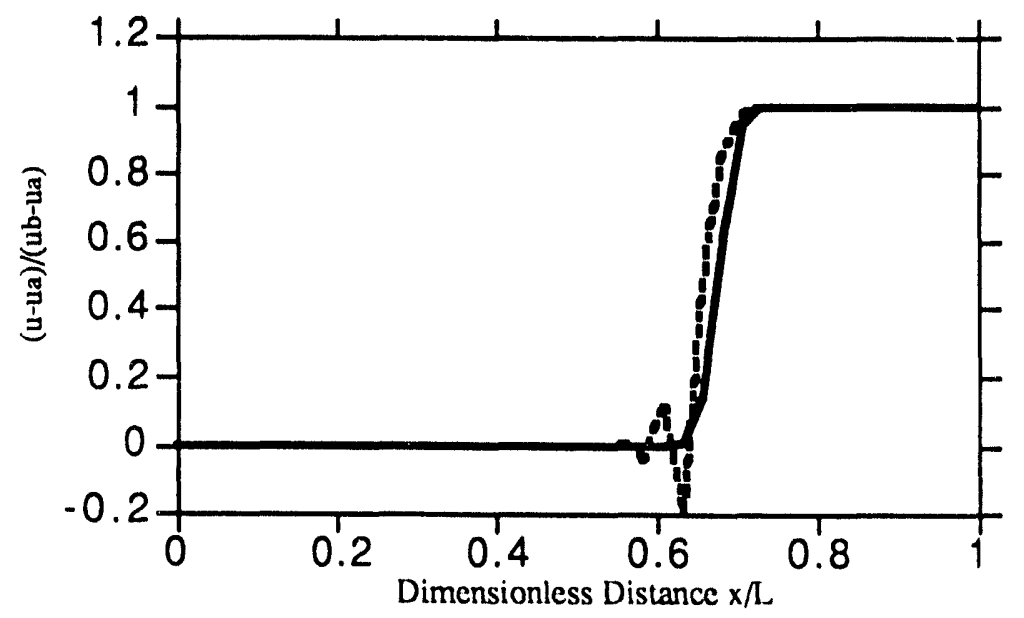

Figure 6. Comparison of the results of the explicit difference method with the analytic solution for $\mathrm{Pe}=100$. 


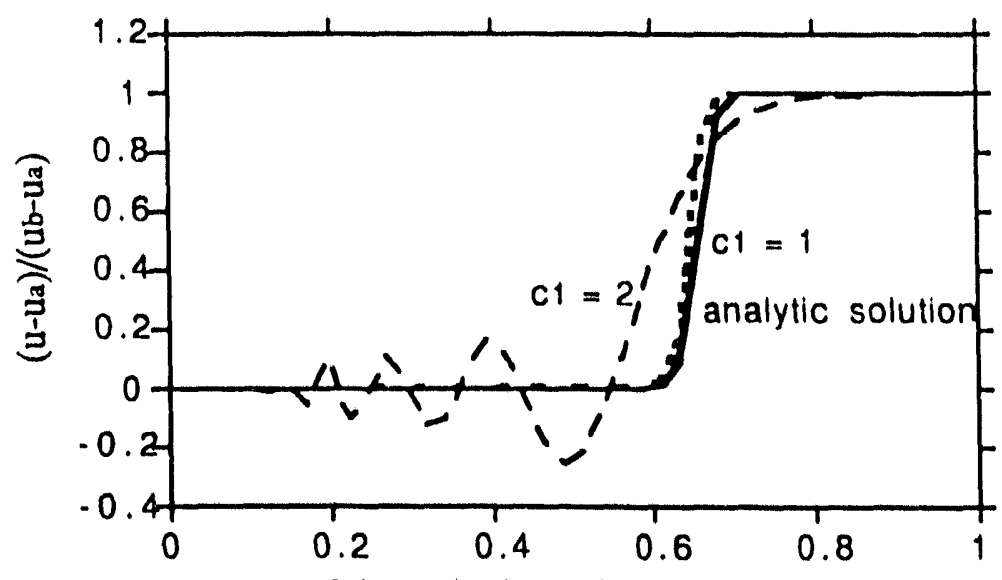

Dimensionless Distance $x / \mathrm{L}$

Figure 7. Comparison of the results of the centered difference method with the analytic result for $\mathrm{Pc}=100$.

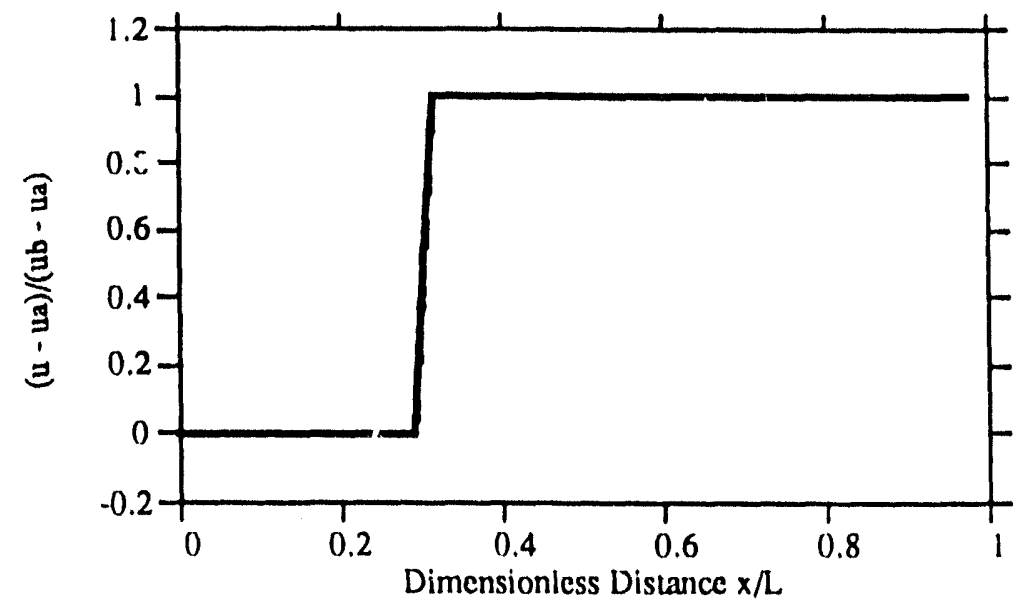

Figure 8 Comparison of the results of the explicit method with the analytic result for pure convection, $\mathrm{Pc}=\infty$. 


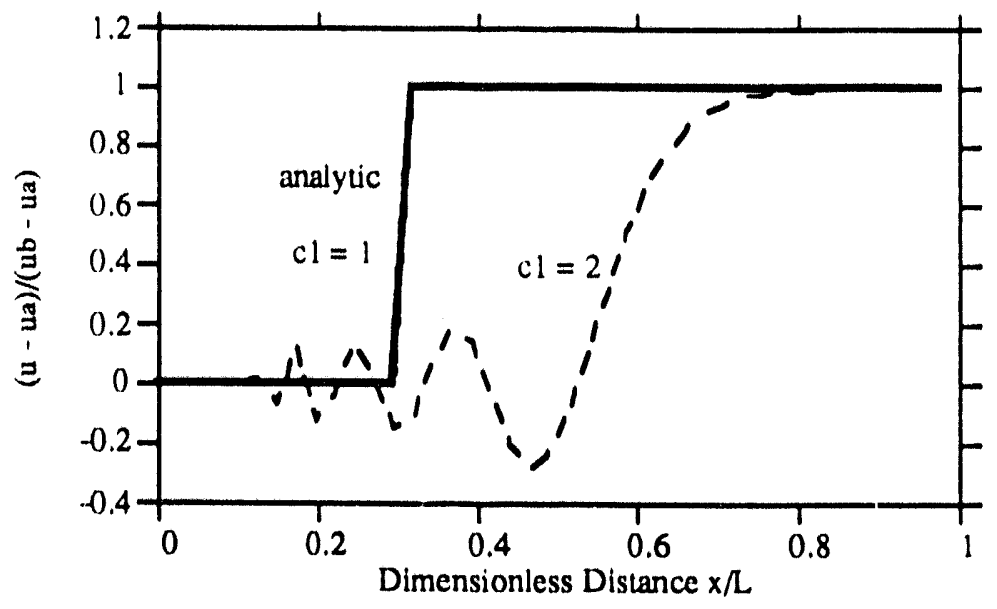

Figure 9. Comparison of numerical and analytic results for the pure convection problem using centered differences. 


\section{References}

1. Avdonin, N.A., "Some Formulas for Calculating the Temperature Field of a Stratum Subject to Thermal Injection," Nefti Gaz, 3, 37-41, 1964.

2. Baker, A.J. and M.O. Soliman, "On the Accuracy and Efficiency of a Finite Element Tensor Product Algorithm for Fluid Dynamics Applications," Comp. Meth. in Applied Mech. and Eng., 27, 215-237, 1981.

3. Dick, E., "Accurate Petrov-Galerkin Methods for Transient Convective Diffusion Problems," Int. J. Numerical Methods Engineering, 19, 1425-1433, 1983.

4. Huyakorn, P.S. and K. Nilkuha, "Solution of transient transport equation using an upstream finite clement scheme," Appl. Math. Modeling, 3, 7-17, 1979.

5. Lapidus, L. and G.F. Pinder, Numerical Solution of Partial Differential Equations in Science and Engineering, John Wiley \& Sons, N.Y., N.Y., 1982.

6. Leismann, H.M. and E.O. Frind, "A Symmetric-Matrix Time Integration Scheme for the Efficient Solution of Advection-Dispersion Problems," Water Res. Research, 25,6,1133-1139, June 1989.

7. Morton, K.W., "Generalised Galerkin Methods for Hyperbolic Probiems," Comp. Meth. Appl. Mech., 52, 847. $871,1985$. 
8. Sclmin, V., J. Donea, and L. Quartapelle, "Finite Element Methods for Nonlinear Advection," Computer Methods in Applied Mechanics and Engineering, 52, 817-845, 1985.

9. Sod, G.A., "A Survey of Several Finite Difference Methods for Systems of Nonlinear Hyperbolic Conservation Laws," J. Comp. Physics, pp1-31, 1978.

10. Updegraff, C.D., Comparison of Strongly Heat-Driven Flow Codes for Unsaturated Media, NUREG/CR5367, SAND88-7145, Sandia National Laboratories, Albuquerque, NM, Aug. 1989.

11. van Genuchten, M.Th. and W. Gray, "Analysis of some Dispersion Corrected Numerical Schemes for Solution of the Transport Equation," Int. J. Numerical Methods Engineering, 12, 387-404,1978.

12. Westerink, J.J. and D. Shea, "Consistent Higher Degree Petrov-Galerkin Methods for the Solution of the Transient Convection Diffusion Equation, Int. J. Numerical Methods Engineering,28, 1077-1101, 1989.

13. Yu, C.C. and J.C. Heinrich, "Petrov-Galerkin Method for Multidimensional, Time-Dependent, Convective Diffusion Equations," Int. J. Numerical Methods Engineering,24, 2201-2215, 1987. 

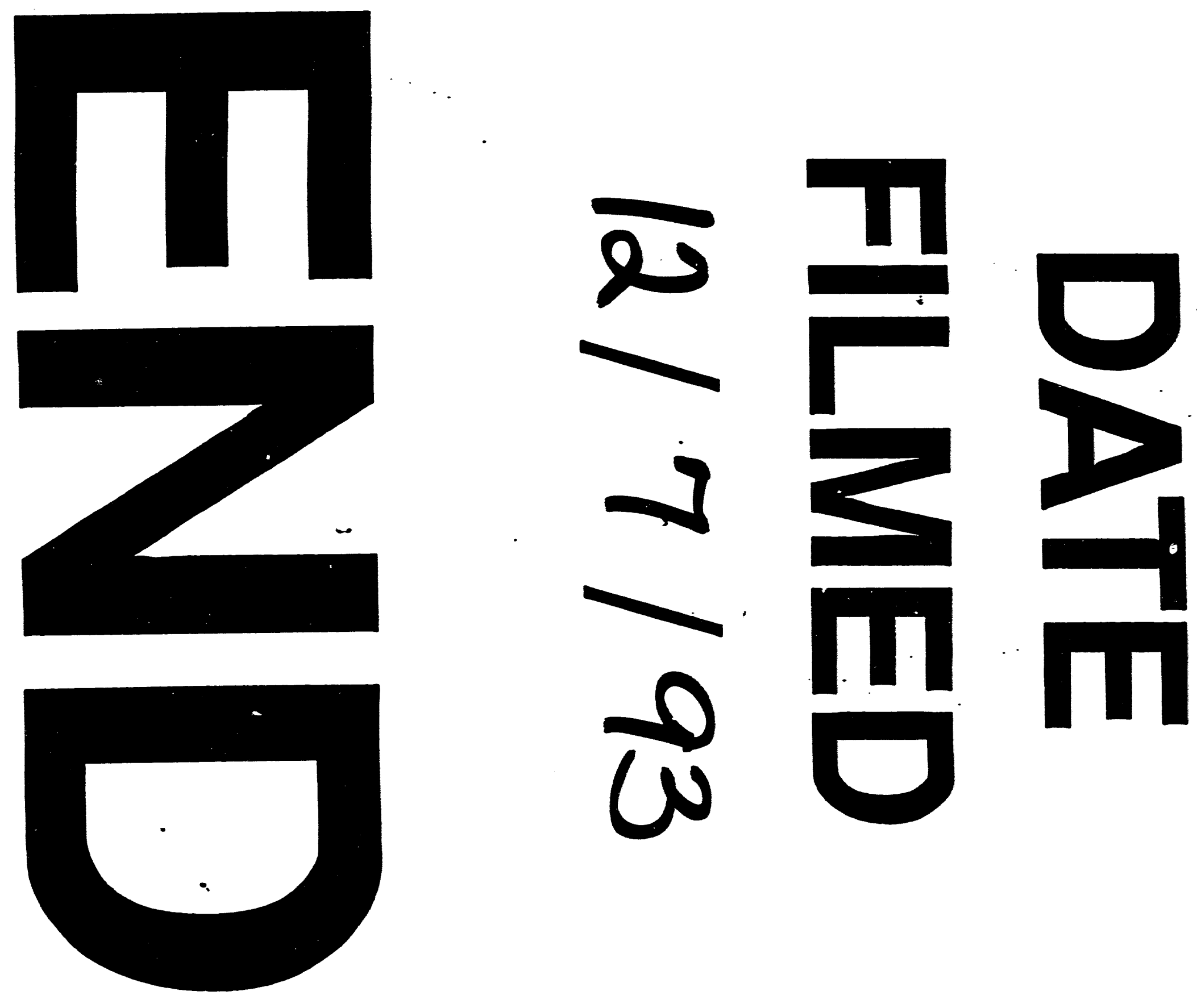
